\title{
Asymmetric Electrophilic Reactions in Phosphorus Chemistry
}

\author{
Anastasy O. Kolodiazhna and Oleg I. Kolodiazhnyi *(D) \\ V.P. Kukhar' Institute of Bioorganic Chemistry and Petrochemistry, NAS of Ukraine, Murmanska st., 1, \\ 02094 Kyiv, Ukraine; nastya_k11@ukr.net \\ * Correspondence: oikol123@bpci.kiev.ua
}

Received: 16 November 2019; Accepted: 27 December 2019; Published: 6 January 2020

\begin{abstract}
This review is devoted to the theoretic and synthetic aspects of asymmetric electrophilic substitution reactions at the stereogenic phosphorus center. The stereochemistry and mechanisms of electrophilic reactions are discussed-the substitution, addition and addition-elimination of many important reactions. The reactions of bimolecular electrophilic substitution $\mathrm{S}_{\mathrm{E}} 2(\mathrm{P})$ proceed stereospecifically with the retention of absolute configuration at the phosphorus center, in contrast to the reactions of bimolecular nucleophilic substitution $\mathrm{S}_{\mathrm{N}} 2(\mathrm{P})$, proceeding with inversion of absolute configuration. This conclusion was made based on stereochemical analysis of a wide range of trivalent phosphorus reactions with typical electrophiles and investigation of examples of a sizeable number of diverse compounds. The combination of stereospecific electrophilic reactions and stereoselective nucleophilic reactions is useful and promising for the further development of organophosphorus chemistry. The study of phosphoryl group transfer reactions is important for biological and molecular chemistry, as well as in studying mechanisms of chemical processes involving organophosphorus compounds. New versions of asymmetric electrophilic reactions applicable for the synthesis of enantiopure P-chiral secondary and tertiary phosphines are discussed.
\end{abstract}

Keywords: electrophilic reactions; stereochemistry of organophosphorus compounds; stereospecificity

\section{Introduction}

Electrophilic reactions are one of the main types of transformations in the chemistry of trivalent phosphorus compounds [1-3]. Electrophilic reactions allow to obtain important products such as phosphine ligands, pharmaceuticals and agricultural substances [3-6]. Electrophilic asymmetric catalysis, which allows one to obtain a number of chiral substances that are difficult to access by other methods, is of particular interest. Therefore, asymmetric electrophilic reactions are of increasing interest to synthetic chemists. Many chiral ligands that are derivatives of trivalent phosphorus (DIOP, DuPhos, PAMP, DIPAMP, etc.) and catalysts generated based on them were obtained using electrophilic reactions of alkylation, arylation and so forth [2,6]. Electrophilic reactions of phosphorus compounds with reagents bearing positive halogen (Appel, Atherton-Todd, Corey-Fuchs reactions and others [2-6]) are widely used for the synthesis of natural compounds and their analogues (Scheme 1).

In contrast to nucleophilic substitution reactions at phosphorus stereogenic centers that have been studied in great detail, electrophilic aliphatic substitution reactions have been relatively unexplored. It is accepted that bimolecular nucleophilic substitution at carbon involves backside attack resulting in an overall inversion of configuration at phosphorus. However, no such general statement can be made concerning bimolecular electrophilic substitution. The mechanistic intricacies of $\mathrm{S}_{\mathrm{E}} 2$ reactions have just begun to be realized and appear to be more complicated and varied than $S_{N} 2$ cleavages. Electrophilic reactions proceed with retention of absolute configuration at the chiral phosphorus center unlike to nucleophilic $\mathrm{S}_{\mathrm{N}} 2(\mathrm{P})$ reactions, which, as a rule, proceed with inversion of absolute 
configuration. This feature of electrophilic $\mathrm{S}_{\mathrm{E}} 2(\mathrm{P})$ reactions is a powerful tool in studying mechanisms of organophosphorus reactions. Moreover, the stereospecificity of electrophilic reactions is important for the syntheses of natural compounds with participation of chiral organophophorus reagents. Therefore, the analysis and systematization of stereospecific electrophilic reactions are important from theoretical and practical viewpoints. At the same time, despite the large number of publications devoted to classical examples of electrophilic reactions involving phosphorus, the stereochemistry of electrophilic reactions has not yet been analyzed and generalized and a review article devoted to the study of these reactions has not been published. At the same time, general conclusions on the stereochemistry and mechanisms of electrophilic reactions are interesting and necessary. Therefore, we propose to discuss stereochemistry of electrophilic reactions proceeding with participation of chiral phosphorus compounds.

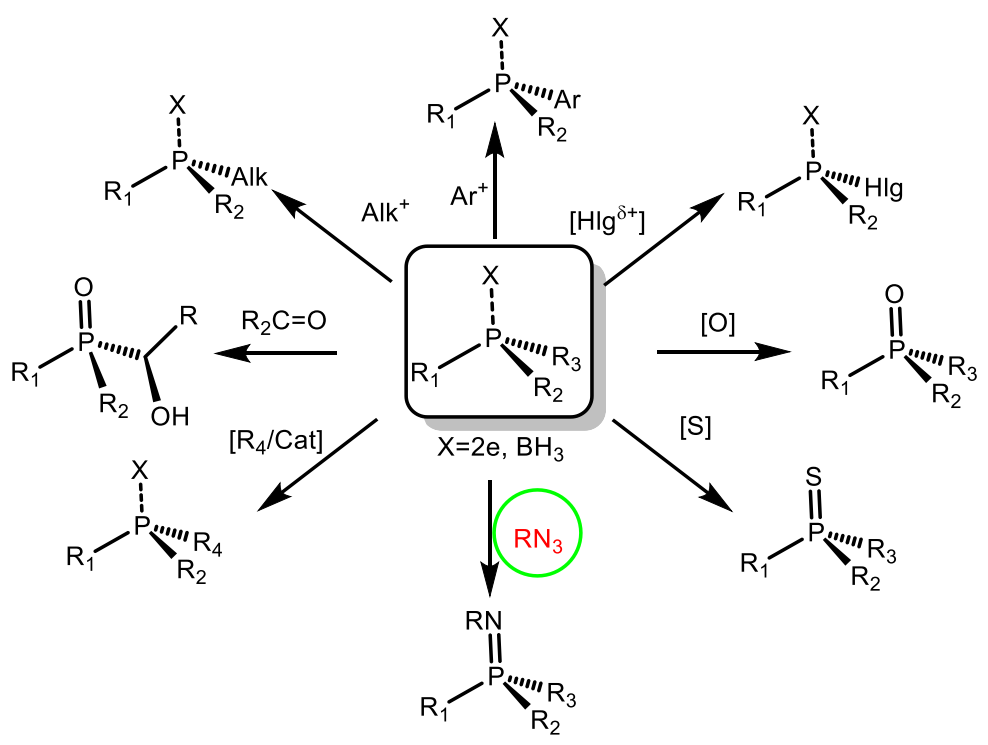

Scheme 1. Versions of electrophilic reactions at the phosphorus atom.

\section{Alkylation and Arylation Reactions}

The alkylation and arylation of chiral tertiary phosphines proceed, as a rule, stereospecifically with retention of absolute configuration. In many cases, the electrophilic reactions of $\mathrm{P}(\mathrm{III})$-compounds proceed via the addition-elimination mechanism, that involves the addition of electrophile to phosphorus with formation of adduct, which then cleaves the leaving group to give the final product. In some cases, the reaction can stop at the first step with the formation of a stable phosphonium cation (Equation (1)). An electrophile providing a free orbital to a substrate interacts with the front-side of the phosphorus center, where a free pair of electrons is located. The limiting step in the case of $S_{E}(P)$ reactions is the first step. Trivalent phosphorus compounds can be electrophiles and nucleophiles. For example, tertiary phosphines easily enter electrophilic and nucleophilic substitution reactions as shown in Equations (1) and (2) [4,5].

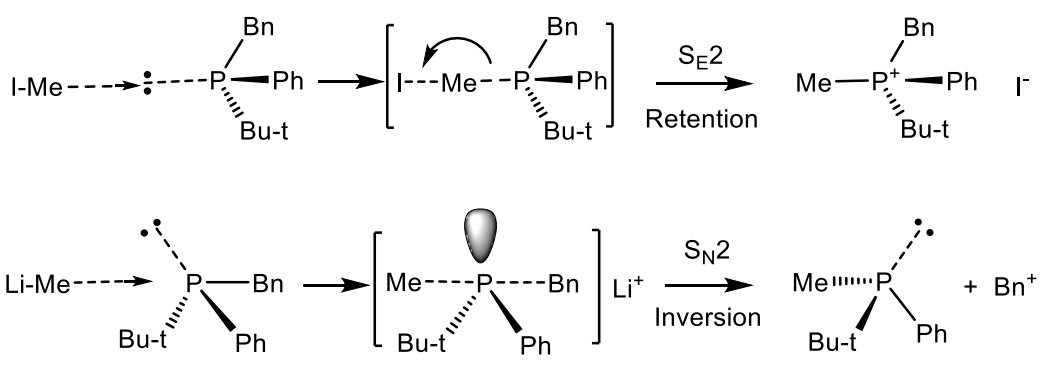


In the case of $S_{E} 2(P)$ reactions a positively charged electrophile $\mathrm{Y}^{+}$interacts with the electron-enriched phosphorus center from the front-side forming a new P-Y bond. As a result, a positively charged intermediate is formed with retention of absolute configuration, which can turn into a final product or remain in the form of a phosphonium salt (Equation $(3))[5,6]$.

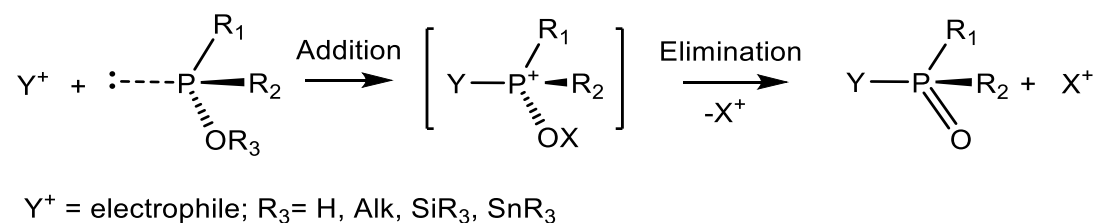

In contrast to the bimolecular nucleophilic substitution, which usually occurs with inversion of configuration due to the orientation of the coupled orbitals and electron pairs, electrophilic substitution, as a rule, proceeds with the retention of absolute configuration. The most common types of electrophilic reactions are the alkylation and arylation of trivalent phosphorus compounds and their boranes, namely: quaternization, substitution of metal phosphides, Michaelis-Arbuzov or Michaelis-Becker reactions (Scheme 2).

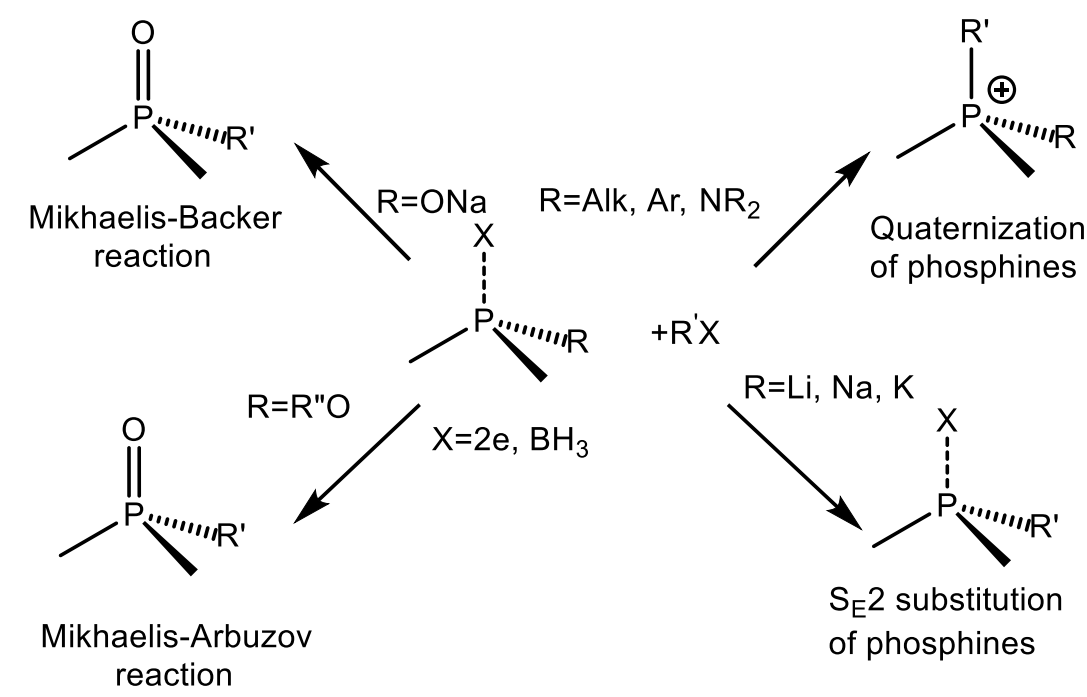

Scheme 2. Versions of alkylation/arylation of P(III) compounds.

Alkylation and arylation of metal phosphides is one of the convenient methods for the synthesis of tertiary phosphines (Equation (4)) [7-10]. The starting metal phosphides can be easily obtained by cleaving the $\mathrm{CP}$ bond in triaryl- or diarylphosphines by various reagents-alkali metals in mineral oil, sodium in liquid ammonia, naphthalene sodium, sodium suspended in THF, sodium or potassium absorbed on silica gel (M-SG reagent) and other methods [7]. The resulting alkali metal phosphides can serve as useful building blocks for a variety of phosphines. For example, methylmenthylphenylphosphine was obtained by alkylation of neomenthylmethylphenylphosphine (Equation (5)) [10-13]. The reaction of sodium methylphenyl phosphide with (+)-(R)-1-chloroethylbenzene afforded $(-)-\left(S_{\mathrm{P}}, S_{\mathrm{C}}\right)$-phosphine oxide with $25 \%$ ee. Stereochemically pure products were obtained after crystallization of the corresponding phosphine oxides.

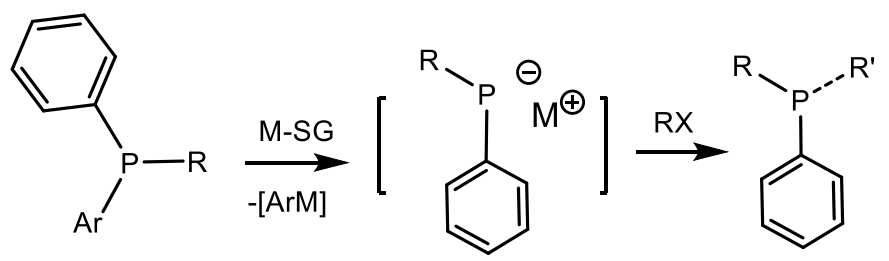




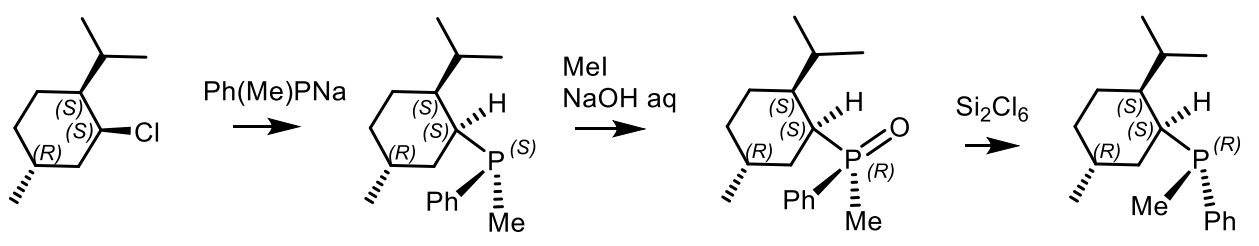

Using this method, a number of phosphine ligands were synthesized, including chiral bis-phosphines (DIOP, DIPAMP, PAMPOP, etc.) [11,12], which use for carrying out asymmetric catalytic hydrogenation reactions (Equation (6)) [2,5,14,15].

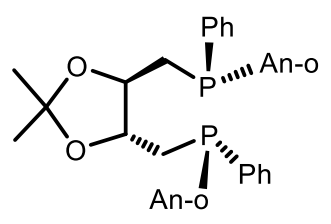

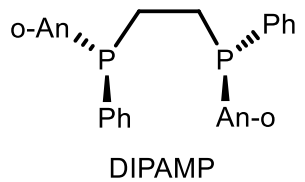<smiles>C[C@H](P)[Pb](C)(C)c1ccccc1</smiles>

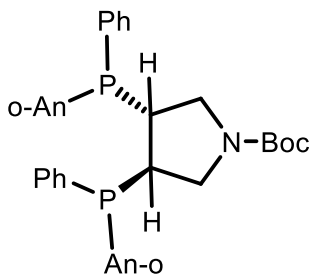<smiles>CC1(C)O[C@@](C)(Cc2ccccc2)[C@@](C)(Cc2ccccc2)O1</smiles>

DIOP<smiles>CP(P)Cc1cccc(CP(C)S)c1</smiles>

$\mathrm{X}=, \mathrm{CH}, \mathrm{N}$

Alkylation and arylation of chiral tertiary phosphines also allow us to obtain chiral phosphonium salts, which have various practical applications as chiral phase transfer catalysts, organocatalysts, ligands in transition metal complexes and chiral reagents [9,16-18]. Chiral phosphonium salts were synthesized and characterized, their practical application has been studied [16-20]. A method for producing chiral phosphonium salts by quaternizing phosphines and their derivatives with arenes formed in situ from 2 (trimethylsilyl)aryl triflates is described. Alkylation and arylation of P-stereogenic phosphines proceeds stereospecifically with retention of absolute configuration and in high yields of phosphonium salts (Equations (7)-(9)) [16-20].

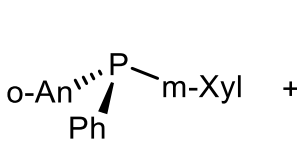<smiles>CS(=O)(=O)c1c(O[Tl])ccc2ccccc12</smiles>
$\underset{\mathrm{MeCN}, \mathrm{rt}}{\stackrel{\mathrm{CsF}}{\longrightarrow}}$<smiles>O=[PH](=O)(O)c1ccccc1</smiles>

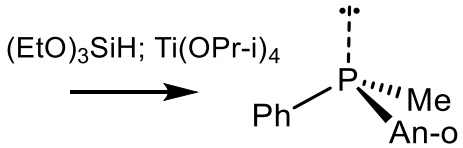

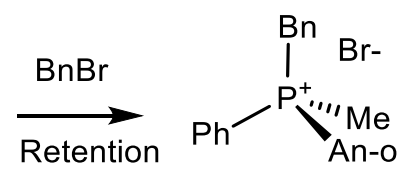<smiles>COC(CC(=O)c1ccccc1)C(C)N(C)[P+]([O-])([O-])c1ccccc1</smiles><smiles>[R]NP(=O)([18OH])[Pb](C)(C)C</smiles>

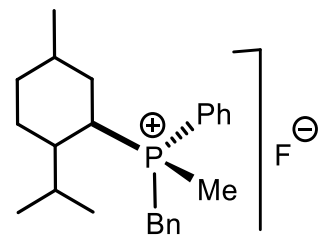


Glueck and colleagues synthesized the $\mathrm{C}_{2}$ symmetric P-stereogenic Benz $\mathrm{P}^{*}$ bisphosphine ligand-a building block for chiral bis(phosphines) — by electrophilic alkylation of benzodiphosphetane with methyl triflate and subsequent reaction with methyl magnesium bromide [21]. The benzodiphosphetane is configurationally stable and does not racemize when heated to $105^{\circ} \mathrm{C}$ in toluene for $18 \mathrm{~h}$. As a result, the $\mathrm{C}_{2}$-symmetric P-stereogenic ligand Benz2* was stereospecifically formed with $>90 \% d e$ (Equation (10)).

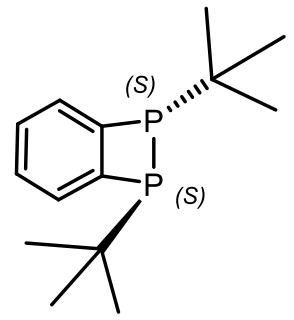

$10: 1$ er
1) $\mathrm{MeOTf}$

2) $\mathrm{MeMgBr}$

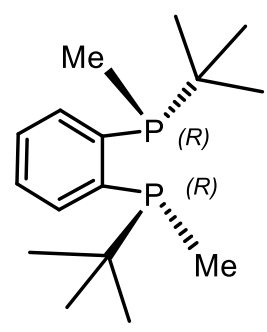

(R)-BenzP* ${ }^{*}, 10: 1$ er

Interesting observations were made during P-alkylation of alkoxycarbonylphosphine with methyl triflate [22,23]. Alkylation of alkoxycarbonylphosphine in methylene chloride at $-78--20{ }^{\circ} \mathrm{C}$ followed by hydrolysis of the intermediate alkoxycarbonylphosphonium led to the formation of tertiary phosphine as a mixture of $\left(R_{\mathrm{P}}\right)$ - and $\left(S_{\mathrm{P}}\right)$-diastereomers with low $d e$. However, dynamic stereoselective crystallization of the resulting mixture of diastereomers from ethanol at room temperature led to the enrichment of the mixture with one diastereomer. The ratio of diastereomers changed to 25:1 $d r$ at room temperature and to $91: 1 d r$ when heated to $50{ }^{\circ} \mathrm{C}$ for $22 \mathrm{~h}$. After removal of the $\mathrm{BH}_{3}$ group, the reaction product was converted into a PAMP ligand with enantiomeric purity of $99.5 \%$ and in yield of $74 \%$ (Equation (11)) [22,23].<smiles>CCOC(=O)P(=O)(O)P(=O)(O)c1ccccc1</smiles><smiles></smiles>

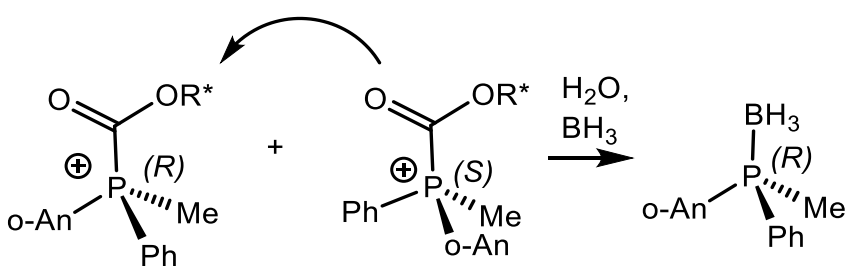

$\mathrm{Ph}$

$$
\text { . }
$$

$$
\text { . }
$$$$
\text { o-An }
$$

$$
\text { . }
$$

$$
\text { . }
$$


Phosphine boranes are configurationally stable compounds that do not racemize at room temperature, although they can racemize at elevated temperatures [31-34]. Phosphine-boranes react with alkali metals to form lithium, sodium or potassium derivatives, which undergo electrophilic substitution at phosphorus when interact with electrophiles (Equation (13)). In solutions, the alkali metal is coordinated to the $\mathrm{BH}_{3}$ hydrides in an $\eta^{2}$-manner. In the condensed crystalline structure of phosphine-boranes, as was found by X-ray diffraction (XRD) analysis, the metal ion is coordinated not only with the $\mathrm{BH}_{3}$ group but also with the phosphorus atom. In some cases, metal-substituted phosphine-boranes can exist as solvent-separated ion-pairs (Scheme 3) [24-26].

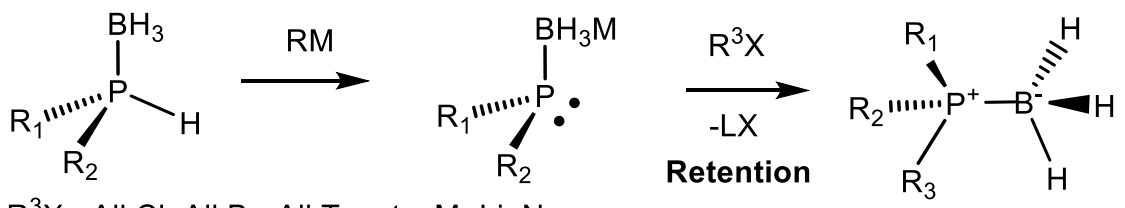

$\mathrm{R}^{3} \mathrm{X}=\mathrm{AlkCl}, \mathrm{AlkBr}$, AlkTs, etc; $\mathrm{M}=\mathrm{Li}, \mathrm{Na}$

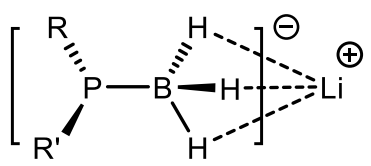

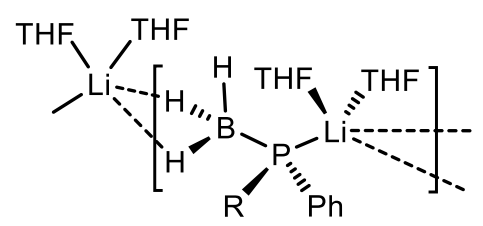

R

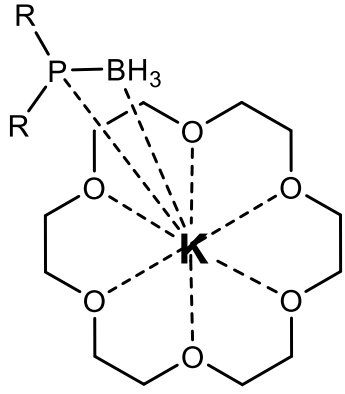<smiles>[B]P(C)(=O)P(N)(=O)OC#N</smiles>

Scheme 3. Coordination of metal cations in phosphine-boranes.

Phosphine-boranes are in general available compounds. Convenient methods for their synthesis have been developed and found practical application [26-32]. For example, phosphine oxides and sulfides can be converted into corresponding phosphine-boranes by treatment with oxalyl chloride and subsequent reduction with sodium borohydride, which acted as a reducing agent and a source of borane (Equation (14)). The reaction proceeds through the formation of secondary phosphine dichlorides, which, after reduction with sodium borohydride, give phosphine-boranes. Using this methodology, various phosphine oxides and phosphine sulfides were stereospecifically converted into corresponding phosphine boranes in high yields [33-35]. In some cases, the reaction proceeded with racemization, probably due to the influence of the nucleophilic chloride counterion. However, the switching from chlorophosphonium to alkoxyphosphonium salts as intermediates and the use of methyl triflates or Meerwein salts as alkylating agents increase the stereospecificity of the reaction with inversion of configuration (Equation (15)) [33]. Thus, from one P-stereogenic phosphine oxide, both optical antipodes of the corresponding phosphine-borane were obtained (Equation (16)). 


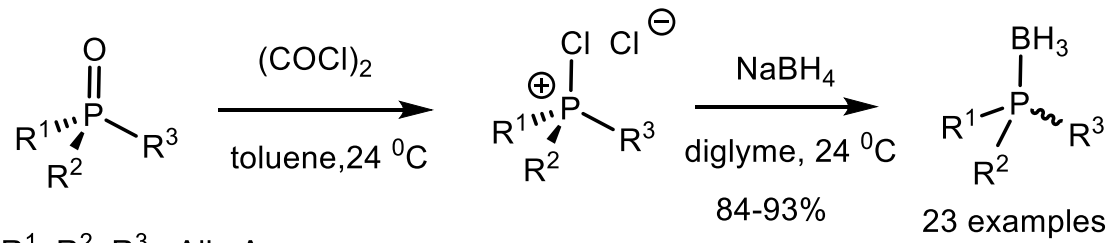

$\mathrm{R}^{1}, \mathrm{R}^{2}, \mathrm{R}^{3}=$ Alk, $\mathrm{Ar}$<smiles>[R][Pb]([R])([B])c1ccccc1</smiles>

(S)-, 62-76\%<smiles>CC[C@@H](N)C(C)(C)C</smiles>

$\mathrm{X}=\mathrm{O}, \mathrm{S}$<smiles>[R]P([R])([Y])([Na])c1ccccc1</smiles>

$(R)$ -

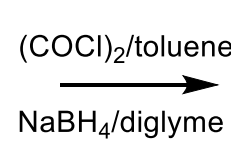<smiles>[2H][PH]([13CH3])([18OH])[PbH2]</smiles>

(R)-, 86-91\%

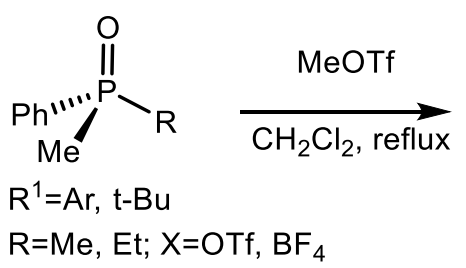<smiles>[R]O[PH]([R])(=O)([Pb])O[Na]</smiles>

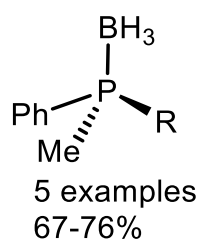

A convenient method for producing tertiary phosphines is the electrophilic substitution of phosphide anions with alkyl halides obtained from phosphine-borane complexes. The alkylation reactions of metal-substituted phosphine boranes proceeds, as a rule, with the retention of absolute configuration, which corresponds to the attack of electrophile to electron-enriched phosphorus atom from the front side. The reaction proceeds through the formation of a transition state, which is stabilized by the removal of electrofuge $\mathrm{M}^{+}$and the formation of the final substitution product (Equation (17)).

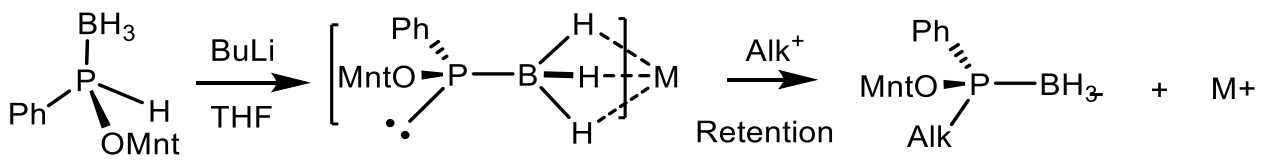

$\mathrm{M}=\mathrm{Li}, \mathrm{Na}$

The treatment of secondary phosphine-borane with butyllithium and subsequent alkylation led to the formation of tertiary phosphine-boranes with retention of configuration and very good ee. The absolute configuration of the reaction products was established by X-ray analysis (Equation (18)) (Table 1) [30]

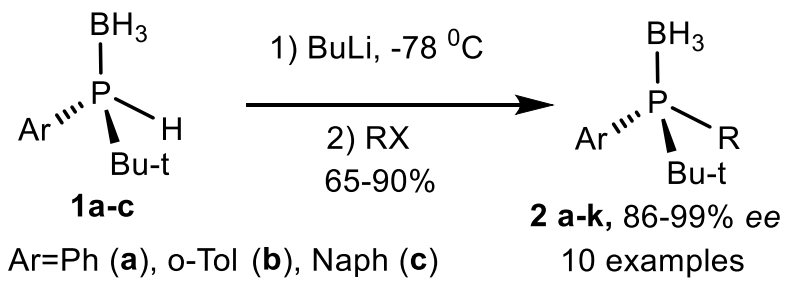

Livinghouse et al. developed a method for enantioselectively producing chiral tertiary phosphine-boranes from racemic secondary phosphine-boranes [35,36]. Alkylation of lithium phosphide was carried out using enantiocontrolled dynamic resolution. Sparteine increased the stereoselective formation of one enantiomer of secondary phosphines under thermodynamic control. Stirring the suspended (-)-sparteine-lithium complex of secondary phosphine at room temperature led to the increase in optical purity of the alkylation product from $40 \%$ to $92-95 \%$ ee (Equation (19)). 
Table 1. Synthesis of optically active tertiary phosphine-boranes 2a-k (Equation (18)) [30].

\begin{tabular}{|c|c|c|c|c|}
\hline Substrate & $\mathbf{R X}$ & Product & Yield, \% & $e e, \%$ \\
\hline$\left(S_{\mathrm{P}}\right) \mathbf{- 1 a}$ & $\mathrm{MeI}$ & $\left(R_{\mathrm{P}}\right)-\mathbf{2 a}$ & 85 & 99 \\
\hline$\left(S_{\mathrm{P}}\right)-\mathbf{- 1 a}$ & $\mathrm{BnBr}$ & $\left(R_{\mathrm{P}}\right)-\mathbf{2 b}$ & 91 & 98 \\
\hline$\left(S_{\mathrm{P}}\right)-\mathbf{1 a}$ & $\mathrm{CH}_{2}=\mathrm{CHCH}_{2} \mathrm{Br}$ & $\left(R_{\mathrm{P}}\right)-2 \mathrm{c}$ & 83 & 89 \\
\hline$\left(S_{\mathrm{P}}\right)-\mathbf{- 1 a}$ & $\mathrm{CH} \equiv \mathrm{CCH}_{2} \mathrm{Br}$ & $\left(R_{\mathrm{P}}\right)-2 \mathrm{~d}$ & 65 & 89 \\
\hline$\left(S_{\mathrm{P}}\right)-\mathbf{1 a}$ & $\mathrm{Me}_{3} \mathrm{SiCH}_{2} \mathrm{I}$ & $\left(R_{\mathrm{P}}\right)-\mathbf{2 e}$ & 93 & 86 \\
\hline$\left(S_{\mathrm{P}}\right)-\mathbf{1 a}$ & o- $\mathrm{PyCH}_{2} \mathrm{Cl}$ & $\left(R_{\mathrm{P}}\right)-2 \mathrm{f}$ & 68 & 99 \\
\hline$\left(S_{\mathrm{P}}\right)-\mathbf{1 b}$ & $\mathrm{MeI}$ & $\left(R_{\mathrm{P}}\right)-2 \mathrm{~g}$ & 77 & 98 \\
\hline$\left(S_{P}\right)-\mathbf{1 b}$ & $\mathrm{BnBr}$ & $\left(R_{\mathrm{P}}\right)-2 \mathrm{~h}$ & 90 & 99 \\
\hline$\left(S_{\mathrm{P}}\right) \mathbf{- 1} \mathbf{b}$ & $\mathrm{CH}_{2}=\mathrm{CHCH}_{2} \mathrm{Br}$ & $\left(R_{\mathrm{P}}\right)-2 \mathbf{i}$ & 90 & 78 \\
\hline$\left(S_{\mathrm{P}}\right)-\mathbf{1} \mathbf{b}$ & $\mathrm{CH} \equiv \mathrm{CCH}_{2} \mathrm{Br}$ & $\left(R_{\mathrm{P}}\right)-\mathbf{2} \mathbf{j}$ & 68 & 77 \\
\hline$\left(S_{\mathrm{P}}\right)-\mathbf{1 c}$ & MeI & $\left(R_{\mathrm{P}}\right)-\mathbf{2 k}$ & 89 & 91 \\
\hline
\end{tabular}
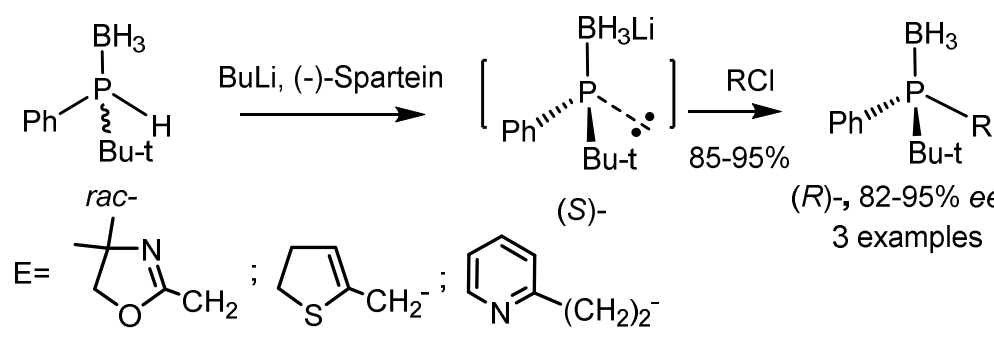
Chiral menthyl phosphinite boranes were stereoselectively reduced to phosphine-boranes by such reducing agents as lithium naphthalene, lithium 4,4'-di-tert-butyl biphenylide (LDBB) or lithium in liquid ammonia. The reaction proceeded through the formation of lithium derivatives. The intermediate phosphide borane was then alkylated with alkyl halides to tertiary phosphines with retention of configuration at the phosphorus atom (Equation (22)) [31,41-43].

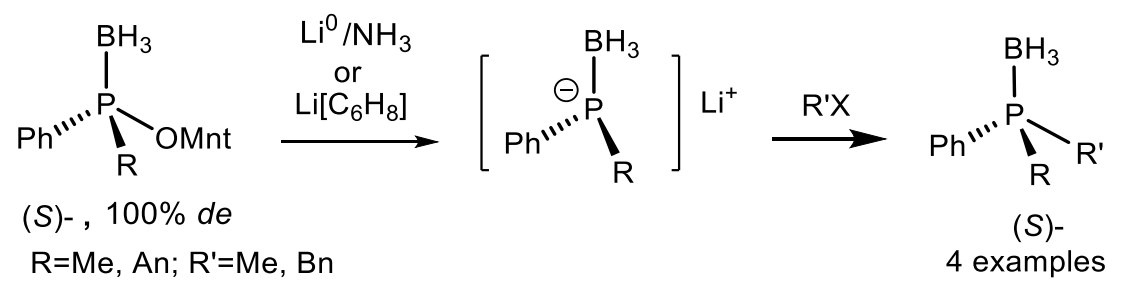

Phosphine-borane complexes reacted under mild conditions with alkyl (or aryl) halides in the presence of an olefin to form quaternary phosphonium salts. For example, the reaction of $(R)-\mathrm{PAMP} \cdot \mathrm{BH}_{3}$ with alkyl bromides led to the formation of enantiomerically pure phosphonium salts with the retained configuration (Equation (23)) [42].<smiles></smiles>

$\mathrm{R}=\mathrm{Ph}, \mathrm{CN}$

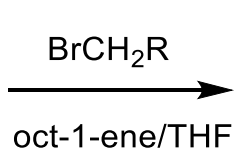

oct-1-ene/THF

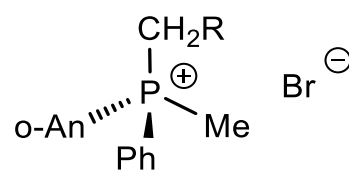

3 examples

The stereoselective synthesis of secondary phosphine-boranes containing amino acid substituents was achieved by alkylation of phenylphosphine-borane with $\gamma$-iodine- $\alpha$-aminoether under phase-transfer catalysis (PTC). Then the amino ester was hydrolyzed and reacted with $\alpha, \gamma$-diamine, which led to the formation of the corresponding dipeptides in good yields. The hydrophosphination reaction of $\mathrm{C}_{60}$-fullerene with phosphine-borane was carried out under PTC conditions, with the formation of P-C derivatives of $\mathrm{C}_{60}$-dipeptides in yield up to $80 \%$. The addition reactions of fullerene $\mathrm{C}_{60}$ were carried out under mild conditions without racemization of the amino acid or peptide moiety (Equation (24)) [44].
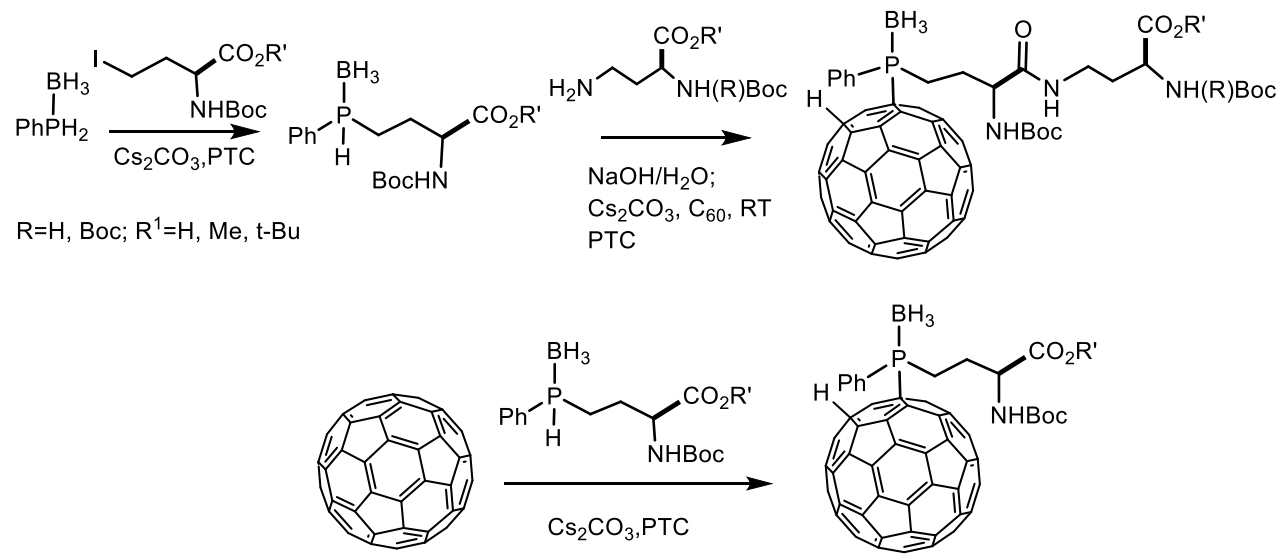

Halogenphosphine-boranes possessing unique chemical properties are very valuable chiral reagents for the preparation of P-chiral phosphine ligands as shown in Equations (25) and (26). For example, enantiomerically pure (S)-tert-butylmethylphosphine-borane was deprotonated with n-BuLi at $-78{ }^{\circ} \mathrm{C}$ and then halogenated with 1,2-dibromoethane or 1,2-diiodoethane to 
form halogenphosphine-boranes, which were isolated as crystalline substances with high yields Equation (25) [32]. The treatment of halophosphine-borane with tert-butyl lithium and subsequent reaction with alkyl halide through the formation of the corresponding phosphide-ion led to the formation of tertiary phosphine-boranes and bis-phosphines (Equation (26)) [32,39].

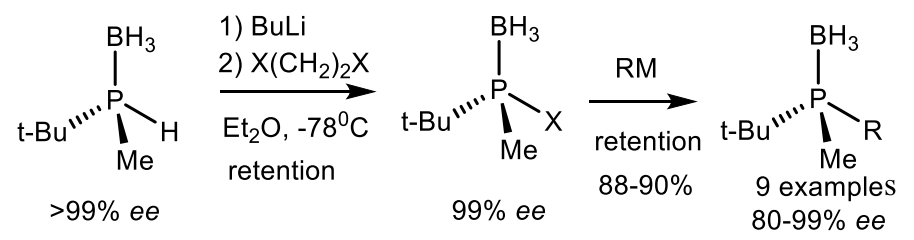

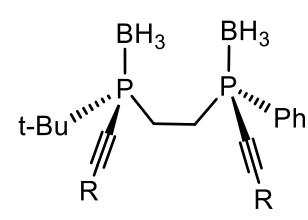

$X=B r, I ; R=B u, B n, A d, C=C R, R^{\prime}=P h, B u-t, i-P r_{3} S i, M_{3} \mathrm{Si}$

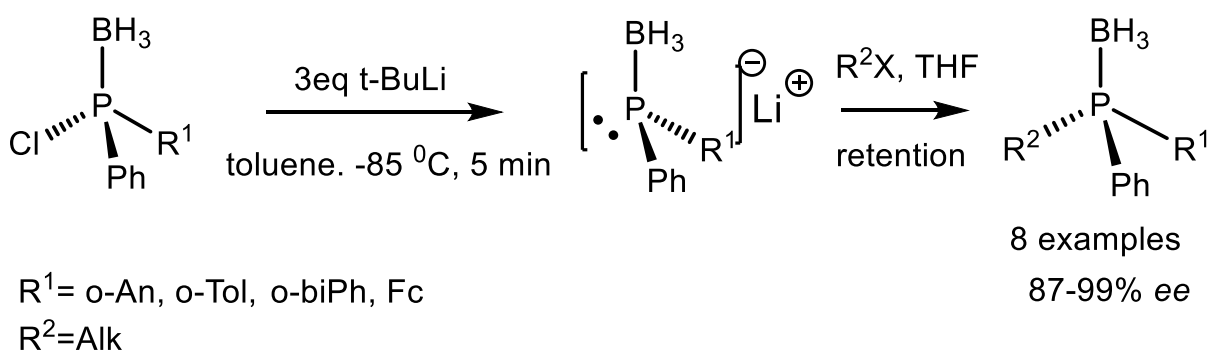

Samarium carbenoid formed from diiodomethane and samarium reacted with secondary phosphine boranes to form P-methylated tertiary phosphines. The reaction proceeded with retention of configuration at the stereogenic phosphorus atom. Experiments with deuterium showed that the methylene group is introduced directly into the $\mathrm{P}-\mathrm{H}$ bond through the transition state $\mathrm{A}$. The $\mathrm{P}-\mathrm{H}$ bonds of secondary phosphine-borane undergo methylene incorporation of a carbenoid to form the corresponding P-methylated derivatives (Equation (27)) [45].

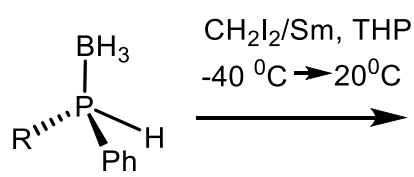

$\mathrm{R}=\mathrm{o}-\mathrm{An}, \mathrm{MntO}, \mathrm{t}-\mathrm{Bu}$<smiles>[2H][Pb]1([2H])CC[C@H]1I</smiles>

A

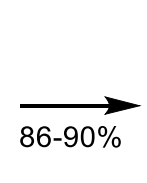
4 examples<smiles>[R][Pb]([B])(C)[Os]</smiles>

Copper complexes, as well as copper salts, were used as cocatalysts in phosphorylation reactions catalyzed by palladium [35]. Aromatic phosphorylation has been shown to occur at low temperatures with the addition of copper iodide. Using this method, the reaction catalyzed by $\operatorname{Pd}(0)-\mathrm{Cu}(\mathrm{I})$ of the enantiomeric secondary methylphenylphosphine-borane with aryl iodides was performed (Equation (28)).

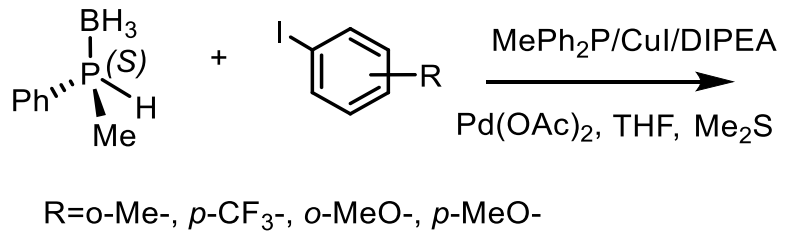<smiles>[R]c1ccc([PH]([B])(C)c2ccccc2)cc1</smiles>

$65-98 \%$

$95-99 \%$ ee 
The P-chiral ligand QuinoxP* was synthesized by deprotonation of chiral secondary phosphine-borane with n-butyl lithium followed by nucleophilic substitution of 2,3-dichloroquinoxaline at low temperature. Subsequent aromatic substitution and deboration reaction resulted in the formation of $(R, R)$-QuinoxP* as an orange crystalline solid (Equation (29)) [46].

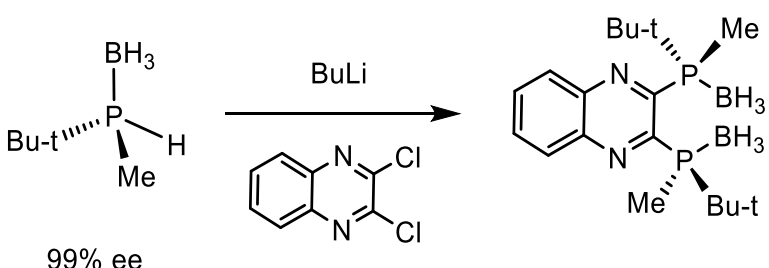

$99 \%$ ee

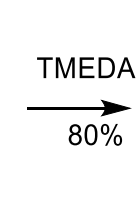

$$
99 \% \text { ee }
$$

An efficient synthesis of -P-stereogenic o-halogenaryl phosphine-boranes based on arine chemistry has been reported [40]. The key step of this synthesis is based on the reaction of a secondary phosphine borane with the 1,2-dibromo- (or diiodo)arene, owing to the formation in situ of an aryne species in the presence of n-butyllithium. When P-chirogenic secondary phosphine boranes were used, the corresponding o-halogenoarylphosphine boranes were obtained without racemization with $e e$ up to $99 \%$ and with complete retention of the configuration at the phosphorus center as shown in Equation (30).<smiles>[X]c1cc([R3])c([R3])cc1[X]</smiles>

$\mathrm{R}^{1}, \mathrm{R}^{2}, \mathrm{R}^{3}=\mathrm{Alk}, \mathrm{Ar}$ $\mathrm{X}=\mathrm{Br}, \mathrm{I}$<smiles>[R9]c1cc([X])c([PH]([R2])([R])[B])cc1[R3]</smiles>

22 examples $73-99 \%$ ee

The reaction mechanism involves the deprotonation of phosphine-borane by $\mathrm{n}$-BuLi to form lithium phosphide, which reacts with aryne (Scheme 4). The latter is generated in situ from 1,2-dihaloarene as a result of the exchange of metal halogene by the excess of $\mathrm{n}-\mathrm{BuLi}$, followed by $\mathrm{LiX}$ elimination. The resulting o-lithiated phosphine-borane undergoes a halogen metal exchange with 1,2-dihaloarene, forming o-halogen phenylphosphine-borane and promoting the formation of aryne. P-stereogenic o-bromophenylphosphine-boranes easily converted into P-stereogenic o-(hydroxyalkyl) phenylphosphines, which served as new functional chiral Lewis bases. It is important to note that the use of enantiomerically enriched ( $R$ )-1,2-dibromoarene $(77 \% e e)$ made it possible to obtain enantiomerically pure $\left(R, R_{\mathrm{P}}\right)$-dibenzophosphine-borane after recrystallization (Scheme 4$)$ [40].

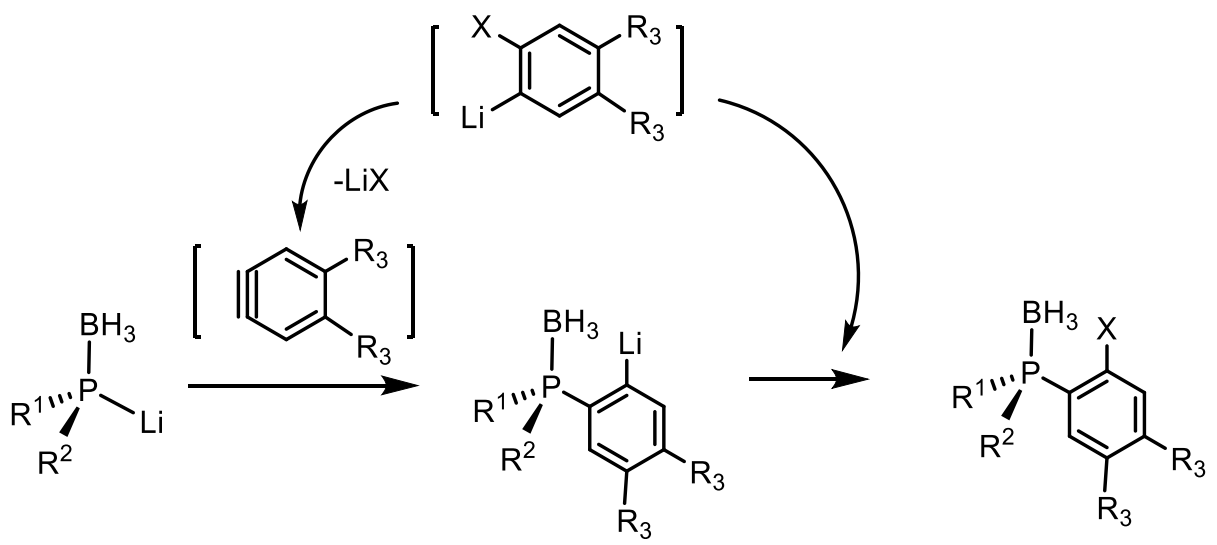

Scheme 4. The mechanism for the formation of o-bromophosphine boranes. 
Bimolecular electrophilic addition and substitution of chiral secondary phosphines, as a rule, proceeds with retention of absolute configuration at phosphorus. However, one exception to the rule is known. The reaction of diastereomerically pure $\left(S_{\mathrm{P}}\right)$-(menthyloxy)phenylphosphine-borane with o-iodoanisole in the presence of $\mathrm{Pd}\left(\mathrm{PPh}_{3}\right)_{4}$ in acetonitrile or dimethylformamide proceeded with the retention of configuration, giving the product with an inverted $\left(S_{\mathrm{P}}\right)$-configuration. However, the reaction in tetrahydrofuran in the presence of $\mathrm{K}_{2} \mathrm{CO}_{3}$ or $\mathrm{CH}_{3} \mathrm{CO}_{2} \mathrm{~K}$ proceeded with inversion of configuration, yielding an $\left(R_{\mathrm{P}}\right)$-product, as shown in Equation (31). Probably in the high polar acetonitrile, deprotonation of secondary phosphine-borane during interaction with $\mathrm{K}_{2} \mathrm{CO}_{3}$ occurred very fast. Therefore, the resulting phosphoric anion interacted with palladium catalyst retaining the configuration of phosphorus intermediate C. On the contrary, in the less polar THF solvent, deprotonation proceeded slowly and therefore the absolute configuration of the product depended on the inversion of configuration (Scheme 5) [31].

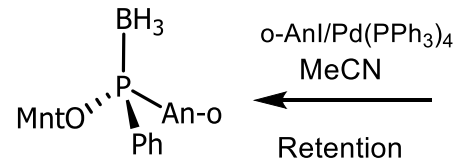

$\left(S_{\mathrm{P}}\right)-, 96 \%, \sim 100 \mathrm{de}$

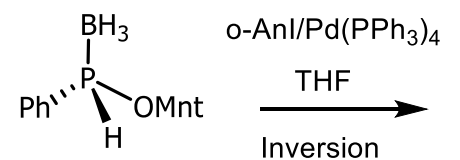

$\left(S_{\mathrm{P}}\right)-, 100 \%$ de<smiles></smiles>

$\left(R_{\mathrm{P}}\right)-,, 76 \%, 92 d e$

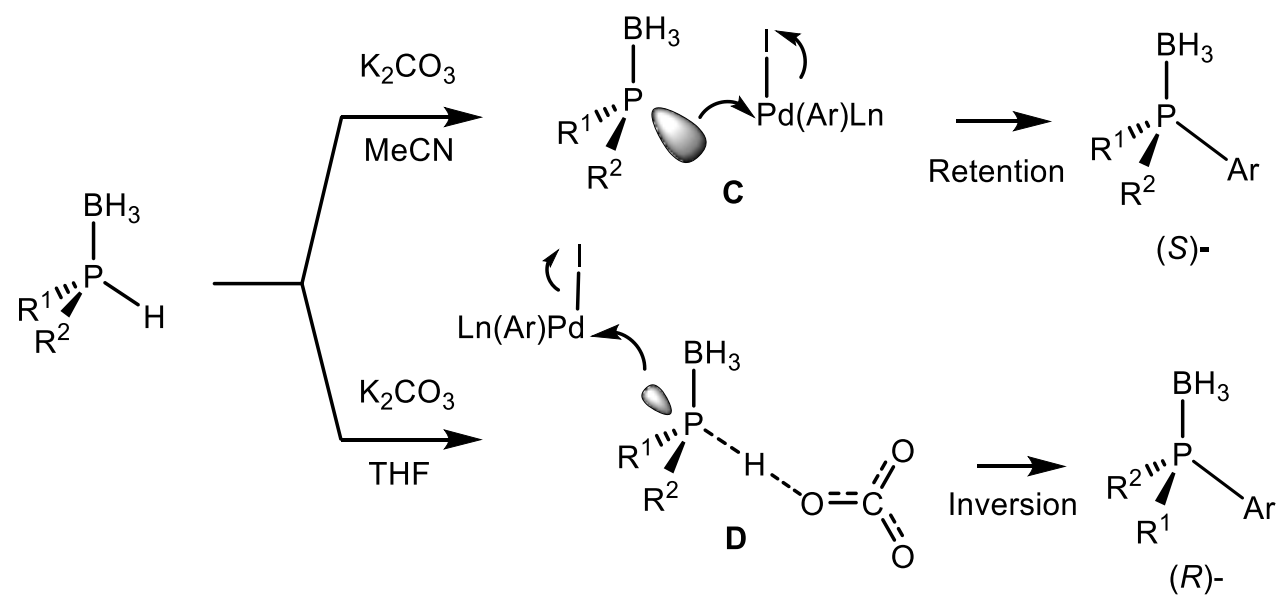

Scheme 5. Effect of solvent on the stereochemistry of arylation of phosphine-boranes.

Reactions of P-chiral secondary phosphine-boranes with fluorobenzene tricarbonylchromium in the presence of sec-butyl lithium led to the formation of phosphine ligands in yields of 75-99\% and complete retention of the absolute configuration (Equation (32)) [47]. Using this method, chiral phosphine ligands containing primary alkyl, sec-alkyl or aromatic substituents, including ferrocenyl and phenyl groups, were obtained. Phosphine ligands were used in the asymmetric catalytic reduction of alkynes and aldehydes with formation of chiral allyl alcohols with high regioselectivity and full (E)-selectivity as shown in Equation (33) [48].<smiles>[R][PH]([2H])([B])C</smiles>

$\mathrm{X}=\mathrm{Cl}, \mathrm{F}$

$\mathrm{R}=\mathrm{t}-\mathrm{Bu}, \mathrm{Ad}, \mathrm{Cy}$<smiles>[X]c1ccc(C(C)([O-])O[Na])cc1</smiles>
co

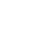

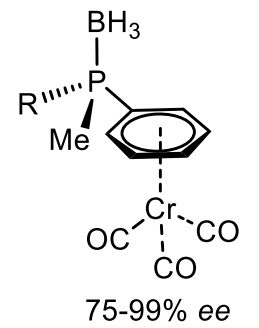




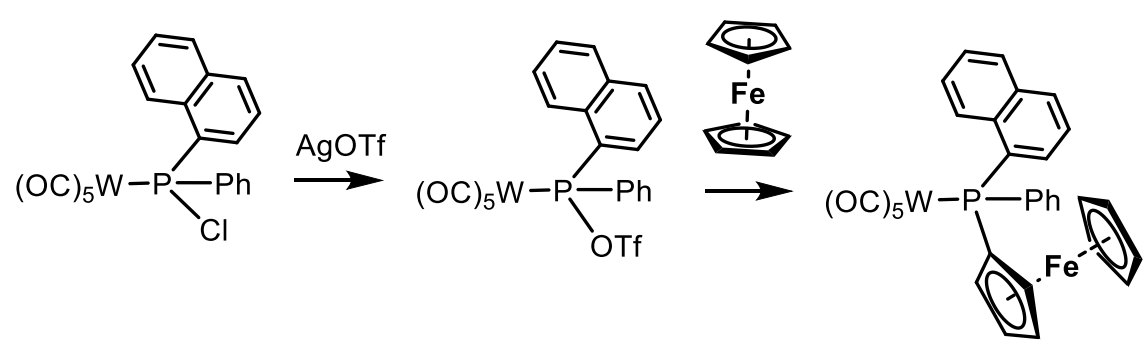

The Michaelis-Arbuzov reaction is one of the most universal methods for the formation of carbon-phosphorus bonds. The classical Michaelis-Arbuzov reaction consists in the alkylation of trivalent phosphorus acid esters with alkyl halides to form derivatives of the corresponding pentavalent phosphorus acids containing a new $\mathrm{P}-\mathrm{C}$ bond: phosphonates, phosphinates or tertiary phosphine oxides (Equation (34)) [49-54]. The stereochemistry of this reaction is of particular interest, the research results of which have not been fully generalized, although intensive studies were carried out.

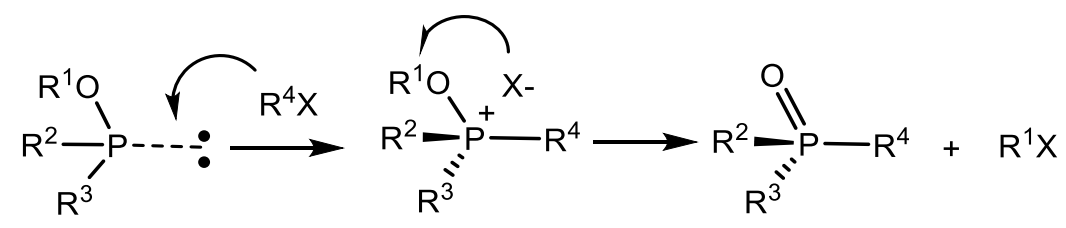

$\mathrm{R}^{2}=\mathrm{AlkO}$ or Alk, $\mathrm{Ar} ; \mathrm{R}^{3}=\mathrm{AlkO}, \mathrm{Alk}, \mathrm{Ar}$

Studies of the mechanism and stereochemistry of the Michaelis-Arbuzov reaction showed that it consists of two stages: at the first stage, the electrophilic reaction of a carbonyl compound with a trivalent phosphorus atom containing a pair of free electrons leads to the formation of alkoxyphosphonium salt. In the next stage, the intramolecular nucleophilic attack of a halide ion to the carbon atom of alkoxy group afforded an alkyl halide and phosphine oxide. The Michaelis-Arbuzov reaction of chiral phosphinites with alkyl halides proceeds stereospecifically with complete retention of absolute configuration at the phosphorus atom (Equation (35)) [49-51].

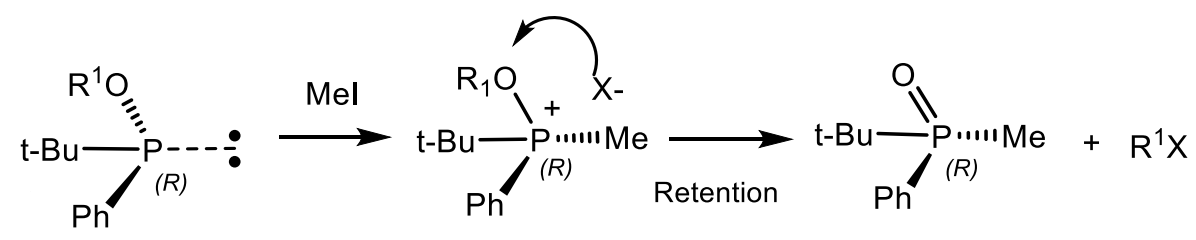

The reaction of trialkylphosphites containing chiral alkoxy groups stereospecifically led to the formation of chiral alkyl halides with the inverted configuration [50]. For example, the Michaelis-Arbuzov reaction of tri-(S)-2-octylphosphite with ethyl iodide resulted in the $(-)-(R)-2$-iodoctane, which, according to the authors, occurs as a result of intermolecular dealkylation of the tri-2-octyloxyethylphosphonium cation with an iodide anion (Equation (36)) [51].

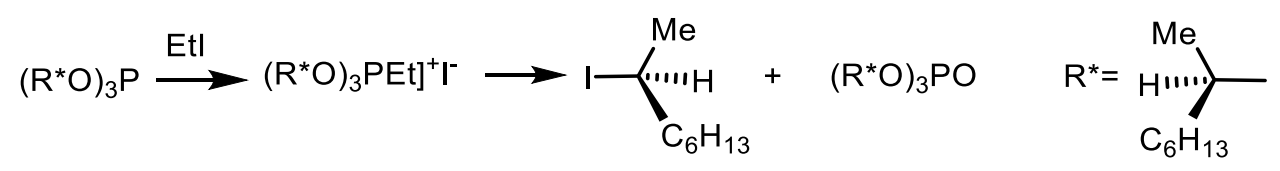


Alkylation of trimethylsilyl or trimethylstannyl derivatives of the ethyl phenylphosphinate, as well as the free radical addition to alkenes, proceeded with complete retention of configuration and with good yields (Equation (37)) [55].

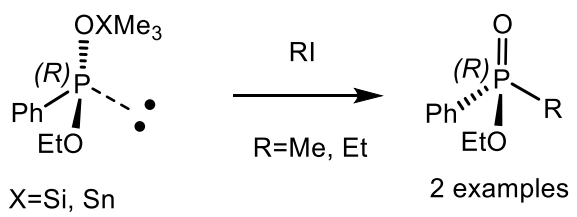

Stereochemical studies of the Michaelis-Arbuzov reaction of dioxaphospholane with alkyl halides, performed by Michalski et al., showed the evidence for equilibrium between phosphorane and phosphonium intermediates as shown in Equations (38) and (39) [54]. The decomposition of alkoxyphosphonium intermediates as a result of a nucleophilic attack of $\mathrm{X}^{-}$to P-OAlk led to the formation of phosphoryl groups. The dealkylation of phosphonium intermediate $\mathbf{D}$ occurs via the $\mathrm{S}_{\mathrm{N}} 2$ mechanism at the chiral carbon atom and is accompanied by inversion of configuration. When optically active secondary alcohol $\mathrm{R}^{*} \mathrm{OH}$ was used, the reaction led to the formation of alkyl halide with inverted configuration in agreement with the $S_{N} 2$. Evidently the concerted dealkylation of the phosphorane intermediate $C$ result in the retention of configuration at the carbon atom of alkyl halide
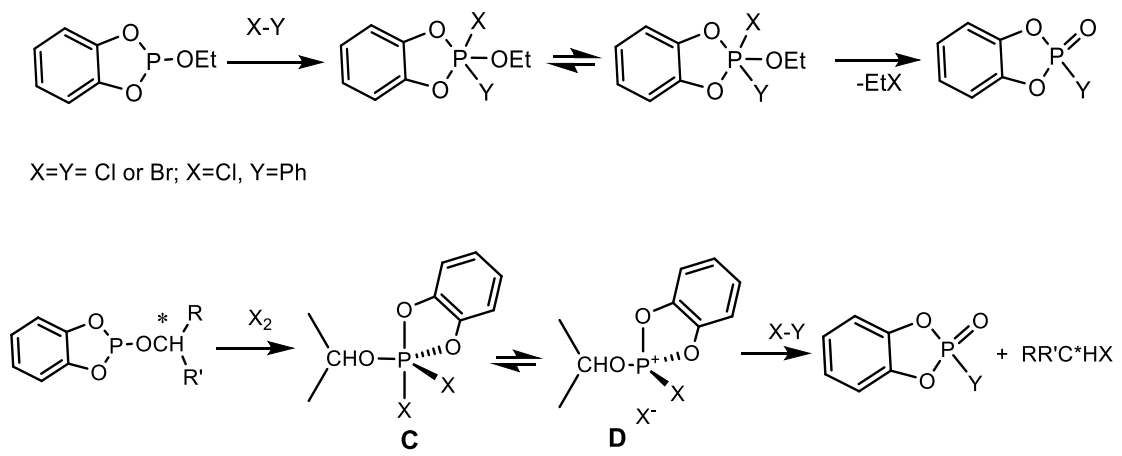

The asymmetric version of the Michaelis-Arbuzov reaction was investigated by several authors. For example, it was found that the cyclic phenylphosphonite obtained from (S)-1,3-butanediol reacts with alkyl halides with ring opening through cleavage of the P-O bonds and the formation of an acyclic product (Equation (40)) [52].

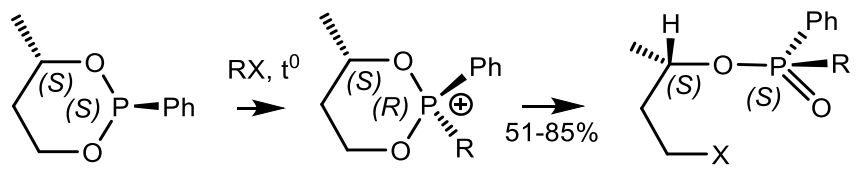

$\mathrm{RX}=\mathrm{Mel}$, Etl, $\mathrm{PrBr}, \mathrm{BuBr}$, AllylBr, BnCl, $\mathrm{Ph}_{3} \mathrm{CCl}$

7 examples

The reaction of diastereomerically pure (2R,4S,5R)-3,4-dimethyl-2,5-diphenyl-1,3,2-oxazaphospholidine with alkyl halides led to the formation of diastereomeres of the phosphonium salt in the ratio 85:15 $($ de $70 \%)$. Using nuclear magnetic resonance (NMR) spectroscopy, it was registered phosphonium intermediates with the same diastereomeric ratio as in the final products (Equation (41)) [43]. The Michaelis-Arbuzov reaction of triethylphosphite with benzyl bromide was studied using ultrafast NMR spectroscopy (UF-HMBC). In the presence of Lewis acids catalyzing the reaction was registered the benzyltriethoxyphosphonium intermediate. Initially, the slow formation of intermediates $\mathbf{A} \rightleftharpoons$ $\mathbf{B}$ occurred, which then quickly turned into phosphonate. The discovery of stable intermediate $\mathbf{A}$, according to the authors, indicates a monomolecular mechanism of reaction (Equation (42)) [53]. 


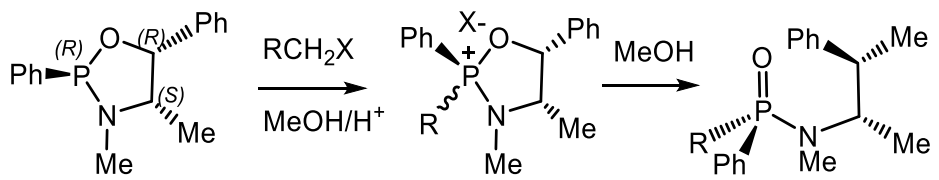

$\mathrm{R}=\mathrm{H}, \mathrm{Me}, \mathrm{Et}, \mathrm{Ph} ; \mathrm{X}=\mathrm{Cl}, \mathrm{Br}, \mathrm{I}$

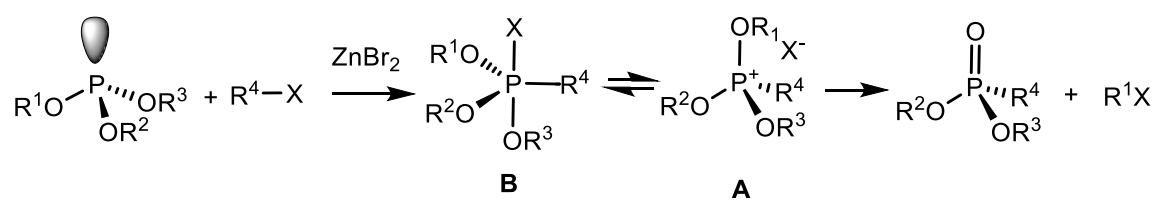

The Michaelis-Arbuzov reaction of (5S, 6S)-dimethoxy-2-phenyl-1,2,3-dioxaphosphacycloheptane with various alkyl halides led to the formation of corresponding phosphinates with a satisfactory enantiomeric excess. These phosphinates were converted into optically active phosphine oxides by reaction with Grignard reagents as shown in Equation (43) [49].

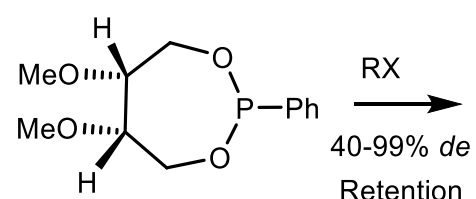

Retention<smiles>[R][C@H](COP([2H])(=O)c1ccccc1)[C@H](C)CBr</smiles>

17 examples

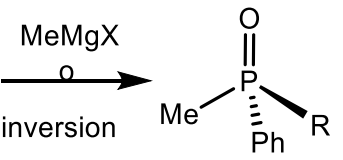

$46-100 \%$ $45-99 \%$ ee

$\mathrm{RX}=\mathrm{BnI}, 4-\mathrm{BrC}_{6} \mathrm{H}_{4} \mathrm{CH}_{2} \mathrm{I}, 4-\mathrm{CNC}_{6} \mathrm{H}_{4} \mathrm{CH}_{2} \mathrm{I}, 4-\mathrm{O}_{2} \mathrm{NC}_{6} \mathrm{H}_{4} \mathrm{CH}_{2} \mathrm{I}$

It was found that the stereochemistry of this reaction is determined by the equilibrium between the threo- and erythro-intermediates (Equation (43)). The interaction of a free electron pair of phosphorus (III) with an alkyl halide occurs through the axial position of phosphonite, with the formation of a quasi-phosphonium intermediate. The thermodynamic equilibrium between threoand erythro-intermediates led to an increase of erythro-diastereomeric excess, which then turned into (S)-phosphinate. This phosphinate was introduced into the Grignard reaction resulted in the tertiary (R)-phosphinates. Thus, the stereospecific Michaelis-Arbuzov reaction of the geometric isomer of 2-methoxy-5-tert-butyl-1,1,3,2-dioxaphosphorinan with the alkyl halide $\mathrm{X}-\mathrm{R}^{1}$ led to the formation of chiral tertiary phosphine oxides (Scheme 6) [49].

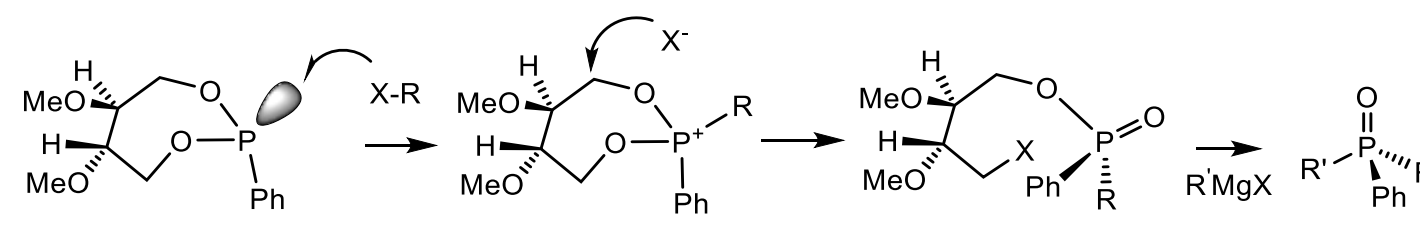

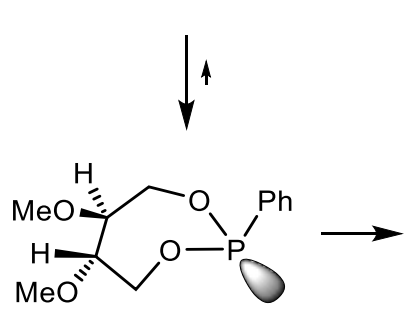
threo-

$(R)-$

$(S)-$

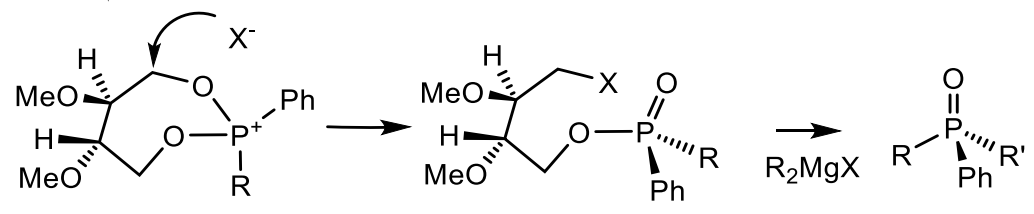

erythro-

Scheme 6. The Michaelis-Arbuzov reaction of the 2-methoxy-5-tert-butyl-1,1,3,2-dioxaphosphorinan with alkyl halides. 
The butoxy(phenyl)(vinyl)phosphine reacts with (-)-menthyl homoacetate to form a diastereomeres of Michaelis-Arbuzov reaction products, which were resolved by crystallization of the crude reaction mixture. After recrystallization, the $\left(S_{\mathrm{P}}\right)$-stereoisomer was obtained with $100 \%$ de (Equation (44)) [56-58].<smiles>C=CP(OCC)c1ccccc1</smiles>

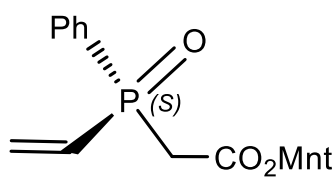

$100 \%$ de, after crystallization

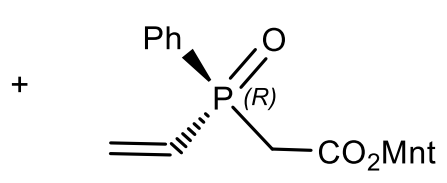

$(44)$

Buono et al. found that a chiral oxazaphospholidine obtained from (S)-(+)-prolinol stereoselectively reacts with benzyl bromide in refluxing methylene chloride to afford the $\left(R_{\mathrm{P}}\right)$-benzylphenyl-[2-(S)-bromomethylpyrrolidine-l-yl]phosphine oxide in $80 \%$ yield (Equation (45)) [59].<smiles>O=P(Cc1ccccc1)(c1ccccc1)N1CCCC1CBr</smiles>

The Michaelis-Becker reaction is the reaction of a H-phosphonates with a base and alkyl halide, followed by a substitution of the hydrogen atom at phosphorus on an alkyl with formation of alkyl phosphonates. The Michaelis-Becker reaction is completely stereospecific. Examples of the stereospecific Michaelis-Becker reaction with alkyl halides and aryl halides are shown in Equations (46) and (47) [60-62]. Sodium ethylate, sodium in THF, sodium hydride, butyllithium, sodium naphthalide, $\mathrm{Ca}(\mathrm{OH})_{2}$ in $\mathrm{DMF}, \mathrm{KOH}$ in acetonitrile and others were used as bases in the Michaelis-Becker reaction. Under the effect of strong bases H-phosphonates are deprotonated with formation of the phosphinite-anion of corresponding P(III)-acid, which easily reacts with electrophiles (Equation (46)). For example, alkylation of the sodium ethyl phenylphosphonite with methyl iodide or ethyl iodide in dimethylformamide gave an enantiomerically pure product in accordance with the stereospecificity of the Michaelis-Becker reaction. The reaction of chiral metal phosphides with alkyl halides afforded tertiary phosphine oxides with retention of absolute configuration at phosphorus center (Scheme 7).

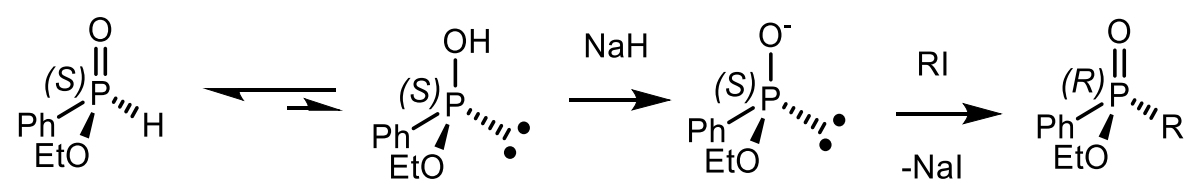

$\mathrm{R}=\mathrm{Me}, \mathrm{Et}$<smiles>O=[PH]([18OH])(Br)c1ccccc1</smiles>

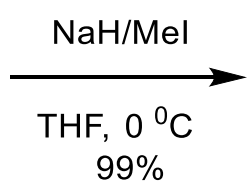<smiles></smiles> 


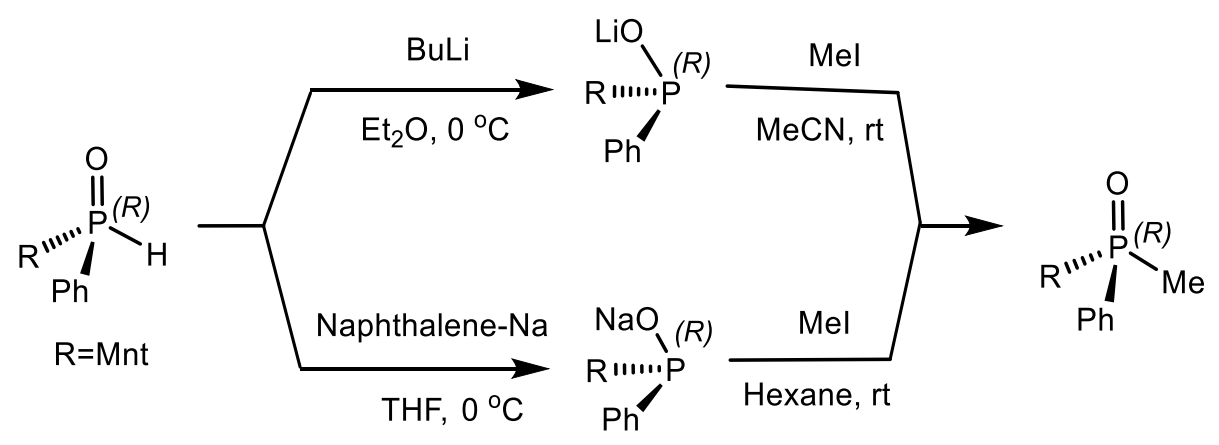

Scheme 7. Alkylation under conditions of Michaelis Backer reaction.

Several other examples of the stereospecific Michaelis-Becker reaction of sterically hindered H-phosponates with alkyl halides are shown in Equations (48) and (49) [31,37].

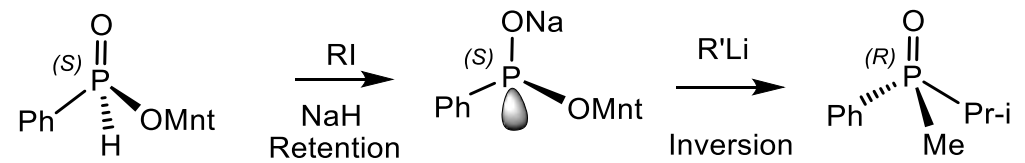

$\mathrm{R}=\mathrm{Me}$, i-Pr; $\mathrm{R}^{\prime}=\mathrm{Me}$, i-Pr

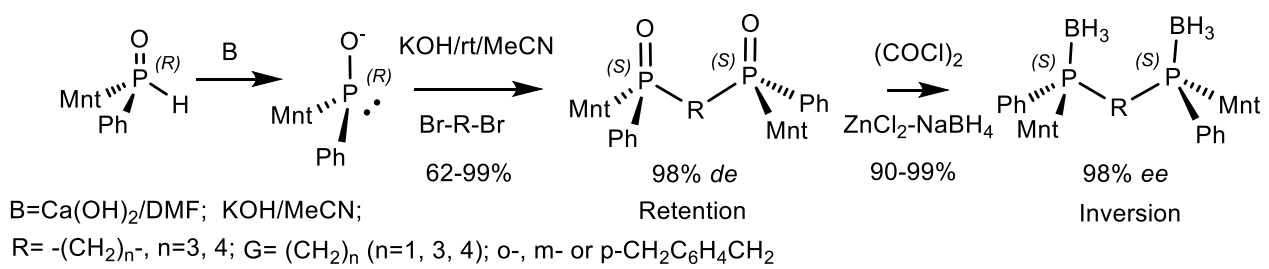

Cis- and trans-2-methoxy-4-methyl-1,3,2-dioxaphosphorinans react with various sulfenyl chlorides stereospecifically with retention of configuration at phosphorus (Equation (50)). The same stereochemical course was observed for the reaction between optically active isopropyl ethylphosphinate and methylsulphenyl chloride, which stereospecifically leads to the O-isopropyl (R)-ethylphosphonothioate (Equation (51)) [63]. Montchamp proposed chiral menthyl $\mathrm{H}$-hydroxymethylene phosphinate as an available P-chiral synthon for the preparation of chiral phosphines. $\left(R_{\mathrm{P}}\right)$-H-Hydroxymethylphosphinate represent a chiral equivalent of alkylphosphinates $\mathrm{ROP}(\mathrm{O}) \mathrm{H}_{2}$, which can be stereospecifically alkylated and then the hydroxymethylene moiety can be removed with formation of $\left(R_{\mathrm{P}}\right)$-methyl phosphonate (Equation $\left.(52)\right)[64,65]$.

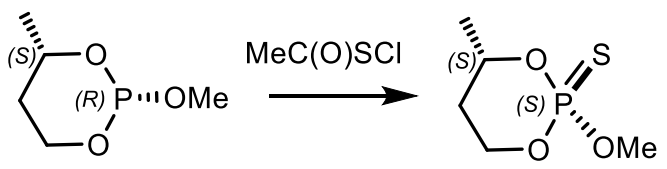

cis-, $93 \% d r \quad$ trans-, $93 \% d r$

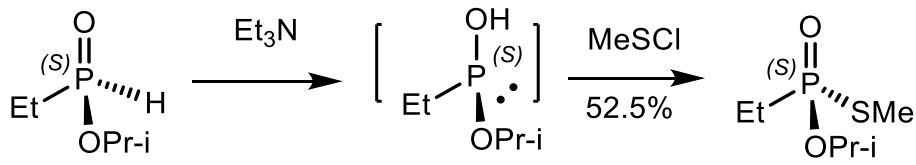


<smiles>CO[PH+]([18OH])CO</smiles>

$\left(R_{\mathrm{P}}\right)-, 98 \%$ de

$\mathrm{R}=\mathrm{Me}$, Allyl $(95-98 \% d e)$

$\mathrm{a}=\mathrm{Me}_{3} \mathrm{SiN}=\mathrm{C}\left(\mathrm{OSiMe}_{3}\right) \mathrm{Me} / \mathrm{Mel}$ or AllylBr; $\mathrm{b}=\mathrm{N}$-chlorosuccinimide $/ \mathrm{Me}_{2} \mathrm{~S} / \mathrm{CH}_{2} \mathrm{Cl}_{2} / \mathrm{Et}_{3} \mathrm{~N}$

In some cases, ultrasonic activation of the $\mathrm{P}=\mathrm{O}$ group reduction increases the reaction rate and yields of enantiomerically pure $\left(R_{\mathrm{P}}\right)$ - and $\left(S_{\mathrm{P}}\right)$-secondary phosphine oxides. For example, allyl- and 2-butenyl-tert-butylphenylphosphine oxides were obtained in two steps from $\left(R_{\mathrm{P}}\right)$ - and $\left(S_{\mathrm{P}}\right)$-tert-butylphenylthiophosphinic acid by ultrasound irradiation in the presence of Raney-Ni at room temperature and then converted into the (S)-tret-butyl(phenyl)phosphine oxide. This compound was then metallated, treated with lithium diethylamide (LDA) and alkenyl bromides, resulting in the allyl and 2-butenyl-tert-butylphenylphosphine oxides in good yields (Equation (53)) [66].
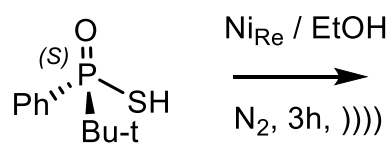

$\mathrm{R}=\mathrm{H}, \mathrm{Me}$

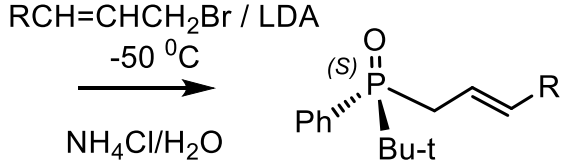

$54-80 \%$

The Hirao cross coupling is a particular case of the Michaelis-Becker reaction. The reaction includes palladium-catalyzed $\left[\mathrm{Pd}\left(\mathrm{PPh}_{3}\right)_{4}\right.$ or $\left.\mathrm{Pd}(\mathrm{OAc})_{4} / \mathrm{PPh}_{3}\right]$ cross-coupling of a trialkylphosphite and aryl halide to form phosphonates containing a new P-C bond (Equation (54)). Cross-coupling is stereospecific and the reaction of chiral $\mathrm{H}$-phosphonates with aryl halides proceeds with retention of absolute configuration at the phosphorus atom [67-74]. For example, it was found that the reaction of $\left(R_{\mathrm{P}}\right)-(+)$-isopropylmethylphosphinate with bromobenzene, catalyzed by tetrakis (triphenylphosphine)palladium and triethylamine, proceeds through the frontal attack of phenylpalladium bromide on the phosphorus center with formation of the isopropyl (S)-methyl(phenyl)phosphinate as shown in Equations (55) and (56) [72].

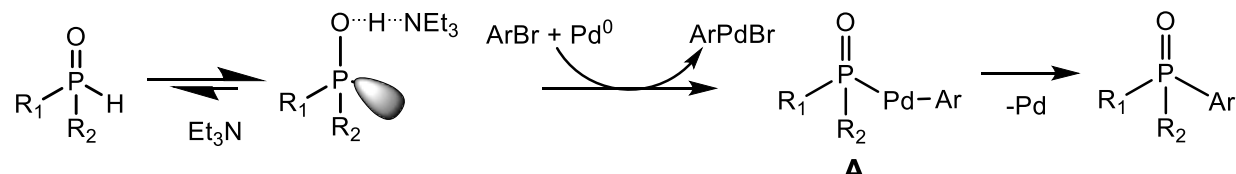
$\mathrm{R}^{1}, \mathrm{R}^{2}=\mathrm{Ph}, \mathrm{OAlk}$

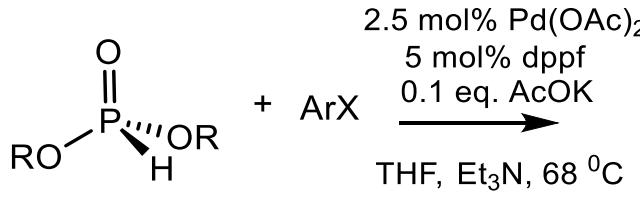

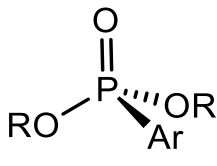

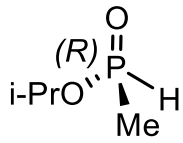<smiles>CCO[N+](=O)[O-]</smiles>

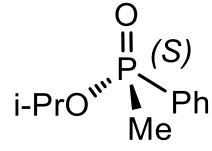

$88 \%$

The enantioselective C-P cross-coupling of secondary phosphine oxides with ortho-substituted aryl iodides was achieved using a kinetic resolution strategy leading to the formation of chiral triarylphosphine oxides in high yields and with good enantioselectivity. The best solvent for the 
reaction is acetonitrile (Equation (57)) [71]. The highest enantioselectivity (61-83\% ee) was achieved for such diarylphosphine oxides as (2-methoxyphenyl)(phenyl)phosphine oxide, phenyl (o-tolyl) phosphine oxide, [1,10-biphenyl-2-yl(phenyl)phosphine oxide in the presence of palladium triflate catalyst with a bis-phosphine ligand in acetonitrile at $70-80{ }^{\circ} \mathrm{C}$ [71].

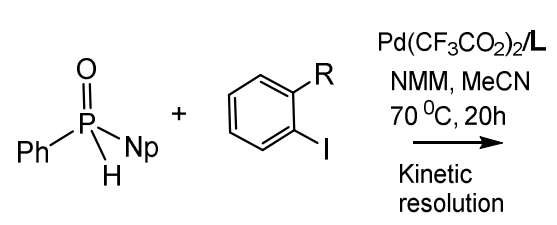

NMM: N-Methyl Morphin $\mathrm{R}=\mathrm{NHCOBu}-\mathrm{t}, \mathrm{NHCOMe}, \mathrm{NHCOCF}_{3}, \mathrm{NHSO}_{2} \mathrm{Ph}$

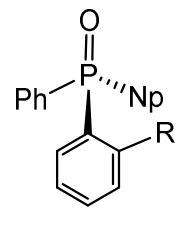

$61-83 \%$ ee

12 examples

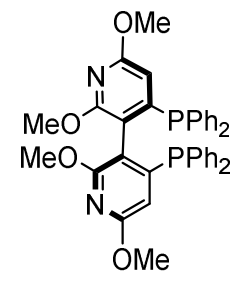

$\mathbf{L}$

The reaction of $(R)-(+)$-isopropyl methylphosphinate with vinyl bromides, catalyzed by tetrakis(triphenylphosphine)palladium and triethylamine, proceeds through the frontal attack of alkenylphosphinates on a phosphorus center with complete retention of configuration [70]. As a result, enantiomerically pure (S)- $\beta$-isopropylalkenylmethylphosphinates were obtained stereospecifically in good yields and with high ee. The absolute configuration of the compounds was determined by chemical correlation, which confirmed the retention of configuration at the chiral phosphorus center (Equation (58)) [69].

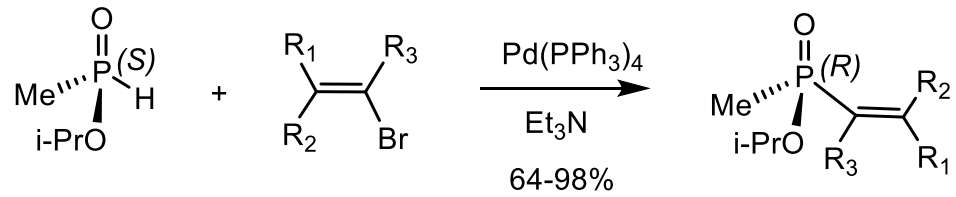

(S)-(+)-, $97 \%$ ee

$$
\mathrm{R}^{1}=\mathrm{R}^{2}=\mathrm{H}, \mathrm{R}^{3}=\mathrm{Me}, \mathrm{R}^{1}=\mathrm{Ph}, \mathrm{R}^{2}=\mathrm{R}^{3}=\mathrm{H}, \mathrm{R}^{2}=\mathrm{Ph}, \mathrm{R}^{1}=\mathrm{R}^{3}=\mathrm{H}
$$

The Hirao cross-coupling reaction is used for the synthesis of biologically active compounds. Using this reaction, various electrophilic aryl iodides, bromides or triflates were combined with H-phosphonates containing cholesterol or nucleoside substituents, providing a convenient approach to biologically active arylphosphonates. For example, in this way, the tyrosine triflate derivative was reacted with diethyl phosphite into the corresponding aryl phosphonate in high yield (Equation (59)) [70].<smiles>CCOP(=O)(O)OCC</smiles><smiles>CC(=O)N[C@@H](Cc1ccc(O)cc1)C(=O)OCc1ccccc1</smiles>

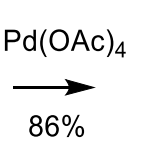<smiles>CCOP(=O)(OCC)c1ccc(C[C@H](NC(=O)OCc2ccccc2)C(C)=O)cc1</smiles>

Asymmetric synthesis of the new calcium antagonist (S)-(+)- and (R)-(-)-NZ-105 was carried out using the modified Hunsdiecker reaction with pyridinium ion and the modified Michaelis-Arbuzov reaction catalyzed by tetrakis(triphenylphosphine)palladium. Phosphination of dihydropyridine carboxylate bromide was carried out by heating trialkylphosphite with bromide in the presence of tetrakis(triphenylphosphine)palladium and triethylamine in toluene for $5 \mathrm{~h}$ at $110{ }^{\circ} \mathrm{C}$. As a result, the product was obtained in yield $87 \%$. The synthesized 1,4-dihydropyridines have a chiral center at position 4 . Therefore their enantiomers show different biological activities; for example, (S)-NZ-105 exhibited no less than 850-fold calcium antagonistic activity compared with that of $(R)$-isomer (Equation (60)) [62]. 


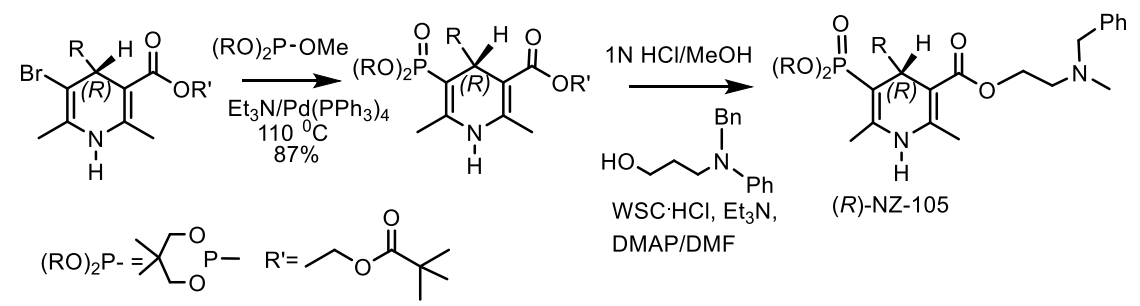

\section{Halogenophilic Reactions of P(III) Compounds}

The reaction of trivalent phosphorus compounds with tetrahalomethanes and other reagents containing a positive halogen atom is a type of halogenophilic transformations. There is an extensive class of reactions in which the nucleophile interacts with a halogen atom and the organic $\mathrm{R}$ moiety in RHal acts as a leaving group, forming a carbanion. The halogenophilic reactions of $\mathrm{P}(\mathrm{III})$ compound with methane tetrahalide proceed via the formation of phosphonium intermediate bearing trihalomethyl anion $\mathrm{CX}_{3}{ }^{-}$. The formation of the phosphonium intermediate was proved by chemical and physicochemical methods [75-78]. For example, the reaction of the intermediate with trimethylchlorosilane led to the formation of $\mathrm{Me}_{3} \mathrm{SiCX}_{3}(\mathrm{X}=\mathrm{Cl}, \mathrm{Br})$, which were isolated and characterized. In the second stage, the phosphonium intermediate reacts with the nucleophile $\mathrm{ROH}$, $\mathrm{RSH}, \mathrm{R}_{2} \mathrm{NH}, \mathrm{RNH}_{2}$ to form a quasi-phosphonium salt, which can be further decomposed to form phosphine oxide and an alkyl halide or rearrange to form a trihalomethylphosphonium salt [75]. The quasi-phosphonium salt can be stabilized by adding water, which increases the stability of the phosphonium salt due to solvation or by converting the phosphonium halide to phosphonium perchlorate The formation of chloroform in halogenophilic reactions in the presence of a proton donor is also an argument in favor of the formation of phosphonium intermediate (Scheme 8).

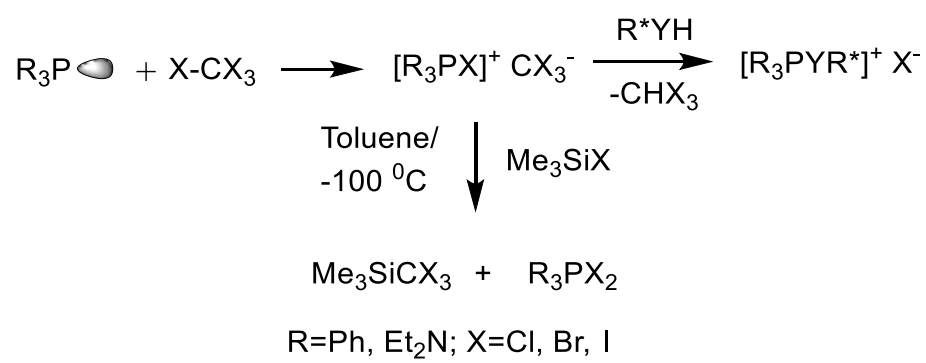

Scheme 8. Mechanism of reaction of tetrahalomethanes with trivalent phosphorus compounds.

The reactions of $\mathrm{P}(\mathrm{III})$ compounds with positive halogen donors are very diverse. The halogenophilic reactions are widely used in synthetic organic and organophosphorus chemistry for halogenation, dehydration and PN binding [79-85]. The most famous and applicable in organic synthesis are such halogenophilic reactions as the Atherton-Todd reaction, Appel reaction, Corey-Fuchs and the reaction of tertiary alkylphosphines with methane tetrahalides [2].

The Atherton-Todd reaction (AT) is a classical synthetic method used to obtain various phosphorus compounds [79-87]. Atherton and Todd described this reaction in 1945 [79]. Steinberg investigated the mechanism of the AT reaction and discovered the formation of intermediate products such as phosphoryl chloride A (Equation (61)) [80]. The AT reaction is a two-stage process. The first stage-the formation of chloride $\mathrm{A}$, proceeds with the retention of configuration and the second stage-substitution, proceeds with the inversion of configuration. This allows to get the final product with inversed absolute configuration at phosphorus [81-84]. 


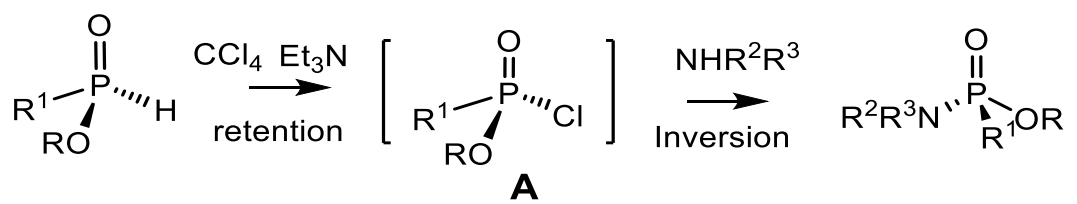

Reiff and Aaron studied the stereochemistry of the AT reaction [85]. Enantiomeric O-isopropylmethylphosphonite was used as a substrate (Equation (62)). The AT reaction of O-isopropylmethylphosphonite with $\mathrm{CCl}_{4}$, tributylamine and aniline afforded the corresponding phosphonoamide with complete stereocontrol. Mikolajczyk studied the stereochemistry of the reaction of optically active phosphoryl halides with alcohols and amines [86]. Optically active phosphonates were obtained from menthyl phosphinates (or secondary phosphine oxides) and nucleophilic compounds (amines or alcohols) under the conditions of the AT reaction [81]. The reaction proceeded with full stereoinversion on the phosphorus atom and led to the formation of optically pure phosphonoamide products with an almost quantitative yield (94\%). In all cases, the authors came to the conclusion that the first stage (i.e., the formation of intermediate phosphoryl chloride) occurs according to the $\mathrm{S}_{\mathrm{E}} 2$ mechanism with retention of the absolute configuration. Then, the attack of a nucleophilic substrate (amine, alcohol or thiophenol) occurs via the $\mathrm{S}_{\mathrm{N}} 2$ mechanism on the opposite side of the phosphorus-chlorine bond with the formation of a substituted product with high stereospecificity and inverted configuration (Equation (63)) [81-84].

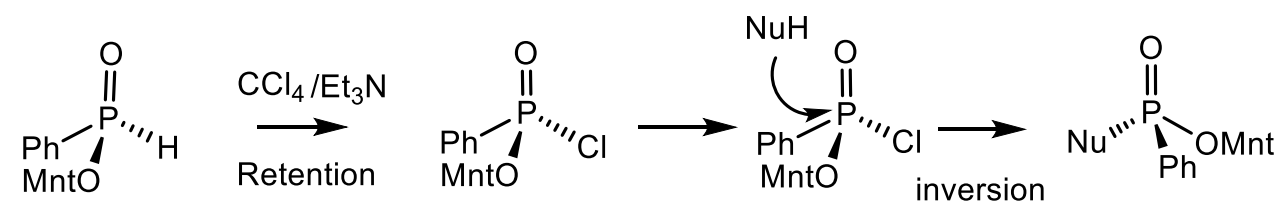

$\mathrm{NuH}=\mathrm{RNH}_{2}, \mathrm{ROH}, \mathrm{ArOH}, \mathrm{ArSH}$

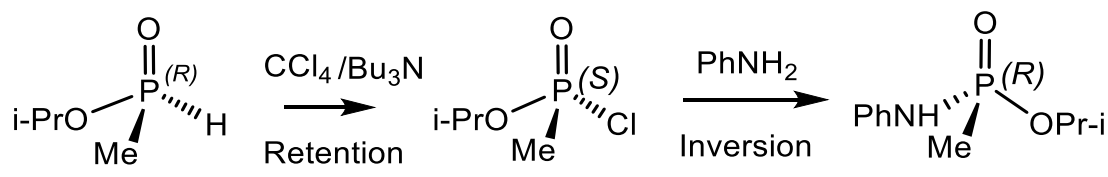

The AT reaction is carried out in the presence of bases, which convert tetracooordinated P-H form 3A into tricoordinated form 3B. The latter easily reacts with methane tetrahalide (in this case, $\mathrm{BrCCl}_{3}$ ) to afford the intermediate $\mathbf{C}$, which converts into a bromide with retention of absolute configuration. At the second stage, the reaction of bromide with a secondary amine (in this case, $\mathrm{Me}_{2} \mathrm{NH}$ ) leads to the formation of the substitution product with the inversion of configuration (Scheme 9) [84].<smiles></smiles>

3A

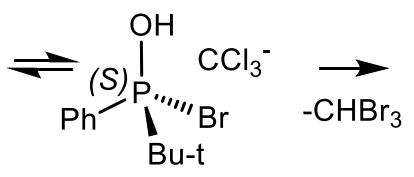

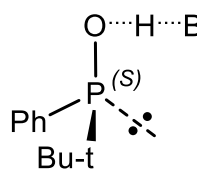

3B<smiles>CC(C)NCC(=O)Br</smiles>

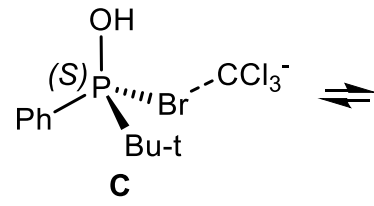

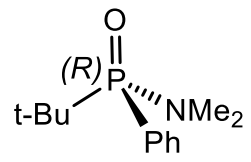

Scheme 9. The mechanism of AT reaction. 
$(1 R, 2 S, 5 R)$-Menthyl-H-phosphinate was prepared by reacting anhydrous hypophosphoric acid with $(1 R, 2 S, 5 R)$-menthol in the presence of trimethoxymethane. The AT reaction of $(1 R, 2 S, 5 R)$-methylphosphinate with $\mathrm{CCl}_{4}$ and isopropylamine led to the formation of the corresponding amide. The $(1 R, 2 S, 5 R)$-Menthylphosphinate also enter into the Heck reaction with iodobenzene in the presence of a palladium complex to form diastereoisomerically enriched $\left(S_{\mathrm{P}}\right)-(-)$-methylphenylphosphonite (Equation (64)) [87].

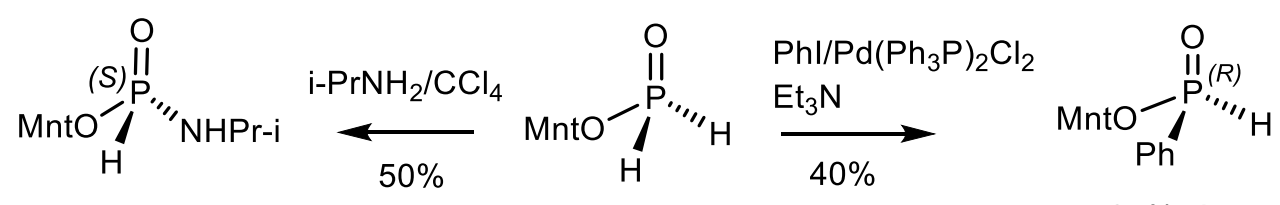

Y. Zhao et al. studied the stereochemistry of the reaction of chiral valine hydroxypyrophosphorane with $\mathrm{CCl}_{4}$ and phenol, which is similar to the AT reaction. The reaction led to the formation of chlorine-substituted spirophosphorane with retention of configuration at phosphorus, that was supported by X-ray diffraction analysis of a single crystal structure. Then, in the second stage, the reaction with phenol proceeded with an inversion of configuration as a result of the $S_{N} 2$ nucleophilic attack (Equation (65)) [88]. The mechanism of the formation of spirophosphorane chloride is not completely clear, although one can assume the opening of one of the five-membered oxazaphospholidinone rings with the formation of a tricoordinated tautomeric form capable of reacting with carbon tetrachloride (Authors).
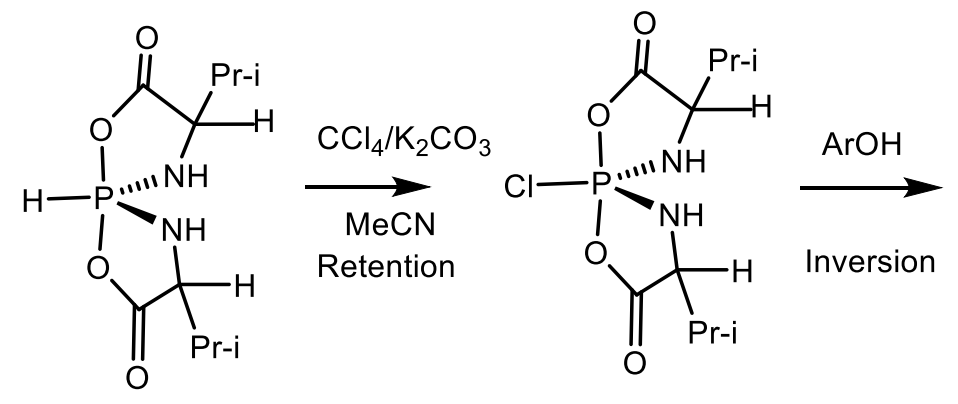

$\mathrm{ArOH}=\mathrm{Ph}, \mathrm{p}-\mathrm{TI}, \mathrm{p}-\mathrm{An}, \mathrm{p}-\mathrm{O}_{2} \mathrm{NC}_{6} \mathrm{H}_{4}, \mathrm{p}-\mathrm{ClC}_{6} \mathrm{H}_{4}$<smiles>CCCCOP12(NC(CCC)C(=O)O1)NC(C(C)C)C(=O)O2</smiles>

$68-80 \%$

The Appel reaction is an important synthetic method for the conversion of alcohol to alkyl halides using triphenylphosphine and carbon tetrahalogenide (Equation (66)). The reaction is named after R. Appel [77], although it was described earlier by Steinberg, who considered this reaction as a special case of the Todd-Atherton reaction [80]. The use of carbon tetrabromide or bromine as a source of halogen gives alkyl bromides, while the use of tetraiodofuran, methyl iodide or iodine allows obtaining alkyl iodide. Today, the Appel reaction is often used in laboratory syntheses of natural compounds [2]. The Appel reaction begins with the formation of a phosphonium salt, bearing $\mathrm{CCl}_{3}$-anion which exists as a tight-ion pair $[75,77]$ and therefore does not enter into the alpha-elimination reaction with the formation of dichlorocarbene. The nucleophilic substitution of a chloride ion with an alkoxide gives an alkoxyphosphonium salt, which, by the type of Michaelis-Arbuzov reaction, turns into an alkyl halide and phosphine oxide (Equation (66)). In the case of optically active alcohols, alkyl halides with inverted configuration are formed.

$$
\mathrm{R}_{3} \mathrm{P} \stackrel{\mathrm{CCl}_{4}}{\longrightarrow}\left[\mathrm{R}_{3} \mathrm{PCl}\right]^{+} \mathrm{CCl}_{3}^{-} \underset{-\mathrm{CHCl}_{3}}{\stackrel{\mathrm{R}^{\prime} \mathrm{OH}}{\longrightarrow}}\left[\mathrm{R}_{3} \mathrm{PCl}\right]^{+} \mathrm{RO}^{-} \longrightarrow\left[\mathrm{R}_{3} \mathrm{POR}^{\prime}\right]^{+} \mathrm{Cl}^{-} \longrightarrow \mathrm{R}_{3} \mathrm{PO}+\mathrm{R}^{\prime} \mathrm{Cl}
$$


The reaction of optically active tertiary phosphines with methane tetrahalides and achiral alcohols leads to the formation of chiral phosphine oxides with an inversion of the absolute configuration at the phosphorus atom (Scheme 10). Optically active alcohols provide optically active alkyl halides with inverted configuration and with complete stereospecificity as shown in Equations (67) and (68) [78].

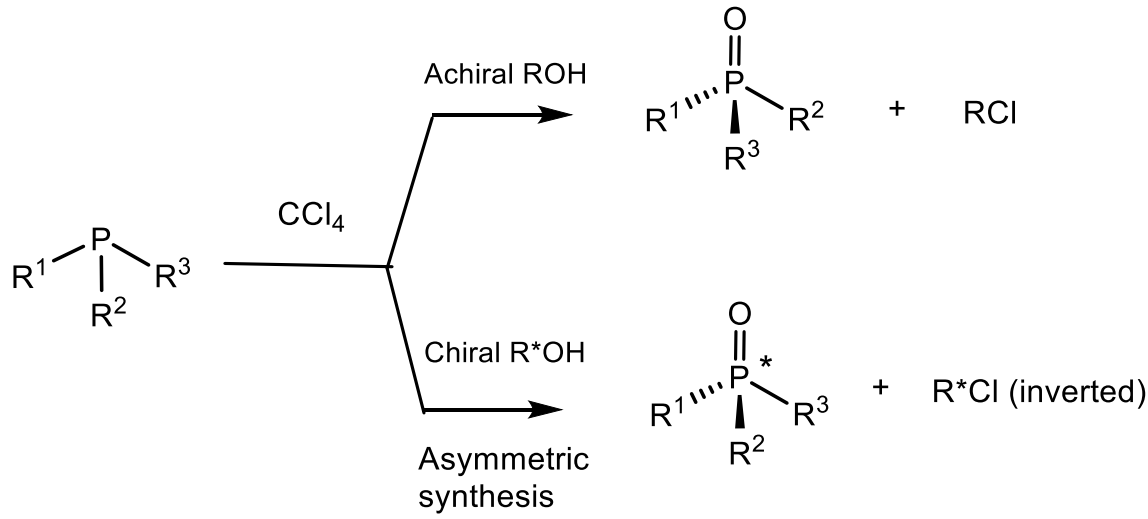

Scheme 10. The Appel reaction with chiral or achiral alcohols.

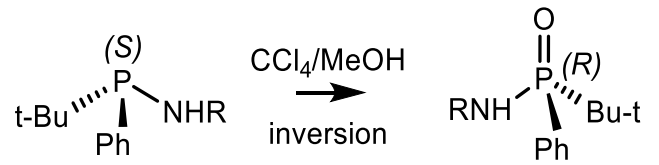

(R)-. $80 \%$ ee

$(S)-, 84 \%$ ee

$95 \%$ after crystallization

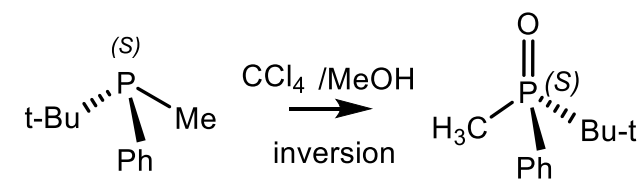

$$
[\alpha]_{\mathrm{D}}=(+)-29.5(\mathrm{MeOH}) \quad[\alpha]_{\mathrm{D}}=(-)-14.9(\mathrm{MeOH})
$$

The reaction of racemic tertiary phosphines with polyhalomethanes and chiral alcohols in some cases can lead to the formation of chiral tertiary phosphine oxides formed under the conditions of asymmetric synthesis. An asymmetric version of the Appel reaction was developed [89,90]. For example, the oxidation of aminophosphines containing a chiral substituent $R^{*}$ occurs stereoselectively with the transfer of chirality from the $\mathrm{R}^{*}$ to the trivalent phosphorus atom to result in phosphinate amide with $50-98 \%$ ee. The compounds were purified by crystallization and obtained as optically pure compounds. Studying the reaction mechanism using NMR showed that the reaction passes through the formation of chlorophosphoranes [89]. In the case of compounds containing a five-membered 1,3,2-oxaphospholane ring, the formation of pentacoordinated hydroxyhalogenphosphoranes $(\mathrm{R}=\mathrm{H})$ or alkoxyhalogenphosphoranes $(\mathrm{R}=\mathrm{n}-\mathrm{Alk})(d r=94: 6)$, which exists in equilibrium with alkoxyphosphonium salts, was discovered. Alkyl groups at the phosphorus atom contribute to a shift of the $\mathrm{P}(\mathrm{V}) \rightleftharpoons \mathrm{P}(\mathrm{IV})$ equilibrium of compounds towards the alkoxyphosphonium salt. The pseudo-rotation of ligands at the $\mathrm{P}(\mathrm{V})$ atom leads to the formation of the most thermodynamically stable diastereomer of the halogen-phosphonium intermediate, which then turns into one diastereomer of the final product (Equation (69)) [89]. 


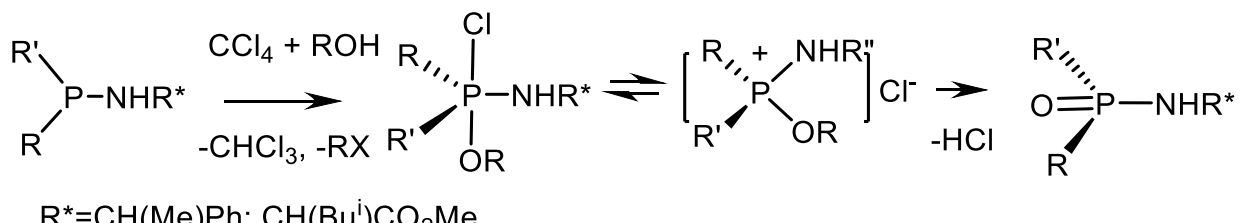

Gilheany et al. [91-94] carried out the asymmetric Appel reaction by oxidizing tertiary phosphines with polyhaloalkanes in the presence of chiral L-menthol. As a result, chiral phosphine oxides were obtained with a good ee. This phosphine oxide by reaction with LDA and copper chloride was converted to the DiPAMP analog, which is used in asymmetric catalysis. A chiral bis- $(R, R)$-phosphine oxide was obtained with $98 \% e e$ and a small amount of the meso isomer impurity was removed by recrystallization from benzene (Equation (70)) [90]. Interesting synthesis routes, providing access to both enantiomers of the reaction product, were developed using double separation of phosphine oxides, which afforded enantiomerically enriched products in yields up to $94 \%$ ee. The synthesis of diastereomeric alkoxyphosphonium salts was achieved by dynamic separation of racemic phosphines in reaction with hexachloroacetone and menthol as shown in Equation (71) [94].
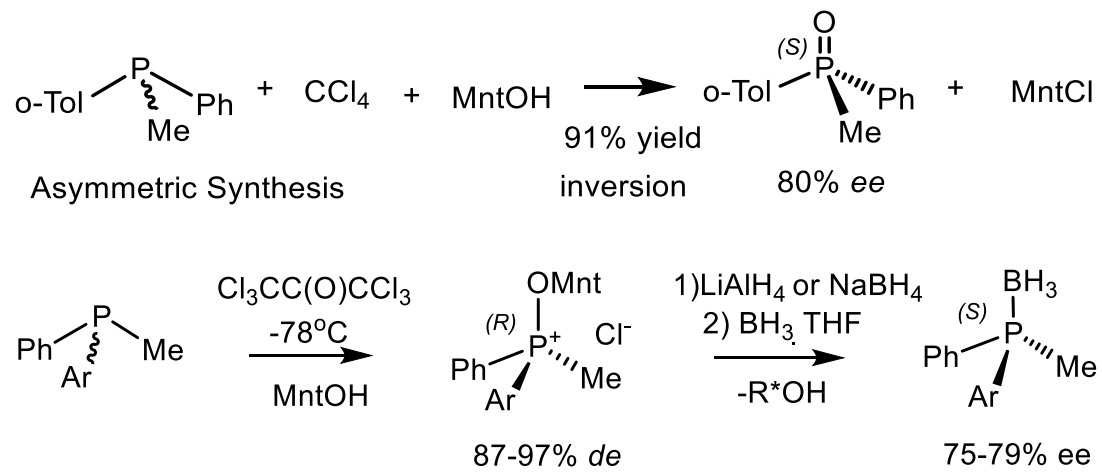

$\mathrm{Ar}=\mathrm{o}-\mathrm{Tol}, \mathrm{o}-\mathrm{An}, \quad \mathrm{o}-\mathrm{C}_{6} \mathrm{H}_{4} \mathrm{Pr}-\mathrm{i}, \quad 2,4-\mathrm{Me}_{2} \mathrm{C}_{6} \mathrm{H}_{3}$

The asymmetric induction in the case of the Appel and Atherton-Todd reactions was explained by the formation of long-lived phosphorane intermediate and Berry pseudorotation. The reaction mechanism was studied using theoretical calculations (Scheme 11) [95].

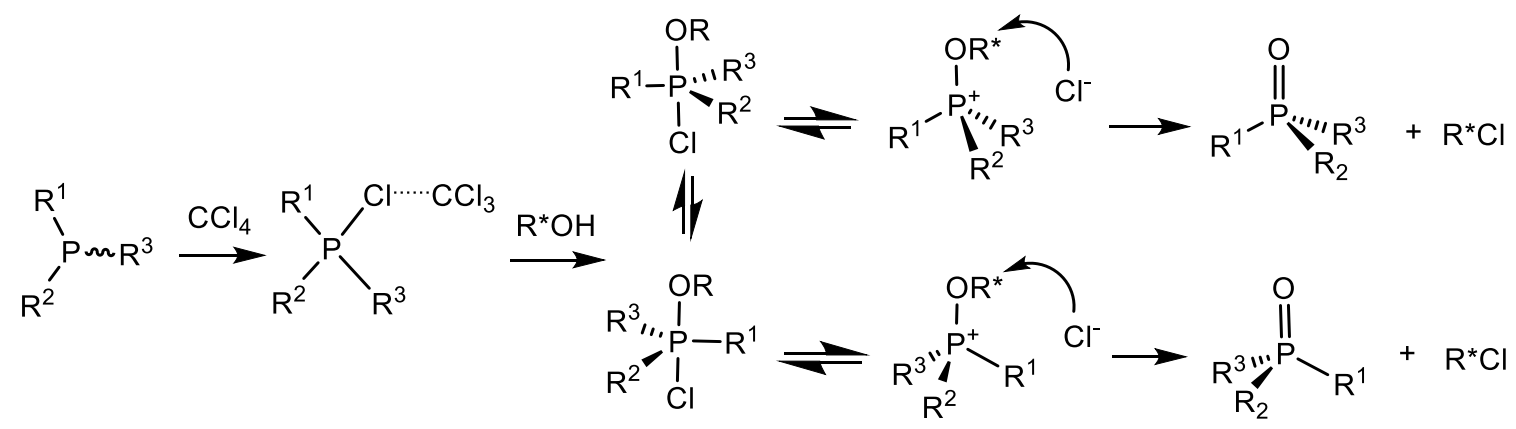

Scheme 11. Mechanism of the Appel reaction.

The reaction of tertiary alkylphosphines with donors of positive halogen leads to the formation of P-halogenylides [96-98]. The reaction of tertiary alkylphosphines with carbon tetrahalide $\left(\mathrm{CC1}_{4}\right.$, $\mathrm{CBrCl}_{3}, \mathrm{CBr}_{4}, \mathrm{C}_{2} \mathrm{Cl}_{6}$ ) is usually carried out in pentane, diethyl ether or dichloromethane under cooling below $0{ }^{\circ} \mathrm{C}$. The reaction with carbon tetrachloride takes place at the temperature below $0{ }^{\circ} \mathrm{C}$, carbon tetrabromide and bromotrichloromethane easily react at $-70^{\circ} \mathrm{C}$. The reaction of tertiary 
alkylphosphines with $N$-halides proceeds at room temperature. The yields of P-halogenylides are very high (up to 99-100\%) as shown in Equations (72)-(74).

$$
\begin{aligned}
& \left.\mathrm{R}_{2} \mathrm{PCH}_{2} \mathrm{R}^{\prime} \stackrel{\mathrm{CX}_{4}}{\underset{-\mathrm{CHX}_{3}}{\longrightarrow}} \mathrm{R}_{2}\right|_{X} ^{\mathrm{P}=C H R^{\prime}} \\
& \mathrm{X}=\mathrm{Cl}, \mathrm{Br} \quad 40 \text { examples } \\
& \mathrm{R}=\mathrm{Alk}, \mathrm{Ar}, \mathrm{Et}_{2} \mathrm{~N}, \mathrm{AlkO} ; \mathrm{R}^{\prime}=\mathrm{H}, \mathrm{Me}, \mathrm{Ph}, \mathrm{Cl}, \mathrm{SiMe}_{3} \text {, и др } \\
& \left(\mathrm{Et}_{2} \mathrm{~N}\right)_{2} \mathrm{PCH}_{2} \mathrm{SiMe}_{3} \underset{-\mathrm{CHX}_{3}}{\stackrel{\mathrm{CX}_{4}}{\longrightarrow}}\left(\mathrm{Et}_{2} \mathrm{~N}\right)_{2} \mathrm{P}=\mathrm{CHSiMe}_{3} \\
& \mathrm{t}-\mathrm{Bu}_{2} \mathrm{PCH}_{3} \underset{-\mathrm{R}_{2} \mathrm{NH}}{\stackrel{\mathrm{i}-\mathrm{Pr}_{2} \mathrm{NCl}}{\longrightarrow}} \mathrm{t}-\mathrm{Bu}_{2} \mathrm{P}_{\mathrm{Cl}}=\mathrm{CH}_{2}
\end{aligned}
$$

Substituents $\mathrm{R}^{1}$ and $\mathrm{R}^{2}$ can be electron acceptors, increasing the $\mathrm{CH}$-acidity of alkylphosphine, electron-neutral or electron-donating groups [99-102]. The reaction mechanism of tertiary alkylphosphines with $\mathrm{CX}_{4}$ is apparently of an ionic nature. The reaction proceeds through the formation of intermediate complex to form an ylide. The mechanism was proved by the reaction of sterically hindered tri-tert-butylphosphine with carbon tetrabromide at $-120{ }^{\circ} \mathrm{C}$ in pentane proceeding with the formation of a phosphonium salt containing $\mathrm{CBr}_{3}{ }^{-}$-anion, which was fixed by chemical methods (Equation (75)) $[99,103,104]$.

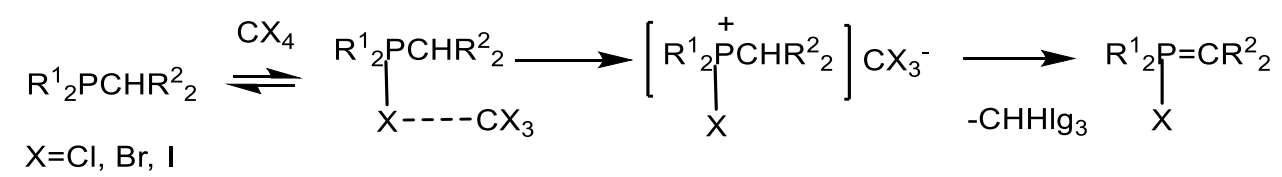

P-Chlorilides are reactive compounds and enter into various reactions. They easily react with aldehydes with the formation of phosphorus-containing alkenes, interact with carbon dioxide to form phosphorus-containing ketenes and give carbon-containing thioketenes with carbon disulfide. The compounds possessing a chiral center at phosphorus react stereospecifically (Equation (76)) [78,96,97].

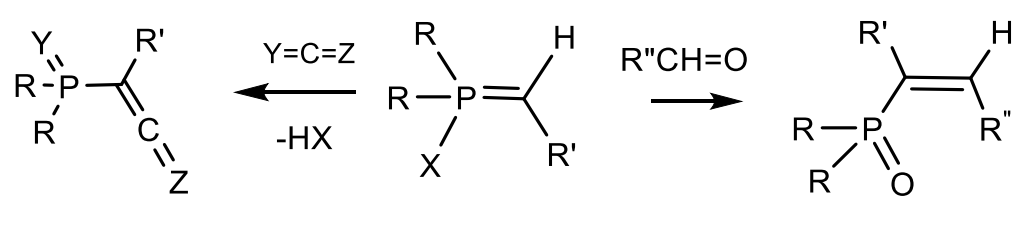

\section{Electrophilic Asymmetric Catalysis}

Asymmetric alkylation or arylation of racemic secondary phosphines, catalyzed by chiral Lewis acids, in many cases led to the formation of enantiomerically enriched tertiary phosphines [105-112]. For example, the chiral platinum complex $\mathrm{Pt}(\mathrm{Me}-\mathrm{Duphos})(\mathrm{Ph})(\mathrm{Br})$ catalyzed the asymmetric alkylation of secondary phosphines with benzyl halides to form tertiary phosphines (or their boranes) in good yields and with 50-93\% ee (Equation (77)) [107]. Secondary phosphines with bulky substituents (Ar') reacted with para-substituted aryl iodides to form tertiary phosphines with an enantiomeric excess 
up to $88 \%[105,106]$. Glueck $[106,107]$ reported that racemic secondary phosphines in the presence of $\mathrm{Pt}(\mathrm{Me}-\mathrm{Duphos})(\mathrm{Ph})(\mathrm{Br})$ and $\mathrm{NaOSiMe}_{3}$ in toluene afforded adducts 4 which interconvert rapidly by P-inversion $\left(S_{\mathrm{P}}\right)-\mathbf{4} \rightleftharpoons{ }_{\left(R_{\mathrm{P}}\right)-4}$ (Equation $(77)$ ). Adducts were isolated and studied by low temperature NMR. X-Ray diffraction analysis showed the $\left(R_{\mathrm{P}}\right)$-absolute configuration of this compound [107]. The treatment of this adduct with benzyl bromide resulted in the formation of $\left(R_{\mathrm{P}}\right)$-tertiary phosphine with $72-78 \%$ ee and the initial catalyst. Alkylation of secondary phosphines occurred with retention of absolute configuration, that confirmed the proposed mechanism. Based on these results, it was concluded that the enantioselectivity of electrophilic substitution is determined by the thermodynamic preference of one of the diastereomers in the equilibrium between the $\left(S_{\mathrm{P}}\right)-4$ and $\left(R_{\mathrm{P}}\right)-4$ complexes.

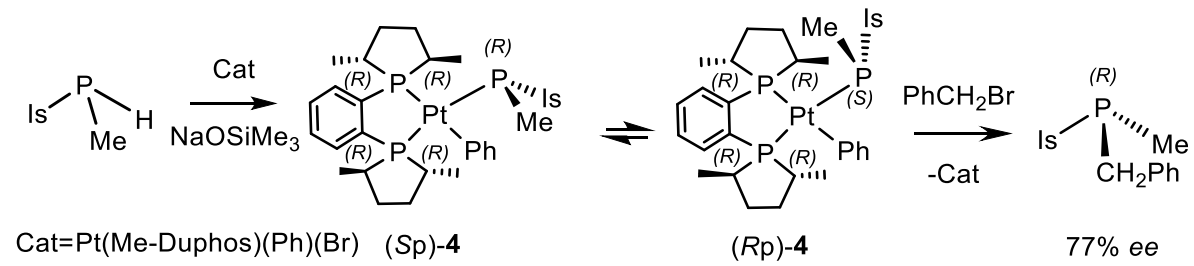

The enantioselective alkylation of secondary phosphines with benzyl halides, catalyzed by ruthenium complex $\left[\mathrm{RuH}(\mathrm{i}-\mathrm{Pr}-\mathrm{PHOX})_{2}\right]^{+}$, led to the formation of tertiary phosphines with $57-95 \%$ ee. Complex $[(R)$-Difluorophos $)(\mathrm{dmpe}] \mathrm{Ru}(\mathrm{H})]\left[\mathrm{BPh}_{4}\right]$ effectively catalyzed the asymmetric alkylation of secondary phosphines with benzyl bromides, while the ruthenium complex with the $(R)$-MeOBiPHEP/dmpe ligand was more effective in the case of benzyl chlorides (Equation (78)) [108-111].

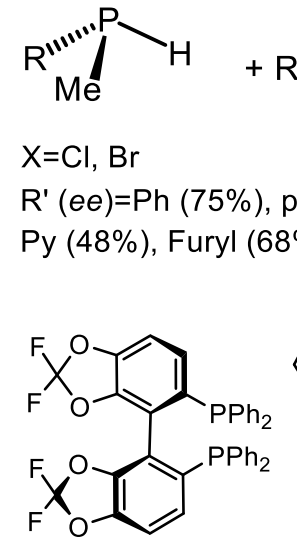

(R)-Diflluorophos

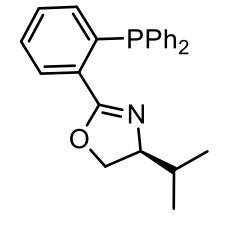

(R)-i-Pr-PHOX

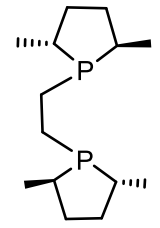

Me-BPE

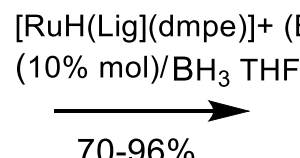

$70-96 \%$<smiles>[R]C[P+]([R])([B])C</smiles>

The reaction of chiral secondary phosphine boranes with anisyl iodide, catalyzed by chiral Pd complex with $(S, S)$-Chiraphos ligand, proceeded with retention of configuration at the phosphorus atom [112]. Addition of $\operatorname{Pd}((S, S)$-Chiraphos)(o-An) to enantiomerically enriched secondary phosphine in the presence of $\mathrm{NaOSiMe}_{3}$ led to the formation of a stable complex, which, when heated in excess diphenylacetylene, was converted to the tertiary $\left(R_{\mathrm{P}}\right)$-phosphine borane in $70-98 \%$ yields (Equation (79)). 


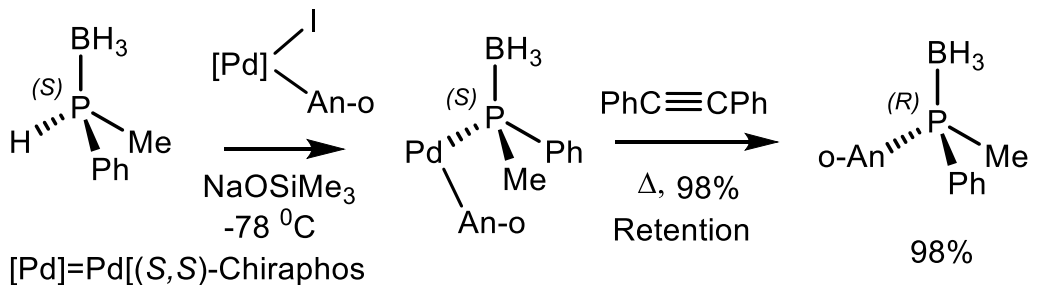

Enantioselective alkylation of secondary phosphines with benzyl halides catalyzed by $\left[\mathrm{RuH}(\mathrm{i}-\mathrm{Pr}-\mathrm{PHOX})_{2}\right]^{+}$complexes produced bisphosphines with high enantiomeric excesses $[108,109]$. The alkylation of 1,2-bis((2R,5R)-2,5-dimethylphospholano)ethane afforded $(R, R)$-Me-BPE) analogues with high diastereoselectivity [109]. Catalytic asymmetric alkylation of bis(secondary phosphines) with benzyl bromide using $\mathrm{NaOSiMe}_{3}$ base and $\mathrm{Pt}((R, R)-\mathrm{Me}-\mathrm{Duphos})(\mathrm{Ph})(\mathrm{Cl})$ led to the formation of bis-tertiary phosphines. Catalytic alkylation of bis-phosphines with 2-(bromomethyl) naphthalene using $10 \mathrm{~mol} \%$ of the $\mathrm{Pt}((R, R)-\mathrm{Me}-\mathrm{DuPhos})(\mathrm{Ph})(\mathrm{Cl})$ catalyst and $\mathrm{NaOSiMe}_{3}$ allowed to obtain diastereomerically pure bis(tertiary)-phosphines as shown in Equations (80) and (81) [110-116].<smiles>CCCP(Cc1ccccc1)P(Cc1ccccc1)CP(Cc1ccccc1)Cc1ccccc1</smiles>

$n=0,81 \%, 91 \%$ ee, $47 \%$ de $n=1,87 \%, 93 \%$ ee, $59 \%$ de

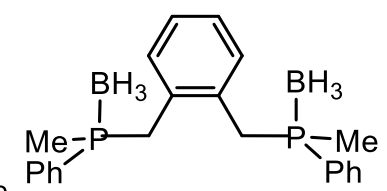

$\mathrm{Ph}$

e, $48 \%$ de $\mathrm{X}=\mathrm{N}, 89 \%, 16 \%$ de

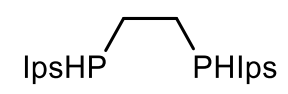

$\mathrm{ArCH}_{2} \mathrm{Br}, \mathrm{NaOSiMe}_{3} /$ Cat.

Cat. $=\mathrm{Pt}(R, R)-\mathrm{Me}-\mathrm{DuPhos})(\mathrm{Ph})(\mathrm{Cl})$

$\mathrm{BH}_{3} \mathrm{SMe}_{2}$

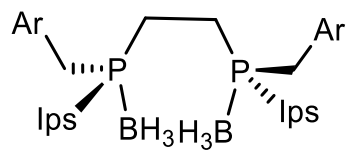

$\mathrm{Ar}=\mathrm{Bn}, \mathrm{Nphth}$

Alkylation of secondary diphosphines with o-trifluoromethylbenzyl bromide using $\mathrm{NaOSiMe}_{3}$ as a base and platinum catalysts $[\mathrm{Pt}((R, R)-\mathrm{Me}-\mathrm{DuPhos})(\mathrm{Ph})(\mathrm{Cl}), \mathrm{Pt}((R, R)-\mathrm{Me}-\mathrm{BPE})(\mathrm{Ph})(\mathrm{Cl})]$ gave tertiary diphosphines, which were isolated as optically pure boranes (Equation $(82))[73,117,118]$.
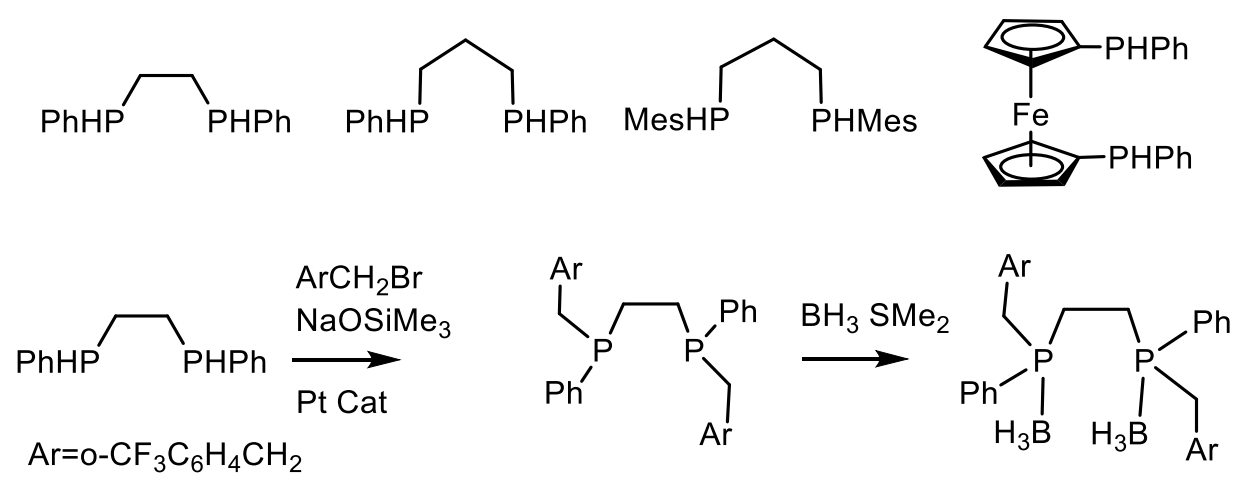

Arylation of secondary phosphines by aryl halides, catalyzed by chiral copper complexes [97], platinum [106,110,115,117], ruthenium [108,109], palladium [73,105,112,118-120] in many cases proceeded with good enantioselectivity and is a convenient method for the synthesis of tertiary phosphines. For example, the reaction of aryl iodides with secondary arylphosphines, catalyzed by chiral complex $\operatorname{Pd}((R, R)-M e-D u p h o s)$ (trans-stilbene), gives tertiary phosphines with enantioselectivity up to $88 \%$ ee [110,119] (Equation (83)). Arylation of secondary phosphines with o-aryl iodides, 
in situ catalyzed by the $\mathrm{Pd}_{2}(\mathrm{dba})_{3}-\mathrm{CHCl}_{3}$ complex containing the chiral ligand Et,Et-FerroTANE and $\mathrm{LiBr}$, led to the formation of corresponding tertiary phosphines with enantioselectivity $90 \%$ ee [121]. Palladium complex $\mathrm{Pd}_{2} \mathrm{dba}_{3} /(R)$-i-Pr-PHOX also showed high enantioselectivity during arylation of secondary phosphines [119,121]. Examples of arylation of secondary phosphines with low enantioselectivity, catalyzed by this complex, are described. Arylation of secondary phosphines with anisyl iodide, catalyzed by the chiral palladium complex (R)-i-Pr-PHOX/MeCN/PdL $/ \mathrm{L}_{2} \mathrm{CO}_{3}$, afforded enantiomerically enriched tertiary phosphines with $45 \%$ ee [119,121,122].
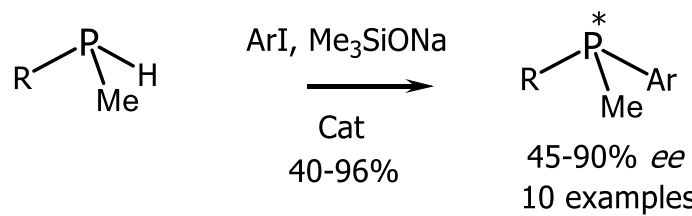

$\mathrm{R}=2-\mathrm{PhC}_{6} \mathrm{H}_{4}, 2-\mathrm{An}, 2-\mathrm{CF}_{3} \mathrm{C}_{6} \mathrm{H}_{4}, 2-\mathrm{PhC}_{6} \mathrm{H}_{4}$, Ips, Bu-t

2-ButOCOC $6 \mathrm{H}_{4}, 2-\mathrm{MeOCOC}_{6} \mathrm{H}_{4}, 2-\mathrm{OCHC}_{6} \mathrm{H}_{4}, \mathrm{Ph}, 4-\mathrm{An}, 3-\mathrm{An}$
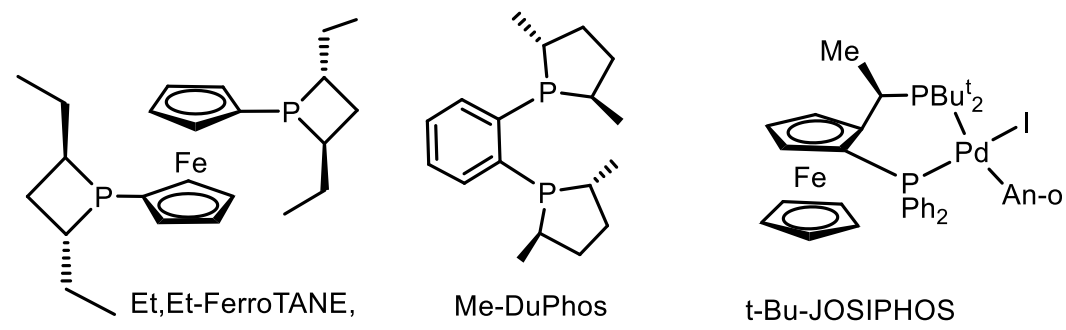

The reaction of secondary phosphine borane with o-anisyl iodide and sodium trimethylsilylanoate catalyzed at room temperature by the complexes $\operatorname{Pd}((R, S)$-Bu-t-Josiphos)-(o-An) or $\operatorname{Pd}((R)$-Tol-Binap)(o-An)(I) led to the formation of tertiary phosphines but no intermediate was detected (Equation (84)), Table 2. When this reaction was carried out at $-78{ }^{\circ} \mathrm{C}$, the formation of PAMP-BH ${ }_{3}$ was observed by ${ }^{31} \mathrm{P}$ NMR-spectroscopy even at $-80{ }^{\circ} \mathrm{C}$, however, in this case, intermediate products could not be detected [118].
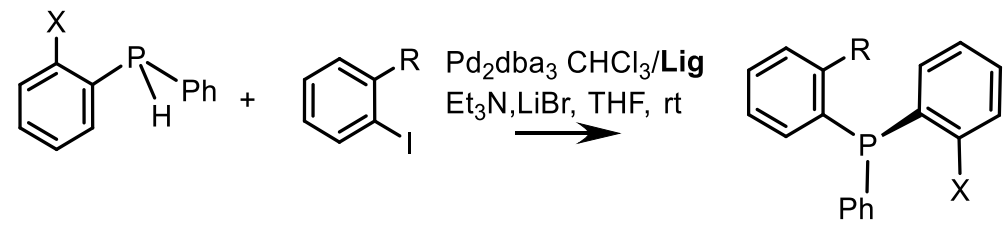

Table 2. Asymmetric arylation of secondary phosphine catalyzed by the complex $\mathrm{Pd} /(R, S)-\mathrm{t}-\mathrm{Bu}-$ JOSIPHOS (Equation (84)).

\begin{tabular}{|c|c|c|c|c|c|}
\hline $\mathbf{R}$ & $X$ & Base & $\operatorname{LiX}$ & Yield, \% & $e e, \% /($ Config) \\
\hline $\mathrm{CO}_{2} \mathrm{Bu}-\mathrm{t}$ & 2-Ph & $\mathrm{NEt}_{3}$ & - & 63 & $71(S)$ \\
\hline $\mathrm{CO}_{2} \mathrm{Bu}-\mathrm{t}$ & 2-Ph & $\mathrm{NBnMe}_{2}$ & - & 45 & $77(S)$ \\
\hline $\mathrm{CO}_{2} \mathrm{Bu}-\mathrm{t}$ & 2-Ph & $N$-Me-piperidine & - & 76 & $84(S)$ \\
\hline $\mathrm{CO}_{2} \mathrm{Bu}-\mathrm{t}$ & 2-Ph & $\mathrm{NEt}_{3}$ & $\mathrm{LiF}$ & 76 & $66(S)$ \\
\hline $\mathrm{CO}_{2} \mathrm{Bu}-\mathrm{t}$ & 2-Ph & $\mathrm{NEt}_{3}$ & $\mathrm{LiCl}$ & 66 & $86(S)$ \\
\hline $\mathrm{CO}_{2} \mathrm{Bu}-\mathrm{t}$ & 2-Ph & $\mathrm{NEt}_{3}$ & $\mathrm{LiBr}$ & 76 & $90(S)$ \\
\hline $\mathrm{CO}_{2} \mathrm{Bu}-\mathrm{t}$ & 2-Ph & $\mathrm{NEt}_{3}$ & LiI & 58 & $87(S)$ \\
\hline $\mathrm{CO}_{2} \mathrm{Bu}-\mathrm{t}$ & 2-MeO & N-Me-piperidine & $\mathrm{LiBr}$ & 43 & $86(S)$ \\
\hline $\mathrm{CO}_{2} \mathrm{Bu}-\mathrm{t}$ & $2-\mathrm{CF}_{3}$ & $\mathrm{NEt}_{3}$ & $\mathrm{LiBr}$ & 39 & $93(R)$ \\
\hline $\mathrm{CO}_{2} \mathrm{Bu}-\mathrm{t}$ & $2-\mathrm{Ph}$ & $\mathrm{NEt}_{3}$ & $\mathrm{LiBr}$ & 69 & $85(S)$ \\
\hline $\mathrm{CHO}$ & 2-Ph & $\mathrm{NEt}_{3}$ & $\mathrm{LiBr}$ & 71 & $63(S)$ \\
\hline
\end{tabular}


The catalyzed $(S, S)$-Me-DUPHOS-PdCl $\mathrm{P}_{2}$ asymmetric cross-coupling reaction of the racemic secondary methylphenylphosphine borane with achiral triflate gave a chiral tertiary phosphine borane with a moderate optical yield (Equation (85)). The activity and selectivity of the reaction were influenced by such parameters as the structure of the chiral ligand, the temperature and nature of the solvent [121]. The use of $\alpha$-amido-enolphosphates to activate the vinyl bond in the palladium-catalyzed $\mathrm{C}-\mathrm{P}$ cross-coupling reaction proceeds with a high ee (Equation (82)). The reaction was carried out under mild conditions due to the activation of P-H bonds of phosphine boranes (or phosphine oxides) with palladium complexes and enol-phosphate binding agents. Optimal conditions included the use of (dppf) $\mathrm{PdCl}_{2}$ as a catalyst, $\mathrm{Cs}_{2} \mathrm{CO}_{3}$ as a base and acetonitrile as a solvent at the temperature of $60{ }^{\circ} \mathrm{C}$. As a result, the chiral and achiral $\alpha-\beta$-alkenylphosphinite boranes containing the amido group were obtained in yields up to $70 \%$ and with $99 \%$ ee as shown in Equations (86) and (87) [12,123].

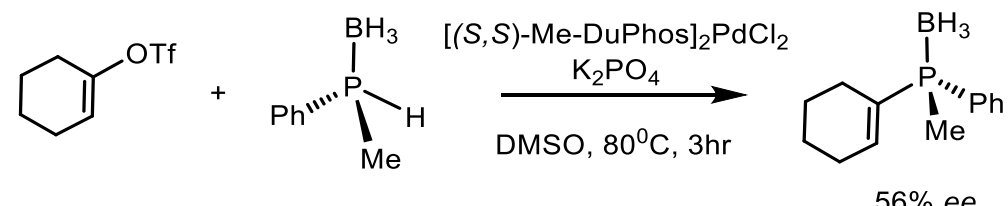<smiles>[R7]OC1=CC[Te]CN1C([R20])=O</smiles>

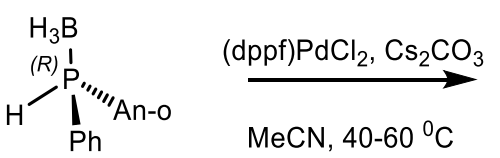

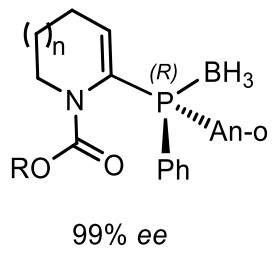<smiles></smiles><smiles>P[C@@H]1CC[C@@H](c2ccccc2)[PH3+]1</smiles>

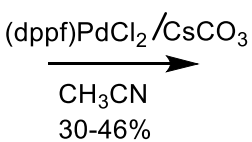

$\mathrm{R}_{\mathrm{P}}=(\mathrm{PhO})_{2} \mathrm{P}(\mathrm{O})-, \mathrm{R}=\mathrm{Me}, \mathrm{t}-\mathrm{Bu}, \mathrm{n}=1-3$<smiles>[R6]C(=O)N1CCCC=C1P1([B])(c2ccccc2)CCC(P)C1c1ccccc1</smiles>

ee> $99.5 \%$

\section{Oxidation, Thionation, Imination}

The oxidation and thionation of trivalent phosphorus compounds usually proceeds with the retention of absolute configuration (Equations (88) and (89)) [124-131]. Despite the complexity of the oxidation processes, in many cases they can be attributed to electrophilic reactions. For example, the oxidation of chiral tertiary phosphines with hydrogen peroxide, hydroperoxide and also with atmospheric oxygen proceeds stereospecifically with retention of absolute configuration [131,132].

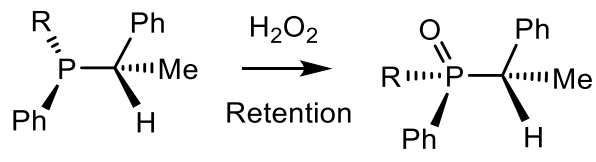

$\mathrm{R}=\mathrm{Me}, \mathrm{Ph}$

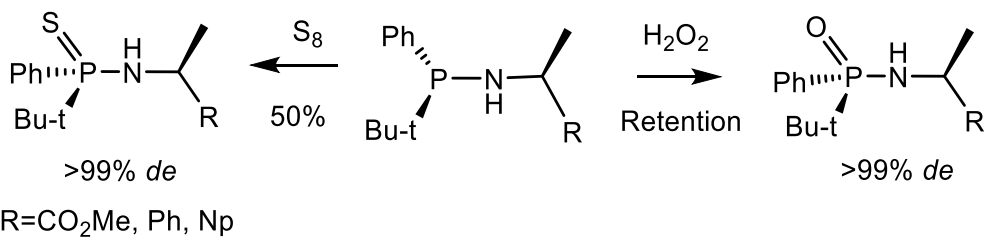


Oxidation of racemic phosphines using a chiral dioxoruthenium(VI) complex containing optically active methoxy(trifluoromethyl) phenylacetyl groups on both sides of the porphyrin plane led to the formation of optically active phosphine oxides with $41 \%$ ee. Oxidation of chiral $(+)-(R)$-benzylmethylphenylphosphine with this complex gives (-)-(S)-benzylmethylphenylphosphine oxide with the same configuration. It was found that the reaction proceeds without racemization, with enantiospecific control of oxygen atom transfer (Equation (90)) [127].

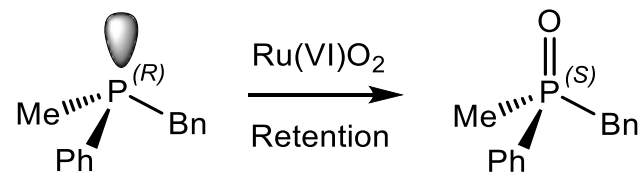

The addition of sulfur to aminophosphines, as well as the oxidation with hydrogen peroxide (Equation (88)), proceed stereospecifically with retention of optical purity and absolute configuration [131,132]. The reactions of chiral tertiary phosphines with sulfur proceed as well with retention of configuration at phosphorus. For example, the optically active $(-)-(S)$-methylthioethyl-tert-butylphenylphosphonium triflate was obtained from methyl triflate and (+)-(S)-ethyl-tert-butylphenylphosphine sulfide, which in turn was prepared by thionation of tertiary (S)-phosphine (Equation (91)) [111,126].

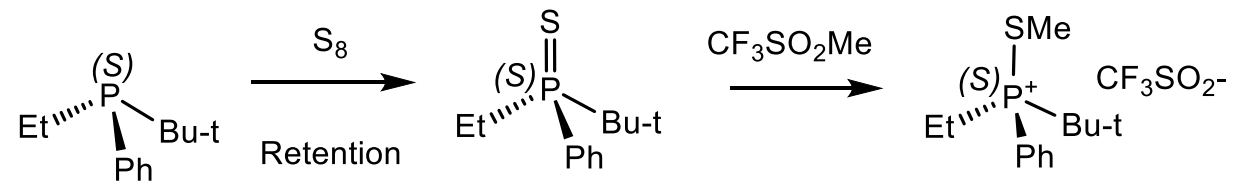

The addition of sulfur to the (S)-(-)-isopropyl methylphosphinate and thiomethylation proceeded with retention of configuration and leads to the formation of (+)-isopropyl (S)-methylphosphonothioate (Equation (92)). The absolute configuration of the compound was confirmed by X-ray analysis [128]. The (R)-tert-butyl(phenyl)phosphine sulfide was converted into optically active thioselenoic acid by addition of selenium in the presence of trimethylamine (Equation (93)). Another optically active selenothioacid $\mathrm{Et}(\mathrm{EtO}) \mathrm{P}(\mathrm{Se}) \mathrm{SH}$ was resolved into enantiomers with high ees by crystallization with quinine $[113,125]$. Thiomethylation of menthyl $(R)$-P-phenylphosphinate followed by reaction of menthyl-S-methylphenylphosphonothioate with methylmagnesium bromide led to the formation of menthyl P-methylphenylphosphinate with retention of configuration (Equation (94)). It follows that the Grignard reaction and thiomethylation proceed with the retention of configuration at phosphorus [128]. In addition, S-alkylphosphonothioates were stereospecifically prepared by the reaction of menthyl phenylphosphinate with sulfur and subsequent $S$-alkylation with alkyl halides (Equation (95)) [124].<smiles>CCOP(C)(=O)O[Na]</smiles>

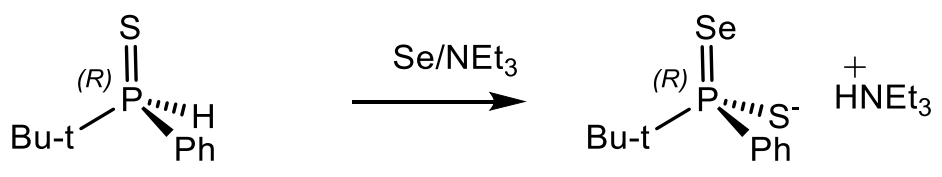



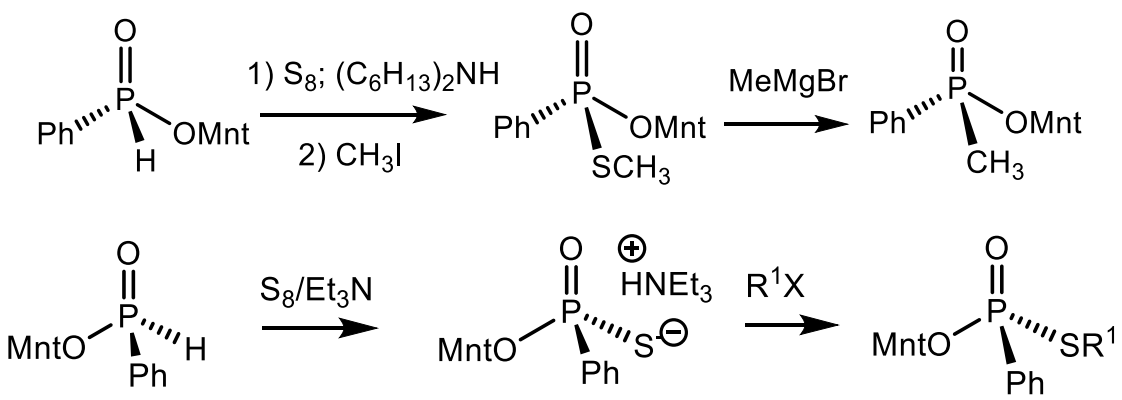

$\mathrm{R}^{1}=\mathrm{Me}, \mathrm{Et}, \mathrm{Ph}$

The treatment of racemic P-stereogenic tertiary phosphines with enantiomerically pure bis-thiophosphoryl disulfides under conditions of kinetically controlled resolution (reagent ratio 2:1) gave enantiomerically enriched tertiary phosphine oxides and phosphine sulfides with enantioselectivity 39\% (Equation (96)) [129]. Under similar conditions, enantiomerically enriched $(S)$ - and $(R)$-O-isopropyl $(R)$-methylphosphinothioate stereospecifically reacted with diphenyl disulfide to form (S)-O-isopropyl S-phenyl (S)-methylphosphinodithioate with the same values of ees (Equation (97)) [128].

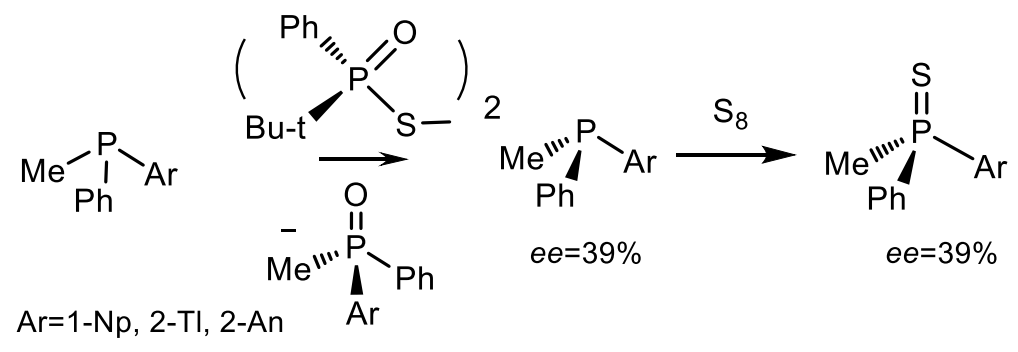<smiles>CCCCO[PH](C)=S</smiles><smiles>CCCC(C)SS(=S)(=S)c1ccccc1</smiles><smiles>CCCP(=S)([AsH2])[SnH2]</smiles>

Chlorination of (S)-tert-butyl(phenyl)phosphine oxide with $N$-chlorosuccinimide yielded the $(R)$-tert-butyl(phenyl)phosphino chloride with retention of configuration, which, after treatment with phosphorus pentasulfide, was stereospecifically converted into $(R)$-tert-butyl(phenyl)phosphinoic chloride. The synthesis of optically active methyl (S)-tert-butyl(phenyl)phosphinodithioate, (S)-tert-butyl(phenyl)phosphintionium iodide and (R)-tert-butyl(phenyl)phosphinoselenothioacid (Equation (98)) was also described [130].

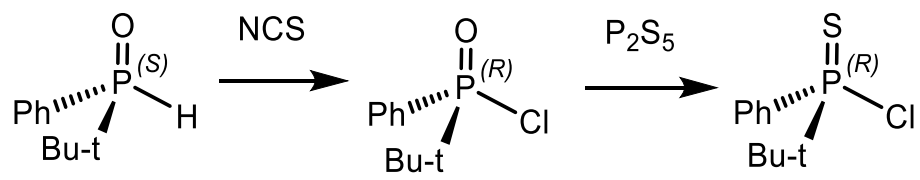

\section{Reduction}

The reduction of phosphorus compounds proceeds along different mechanisms, sometimes complex and multi-step, including electrophilic mechanisms. The reaction can lead to the formation of products with the retention or inversion of the phosphorus configuration depending on the nature of the reducing agent $[133,134]$. For example, in one of the early works, the reduction of tertiary phosphine oxides by chiral aminoalanes (aluminum hydrides bound to chiral (S)-phenylethylamine) led to the formation of chiral tertiary phosphines with a moderate enantiomeric excess [135]. Moreover, hydride 
transfer from alane to phosphorus can occur in two different paths: monomolecular, proceeding with retention of configuration or bimolecular, flowing with the inverse configuration. The advantage of one of two competing mechanisms determines the stereoselectivity of reduction (Equation (99)).<smiles>CC1=CC[P@](=O)(c2ccccc2)C1</smiles><smiles>CP(=O)(P)c1ccccc1</smiles>

At present, stereospecific methodologies for the synthesis of optically pure tertiary phosphines from P-stereogenic phosphine oxides have been developed [136-142]. Some of them proceed according to the electrophilic mechanism with retention of configuration. For example, the trichlorosilane-triphenylphosphine system reduces $(R)$-(2-methoxyphenyl)methylphenylphosphine oxide [(R)-PAMPO] to (S)-PAMP with complete retention of configuration and high optical purity (Equation (100)) [136]. At the same time, reduction with trichlorosilane in the presence of triethylamine took place with an inverse configuration. Hexachlorodisilane reduces 1,1'-binaphthalen]-2-yl)(methyl)(phenyl)phosphine oxide to tertiary phosphine with complete stereospecificity [137]. Reduction with phenylsilane under the same conditions also proceeded with retention of configuration at the phosphorus atom (Equation (101)) [139-141].<smiles></smiles>

$(R)$-PAMPO $99 \%$ ee<smiles>COc1ccc2ccccc2c1-c1c(P(=O)([O-])c2ccccc2)ccc2ccccc12</smiles>

$100 \%$ ee

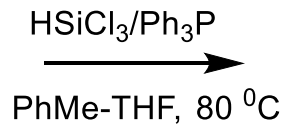
$95 \%$

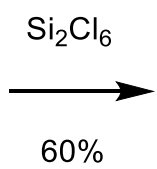

$\mathrm{R}_{1}=\mathrm{Me}, \mathrm{Ph} ; \mathrm{R}_{2}=\mathrm{Ph}, \mathrm{Me}$<smiles></smiles>

(S)-PAMP $99 \%$ ee<smiles>COc1ccc2ccccc2c1-c1c(P(C)(=O)c2ccccc2)ccc2ccccc12</smiles>

The reactivity of silane can be increased by adding titanium(IV)isopropoxide. In this case, the reduction proceeds with the retention of configuration. The catalytic cycle probably involves the formation of an intermediate silyl radical that reacts with phosphine oxide. For example, under these conditions, DIPAMP was obtained with $86 \%$ ee from optically pure diphosphine oxide (Equation (102)) [137].<smiles>COc1ccccc1P(=O)(CCP(=O)(c1ccccc1)c1ccccc1)c1ccccc1</smiles>

$100 \%$ ee

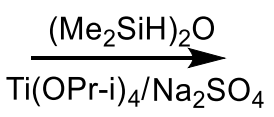

Methylcyclohexane $60{ }^{\circ} \mathrm{C}$<smiles>COc1ccccc1P(CCP(c1ccccc1)c1ccccc1)c1ccccc1</smiles>

$85 \%$ ee 
Keglevich et al. [138] used dimethyl sulfide borane under mild conditions to directly convert dimethyl-1-phenylphospholane-1-oxide to phosphine boranes. Five-membered cyclic phosphine oxides smoothly reacted with a 4-5-fold excess of borane-dimethyl sulfide complex in chloroform at $25-65{ }^{\circ} \mathrm{C}$ with the formation of phosphine boranes in yields 39-92\%. It should be noted that under these conditions the reduction of phosphine oxide occurs with full stereospecificity, that was confirmed by X-ray diffraction analysis (Equation (103)).
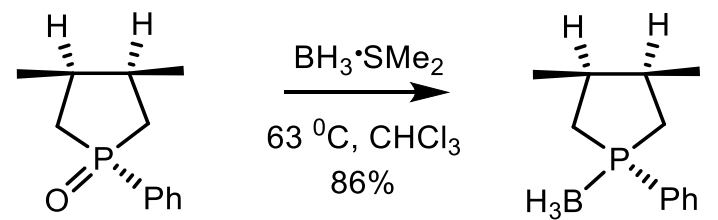

The MeOTf $/ \mathrm{LiAlH}_{4}$ system proved to be a good reagent for reducing chiral phosphine oxides (Equation (104)) [133,134]. Chiral phosphines and phosphine boranes were obtained with high enantiospecificity and inversion of configuration $(88-98 \% e e)$. Among the various electrophiles, methyl triflate, tosylates, mesylates and iodides were most effective, which reduced phosphine oxides with very good yields of tertiary phosphines (Table 3) [133].

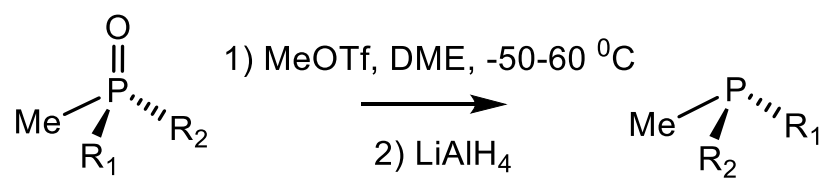

Table 3. Reduction of enantiomerically pure phosphine oxides (Equation (104)).

\begin{tabular}{ccccc}
\hline $\mathbf{R}^{\mathbf{1}}$ & $\mathbf{R}^{\mathbf{2}}$ & Yield, (\%) & \% e e & Configuration \\
\hline $\mathrm{Np}$ & $\mathrm{Ph}$ & 92 & 97 & $(S)$ \\
$\mathrm{Np}$ & $\mathrm{Ph}$ & 90 & 98 & $(S)$ \\
$\mathrm{Ph}$ & o-An & 85 & 98 & $(R)$ \\
$\mathrm{c}-\mathrm{C}_{6} \mathrm{H}_{11}$ & o-An & 74 & 95 & $(R)$ \\
$\mathrm{c}-\mathrm{C}_{6} \mathrm{H}_{11}$ & $\mathrm{~Np}$ & 81 & 88 & $(R)$ \\
$\mathrm{Ph}$ & $\mathrm{o}-(\mathrm{Pr}-\mathrm{i}) \mathrm{C}_{6} \mathrm{H}_{4}$ & 97 & 98 & $(R)$ \\
$\left(\mathrm{CH}_{2}\right)_{2} \mathrm{Ph}$ & $\mathrm{Bu}-\mathrm{t}$ & 55 & 97 & $(R)$ \\
$\left(\mathrm{CH}_{2}\right)_{2} \mathrm{Ph}$ & $\mathrm{c}-\mathrm{C}_{6} \mathrm{H}_{11}$ & 96 & 92 & $(R)$ \\
\hline
\end{tabular}

The reduction of phosphinite boranes with sodium borohydride and mesyl anhydride proceeded with the formation of phosphinic acid boranes. Optically pure phosphine boranes were stereoselectively converted into mesylates by reaction with mesyl anhydride, which was reduced with sodium borohydride in ethanol to form chiral secondary phosphine boranes in yield $90 \%$, complete stereospecificity and configuration inversion (Equation (105)) [30,133].

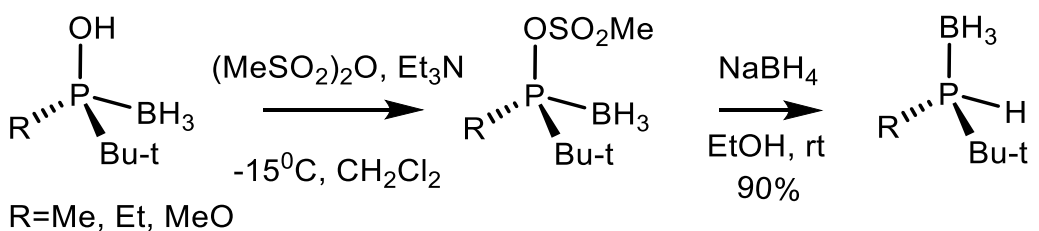

\section{Imination}

The Staudinger reaction is a two-step process, including the initial electrophilic addition of azide to a compound of trivalent phosphorus, followed by removal of nitrogen from intermediate 
phosphazide $\mathbf{A}$, which is converted into iminophosphorane. The reaction rate is controlled by the inductive effect of the substituents and the electrophilicity of azide. The formation of phosphazides $\left(\mathrm{Me}_{2} \mathrm{~N}\right)_{3} \mathrm{P}-\mathrm{N}_{3} \mathrm{R}{ }^{\prime}(\mathrm{R}=\mathrm{Me}, \mathrm{Ph})$ is practically irreversible. The equilibrium of phosphite amination with arylazides is significantly shifted towards the formation of imines. Phosphazide A decomposes with the formation of corresponding iminophosphoranes via the intramolecular mechanism through the 4-membered cyclic transition state B, as was established by Gololobov and Kasukhin (Scheme 12) [143]. Staudinger imination proceeds with retention of configuration at the phosphorus atom [144-149]. This conclusion has been confirmed by a number of examples of the imination of optically active phosphines. The chiral phosphines were used to study the mechanisms of the Staudinger reactions (Equation (106)) [145,149]. For example, the chiral methyl-propyl-phenylphosphine reacts with tosylazide to form chiral iminophosphorane with the retention of configuration at phosphorus.

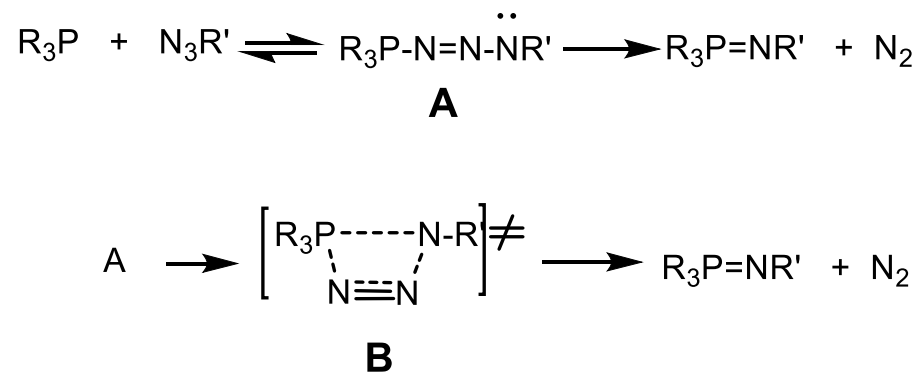

Scheme 12. The mechanism of Staudinger reaction.

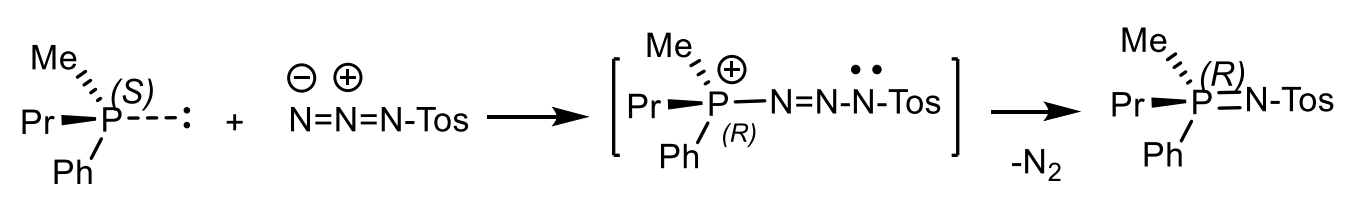

Nuretdinov investigated the reaction of O-trimethylsilyl-O-ethyl ethylphosphonite with 3-azido-1,4-diphenylazetidin-2-one in benzene [148]. The reaction proceeded with migration of silyl group from oxygen to nitrogen, desilylation in the presence of atmospheric moisture and consecutive formation of (-)-O-ethyl ethylphosphonamino-1,4-diphenylazetidin-2-one. It was found that the Staudinger reaction of silylphosphinite with 3-azido-1,4-diphenylazetidin-2-one proceeds with the retention of configuration at the phosphorus atom as shown in Equation (107).

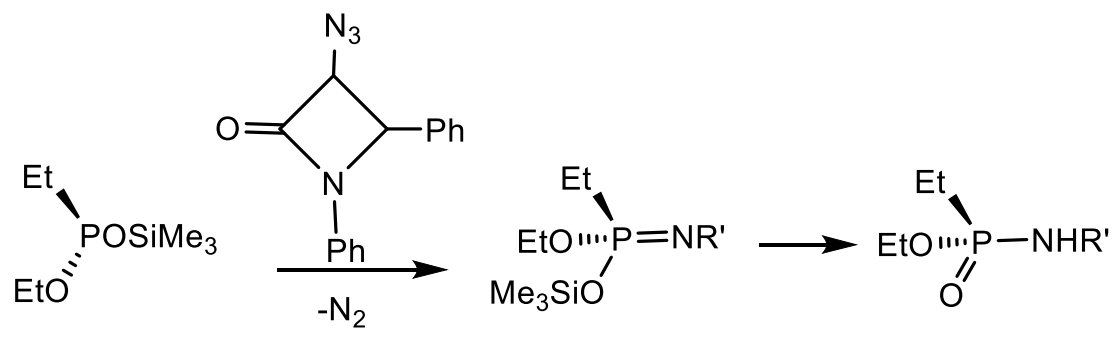

The reaction between aromatic azides and diastereomeric diazaphospholenes gives the corresponding cyclic phosphazenes (Scheme 13). Hydrolysis of phosphazenes led to the formation of the corresponding acyclic compounds. The stereochemistry of the reaction and cis-trans isomerization observed during the imination of diazaphosphole is explained by the pseudorotation of the pentacoordinated phosphorane intermediate 5A $\rightleftharpoons$ 5B [148]. 

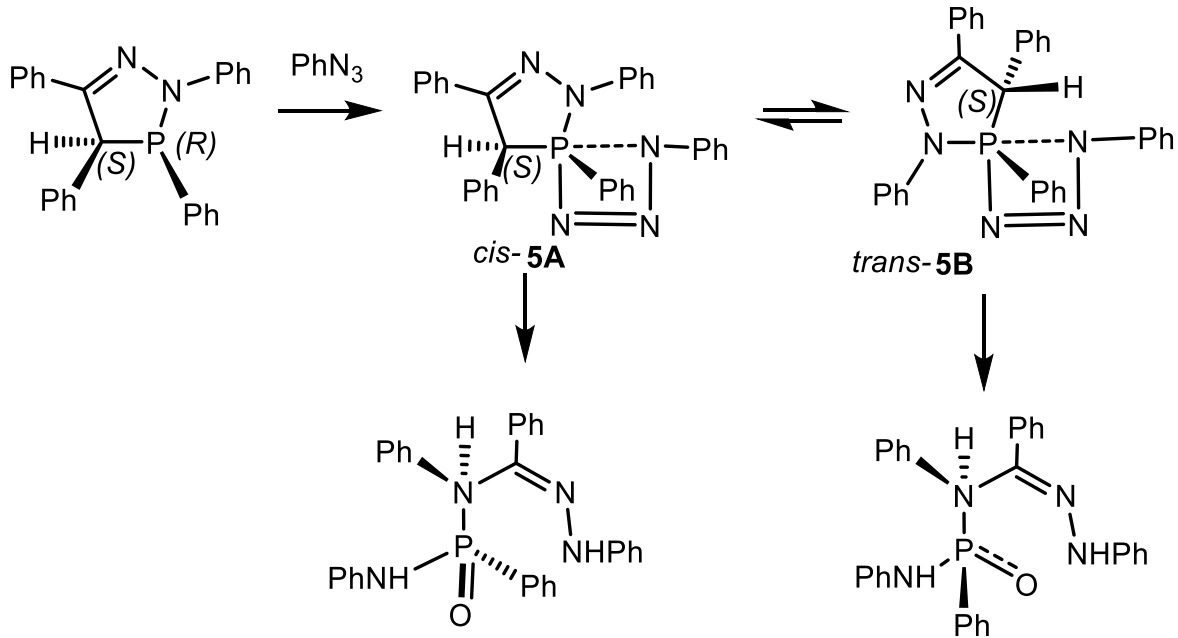

trans-5B
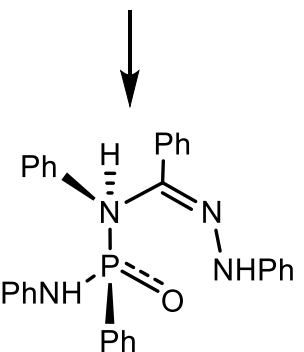

Scheme 13. The mechanism of diazophosphole imination.

The separation of racemic $\alpha$-P-stereogenic phosphines into enantiomers was achieved by the reaction of racemic phosphine with enantiomerically pure $(1 S, 2 R)$-O-(tert-butyldimethylsilyl) isobornyl-10-sulfonylazide. The resulting mixture of diastereomers of phosphinimines was separated by fractional crystallization and flash chromatography. Subsequent acid hydrolysis led to the formation of corresponding optically pure phosphine oxides in high yield and inversion of configuration at the phosphorus atom (Equation (108) and Table 4) [150]. By this method, were obtained phosphine ligands which are used in rhodium (I) complexes [151-153].

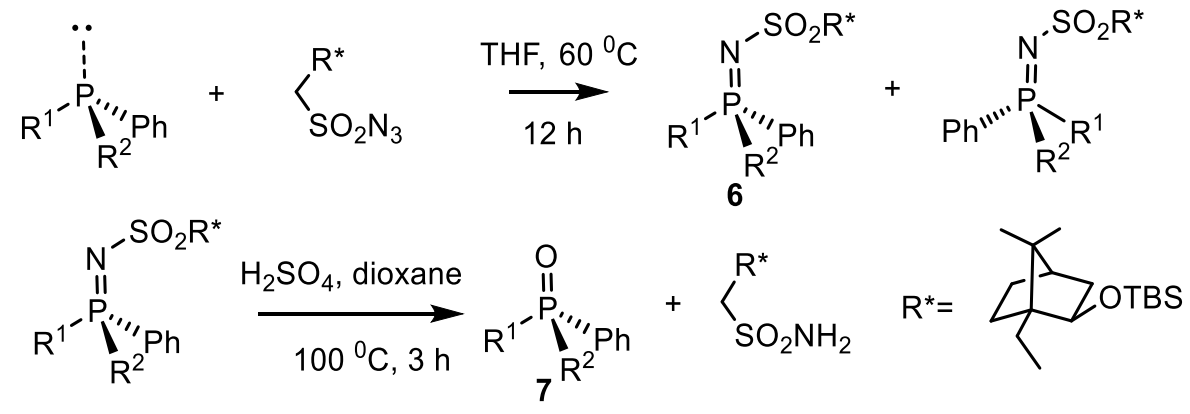

Table 4. The reaction of racemic tertiary phosphines with enantiomerically pure $(1 S, 2 R)$-O-(tertbutyldimethylsilyl) isobornyl-10-sulfonylazide (Equation (108)).

\begin{tabular}{ccccc}
\hline \multirow{2}{*}{$\mathbf{R}^{\mathbf{1}}$} & \multirow{2}{*}{$\mathbf{R}^{\mathbf{2}}$} & Yield, (\%) & Yield, (\%) & Configuration \\
& & $\mathbf{6}$ & $\mathbf{7}$ & $S_{\mathrm{P}}$ \\
$\mathrm{Me}$ & $\mathrm{C}_{6} \mathrm{H}_{11}$ & 94 & 93 & - \\
$\mathrm{Me}$ & $\mathrm{C}_{5} \mathrm{H}_{9}$ & 90 & 93 & $R_{\mathrm{P}}$ \\
$\mathrm{Me}$ & $\mathrm{CH}\left(\mathrm{CH}_{3}\right)_{2}$ & 87 & 94 & $S_{\mathrm{P}}$ \\
$\mathrm{Me}$ & $1-\mathrm{Np}_{\mathrm{p}}$ & 94 & 96 & - \\
$\mathrm{Me}$ & $9-\mathrm{Phnt}_{\mathrm{Nh}}$ & 89 & $>99$ & $R_{\mathrm{P}}$ \\
\hline
\end{tabular}

\section{Addition to Multiple Bonds}

Unsaturated compounds $\mathrm{C}=\mathrm{X}$ enter into electrophilic reactions with phosphorus reagents, representing anions, which use their pair of electrons for the formation of a new bond. In phosphorus chemistry, the most well-known electrophilic additions to multiple bonds are the phospha-aldol 
reaction (the Abramov reaction) $[154,155]$, the phospha-Mannich reaction and the phospha-Michael reaction (the Pudovik reaction) [155-159].

The phospha-aldol reaction (the Abramov's reaction) is the addition of dialkylphosphite to carbonyl compounds with formation of $\alpha$-hydroxyphosphonates. Haines et al. [160] studied the stereochemistry of the phospha-aldol reaction. The addition of a configurationally stable P-chiral base-ionized tert-butylphenylphosphine oxide to various saturated aldehydes or unsaturated carbonyl compounds leads to the formation of functionalized phosphonates with diastereoselectivity from $33 \%$ to $98 \% \mathrm{de}$ and retention of the absolute configuration (Equation (109)).

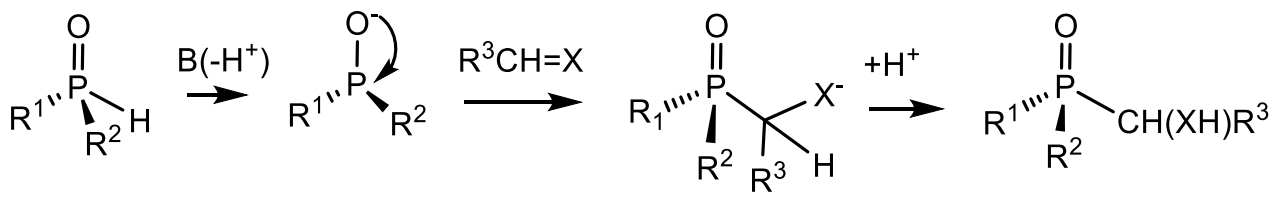

$X=O(a), S(b), N R^{\prime}(c), C R_{2}^{\prime}(d)$

The addition of phosphorous acid esters to carbonyl compounds involves two steps: the formation of a P-C bond and the removal of the ester function with formation of phosphonyl group. The first step of the addition reaction is reversible [156-158]. In the presence of strong bases, hydroxyalkyl phosphonates dissociate to form the starting dialkyl phosphite and carbonyl compound. This transformation is known as the retro-phospho-aldol reaction [157] and it significantly affects the stereochemistry of hydroxyphosphonates. The chiral substrates in the asymmetric phosphoaldol reaction may be chiral phosphonites having a stereogenic phosphorus atom or phosphites derived from chiral alcohols, amino alcohols or amines. The addition of achiral aldehydes to chiral dialkyl phosphites leads, as a rule, to the formation of hydroxyphosphonates with moderate stereoselectivity (Equation (110)) [157-162].

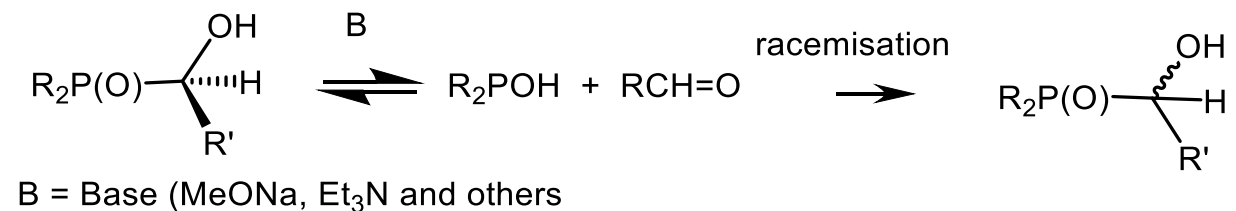

The one-step reaction of $(1 R, 2 S, 5 R)$-menthyl- $\left(R_{\mathrm{P}}\right)$-phenylphosphine oxide with $\alpha, \beta$-unsaturated aldehydes, catalyzed by $\mathrm{KOH}$ at room temperature, leads to the formation of $\mathrm{P}, \mathrm{C}$-stereogenic 1,3-bis-phosphinyl-propane as one stereoisomer bearing five stereogenic centers. The reaction proceeded with retention of absolute configuration at the phosphorus atom as shown in Equations (111) and (112) and Table $5[160,161]$.
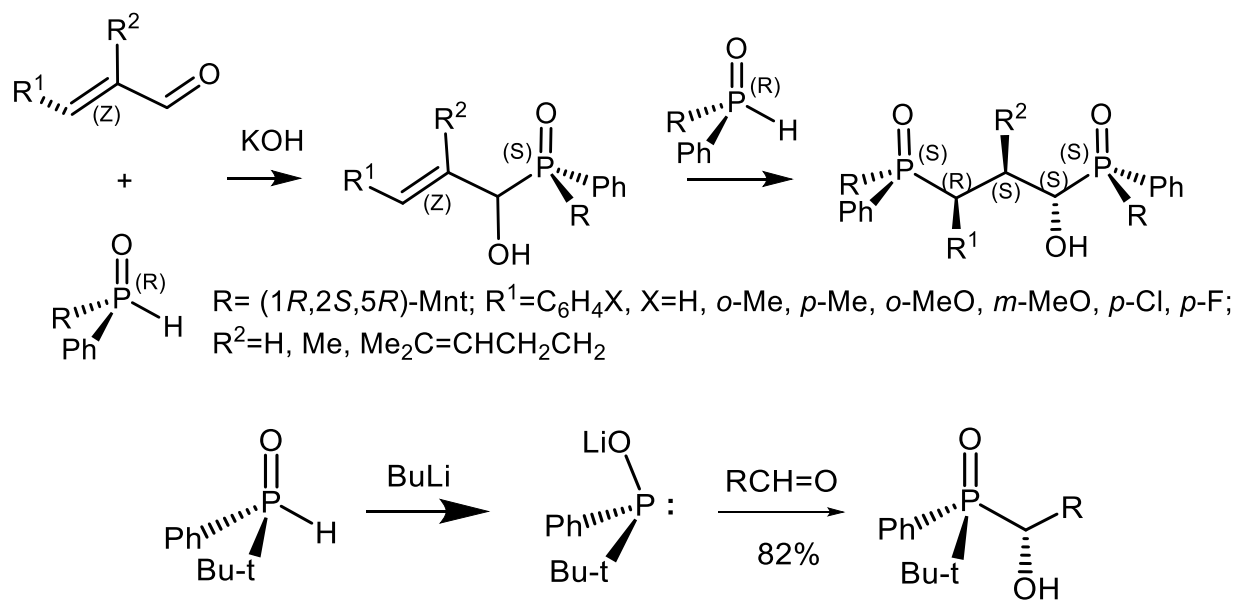
Stereochemically pure secondary phosphine oxides were prepared using a crystallization-induced asymmetric transformation (CIAT) involving radical-dynamic resolution. This methodology provides access to enantio- and diastereomerically pure tert-butyl(hydroxyalkyl)phenylphosphine oxides [163]. To this end, an equimolar mixture of secondary phosphine oxide and benzaldehyde was reacted in the presence of $0.05 \mathrm{M}$ aqueous sodium hydroxide. As a result, diastereomers of tert-butyl(hydroxybenzyl)phenylphosphine oxide were obtained in a ratio of 1:1. However, heating this mixture to $80^{\circ} \mathrm{C}$ was accompanied by a reversible dynamic transformation, which led to the predominant formation of a single diastereomer in $89 \%$ isolated yield. Treatment of the complex with $1 \%$ iodine solution, stoichiometric amount of L-dibenzoyl tartaric acid (DBTA), aldehyde and subsequent crystallization in a mixture of toluene-diisopropyl ether under CIAT conditions led to the formation of tertiary phosphine oxides with good yields and high enantioselectivity (Equation (113)), Table 6.

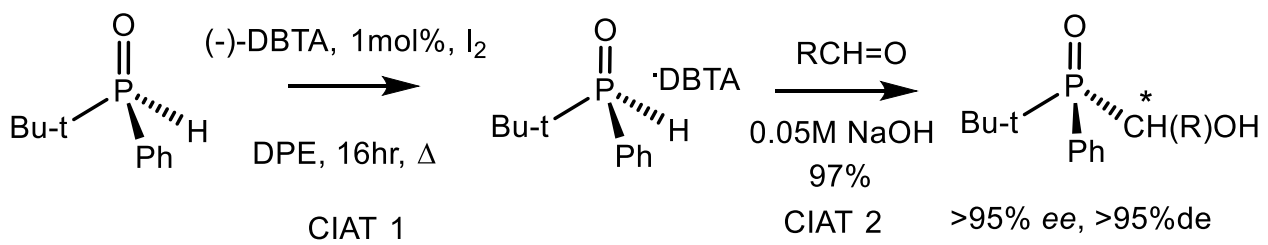

Table 5. Stereospecificity of the phosphaaldol reaction (Equation (112)).

\begin{tabular}{|c|c|c|}
\hline $\mathrm{RCH}=\mathrm{O}$ & Yield, (\%) & $d r$ \\
\hline $\mathrm{PhCH}=\mathrm{CHCHO}$ & 77 & $80: 20$ \\
\hline $\mathrm{PhCH}=\mathrm{CHCHO}$ & 83 & $80: 20$ \\
\hline $\mathrm{CH}_{2}=\mathrm{CHCHO}$ & 65 & $78: 22$ \\
\hline $\mathrm{MeCH}\left(=\mathrm{CH}_{2}\right) \mathrm{CHO}$ & 77.2 & $82: 18$ \\
\hline $\mathrm{c}-\mathrm{C}_{6} \mathrm{H}_{11} \mathrm{CHO}$ & 80 & $85: 15$ \\
\hline $\mathrm{PhCHO}$ & 77 & $98: 2$ \\
\hline $\mathrm{MeCHO}$ & 80 & 70:30 \\
\hline 2-РуСНO & 76 & $80: 20$ \\
\hline $\mathrm{Me}_{2} \mathrm{CHCH}_{2} \mathrm{CHO}$ & 78 & $67: 33$ \\
\hline 1-NpCHO & 71 & $98: 8$ \\
\hline 2-NpCHO & 71 & $85: 15$ \\
\hline 2-ThienylCHO & 68 & $82: 18$ \\
\hline 2-FurylCHO & 76 & $90: 10$ \\
\hline
\end{tabular}

The reaction of diphenyl(trimethylsilyl)phosphine with chiral aldehydes proceeding with high stereoselectivity gives diastereomerically pure tert- $\alpha$-trimethylsiloxyalkyl phosphines. The diastereomeric purity of the adducts was $90 \% d e$. The products were purified through the formation of borane-phosphine complexes. The reaction of bis(trimethylsilyl)phenylphosphine with acetonide $(R)$-glyceraldehyde provides tertiary bis(glyceryl)phosphines (Equation (114)) [162].

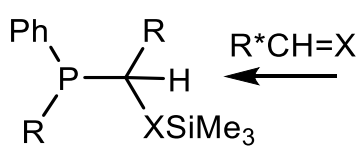

$\mathrm{R}^{*}=(S)$-Leu, (S)-Phe, Gal, Gly; $\mathrm{X}=\mathrm{O}, \mathrm{NR}, \mathrm{R}=\mathrm{Ph}, \mathrm{Me}_{3} \mathrm{Si}$

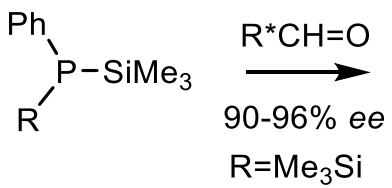
$\mathrm{R}=\mathrm{Me}_{3} \mathrm{Si}$ 
Aromatic and enolizable aliphatic aldehydes turned out to be the most suitable reagents in this case, leading to the formation of one diastereomer at room temperature. Quantitative addition of formaldehyde to secondary phosphine oxides gave enantiomerically pure (hydroxyalkyl)phosphine oxides in quantitative yield. Phosphine boranes were obtained from the tert-butyl(hydroxyalkyl)phenylphosphine oxide by treatment with an excess borane complex $\left(\mathrm{BH}_{3} \cdot \mathrm{Me}_{2} \mathrm{~S}\right.$ or $\left.\mathrm{BH}_{3} \mathrm{THF}\right)$ (Equation (115)) $[164,165]$.

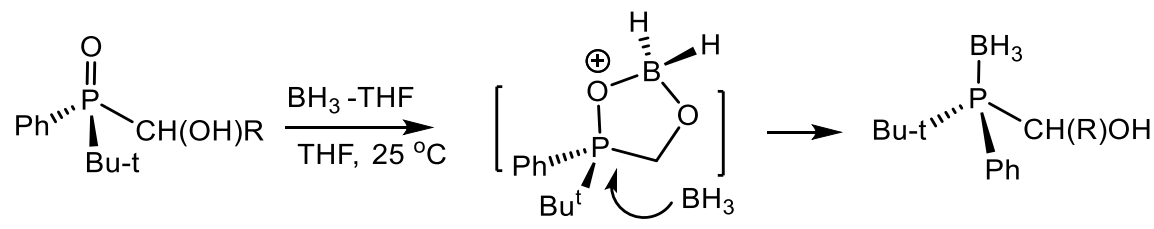

Table 6. Synthesis of tert-butyl (hydroxyalkyl) phenylphosphine oxide using the CIAT methodology (Equation (113)).

\begin{tabular}{cccc}
\hline $\mathbf{R}$ & $d r$ & Configuration & Yield, $\%$ \\
\hline $\mathrm{Ph}$ & $20: 1$ & $R_{\mathrm{P}}, R$ & 89 \\
$\mathrm{p}-\mathrm{Tl}$ & $1: 20$ & $R_{\mathrm{P}}, S$ & 94 \\
$\mathrm{o}-\mathrm{Tl}$ & $1: 20$ & $R_{\mathrm{P}}, S$ & 94 \\
$\mathrm{p}-(\mathrm{i}-\mathrm{Pr}) \mathrm{C}_{6} \mathrm{H}_{4}$ & $20: 1$ & $R_{\mathrm{P}}, R$ & 96 \\
$\mathrm{p}-\mathrm{An}$ & $20: 1$ & $R_{\mathrm{P}}, S$ & 96 \\
$\mathrm{~m}-\mathrm{HOC}_{6} \mathrm{H}_{4}$ & $1: 20$ & $R_{\mathrm{P}}, S$ & 90 \\
$\mathrm{p}-\mathrm{ClC}_{6} \mathrm{H}_{4}$ & $1: 3.5$ & - & 90 \\
$\mathrm{p}-\mathrm{O}_{2} \mathrm{NC}_{6} \mathrm{H}_{4}$ & $1: 4.4$ & - & 93 \\
$\mathrm{Pr}-\mathrm{i}$ & $1: 20$ & $R_{\mathrm{P}}, S$ & 95 \\
$\mathrm{Bu}-\mathrm{t}$ & $1: 20$ & $R_{\mathrm{P}}, S$ & 89 \\
$\mathrm{H}$ & - & - & 100 \\
\hline
\end{tabular}

A number of optically pure $\alpha$ - and $\beta$-hydroxyalkylphosphine boranes were prepared using a three-step method from readily available adamantyl H-phosphinates. First, an one-pot reaction gave enantiomerically pure tertiary hydroxyalkylphosphine oxides in good yield and high ee. Then, the treating the product with excess $\mathrm{BH}_{3}$ resulted in the formation of phosphine borane, with high stereospecificity (Equation (116)). Adamantyl H-phosphinates as precursors of P-stereogenic ligands were obtained in one step from chlorophosphines. Enantiomers of these air- and moisture-stable intermediates were separated by chiral HPLC on a multigram scale and introduced into stereoselective transformations to afford enantiomers of various P-stereogenic compounds such as secondary phosphine oxides and boron-protected monophosphines. The strategy is based on the introduction of a hydroxymethyl group to the phosphorus center of adamantyl phenylphosphinates, which serves as a protective group. The stereoselective conversion of tertiary hydroxyalkylphosphine oxides to the corresponding tertiary hydroxyalkylphosphine borane is achieved by reduction of $\mathrm{P}=\mathrm{O}$ bond with excess $\mathrm{BH}_{3}$ under mild conditions. The distance between the $\mathrm{P}=\mathrm{O}$ bond and the $\mathrm{OH}$ groups in $\alpha$ - to $\beta$-positions leads to a noticeable lowering of the propensity of the $\mathrm{P}=\mathrm{O}$ toward reduction by $\mathrm{BH}_{3}$ and elevation of the reaction temperature which is required that the reduction was effective. The reduction of the $\mathrm{P}=\mathrm{O}$ bond with $\mathrm{BH}_{3}$ is possible due to the intramolecular complexation of $\mathrm{P}=\mathrm{O} \cdot \mathrm{B}$ coordinated by $\alpha$ - or $\beta$-hydroxy groups present in the phosphine oxide structure. The conversion of hydroxyalkylphosphine oxides to hydroxyalkylphosphine boranes were obtained with a full inversion of the configuration at phosphorus [163,165-168]. It was found that the P-alkylation reaction proceeds with good yield and high enantiospecificity $(e e>95 \%)$ with various alkyl halides. Chiral phosphine boranes obtained from adamantylphosphinates are of interest as synthetic blocks (Equations (117) and (118)) [137]. 
<smiles>[R]C(C)=O</smiles>

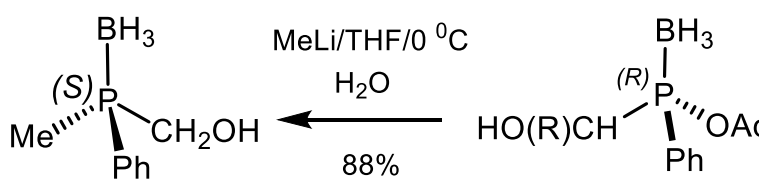

$97 \%$ ee

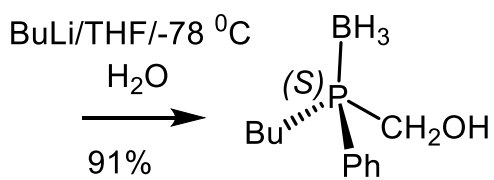

$97 \%$ ee

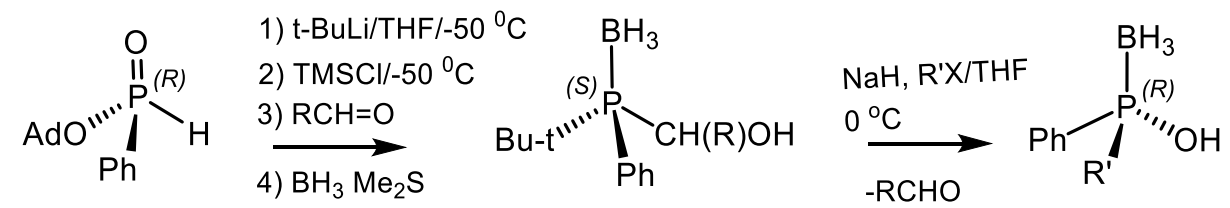

$\mathrm{R}=\mathrm{H}, \mathrm{Me}, \mathrm{Ph} ; \mathrm{R}^{\prime}=\mathrm{Me}, \mathrm{CH}_{2}=\mathrm{CHCH}_{2}, \mathrm{Pr}-\mathrm{i}, \mathrm{ArCH}_{2} ; \mathrm{Ad}$

An alternative method for the synthesis of P-stereogenic adamantyl phosphinates is based on the introduction of a hydroxymethyl group into phosphinates to control the stereoselectivity of the subsequent reduction by borane-THF complex [166-168]. The reaction of adamantylphosphinates with formaldehyde led to the formation of optically pure hydroxymethylphosphinates (Equation (119)). The synthesis of functionalized (R)-benzyl(butyl)(adamantoxy)phosphine borane was achieved by the conversion of (hydroxymethyl)phosphine borane into secondary phosphine borane and subsequent alkylation to form adamantyl phosphinates. Alkylation of adamantyl H-phosphinate proceeded with good yields and high enantiospecificity (es $>95 \%$ ) of the formed phosphine boranes using various alkyl halides as electrophiles (Equation (120)).

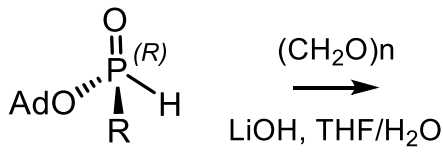<smiles></smiles><smiles>[R][Pb]([B])([18OH])CO</smiles>

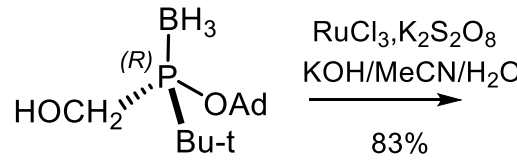

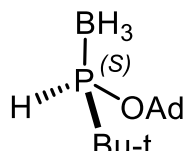

$\mathrm{R}=\mathrm{Bu}, \mathrm{Bu}-\mathrm{t}, \mathrm{c}-\mathrm{C}_{6} \mathrm{H}_{11}, \mathrm{Ph}, \mathrm{o}-\mathrm{Tol}, \mathrm{o}-\mathrm{An}$

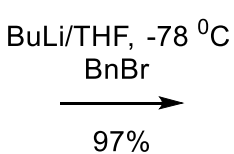<smiles></smiles>

$95 \%$ ee

The synthesis of functionalized tertiary phosphine boranes was developed using a chemodivergent approach from readily available (hydroxymethyl)phosphine boranes under mild conditions and high regioselectivity with the formation of an exclusively O-alkylation product. The reaction proceeded with a moderate or very good yields and high enantiospecificity (es> 95\%) (Equation (121)) [168]. 


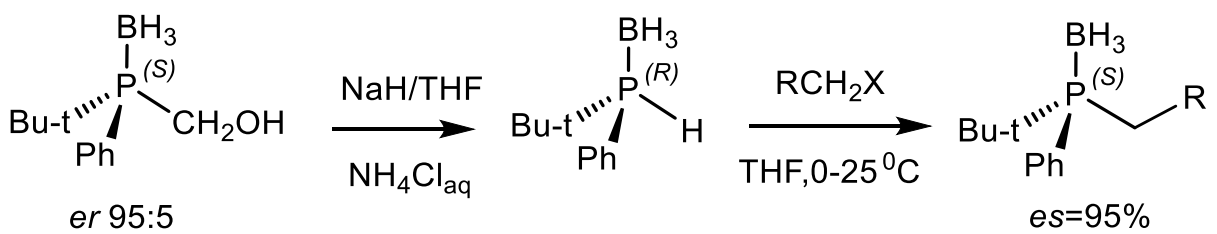

R=Me, Allyl, Pr-i, 2-Py, 2-An, 2-Tol

The phospha-Mannich reaction is the addition of phosphites to imines leading to the formation of aminophosphonates possessing diverse biological activity [169-172]. A special case of the phospha-Mannich reaction is the Kabachnik-Fields reaction, which is a three-component methodology that involves the interaction of a carbonyl compound, amine and dialkylphosphite leading to the formation of aminophosphonate. The stoichiometric and catalytic activity of the geometrically hindered triamide phosphate with pinacoloborane (HBPin) under the conditions of the phospha-Mannich reaction was reported. The addition of HBPin to phosphorus triamide led to the formation of phosphine with a cleavage of the $\mathrm{B}-\mathrm{H}$ bond in pinacolborane. Activation of the $\mathrm{B}-\mathrm{H}$ bond gives a P-hydride-1,3,2-diazaphospholine intermediate, which reacts with imines to form an intermediate phosphorus triamide, as confirmed by independent synthesis. First-order kinetics indicates the monomolecular mechanism of this process [171]. Triamidophosphite reacted with $N$-tosylbenzaldimine at room temperature in a benzene solution with complete conversion into the addition product (Scheme 14).

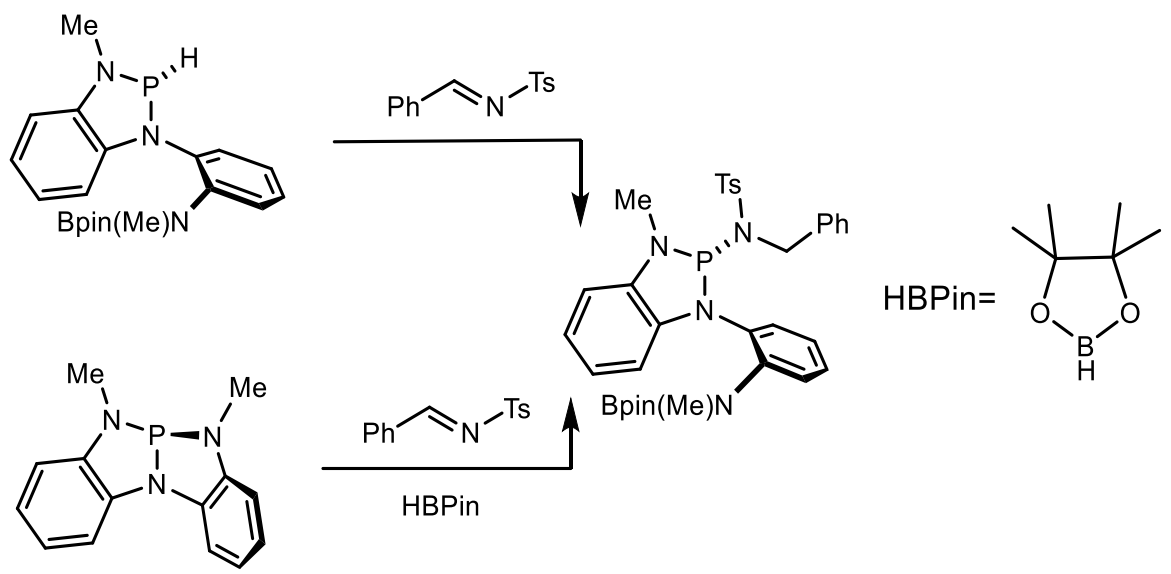

Scheme 14. The phospha-Mannich reaction of the geometrically hindered triamide phosphite with pinacoloborane.

The addition of alkylphosphinates to imines catalyzed by guanidinium salts in the presence of $\mathrm{K}_{2} \mathrm{CO}_{3}$ proceeded with good diastereoselectivity, high $e e$ and very good yields leading to the formation of corresponding addition products (Table 7). It was possible to obtain unreacted alkylphosphinate with $87 \% e e$, if the reaction was stopped at $63 \%$ conversion (Equation (122)) [170].

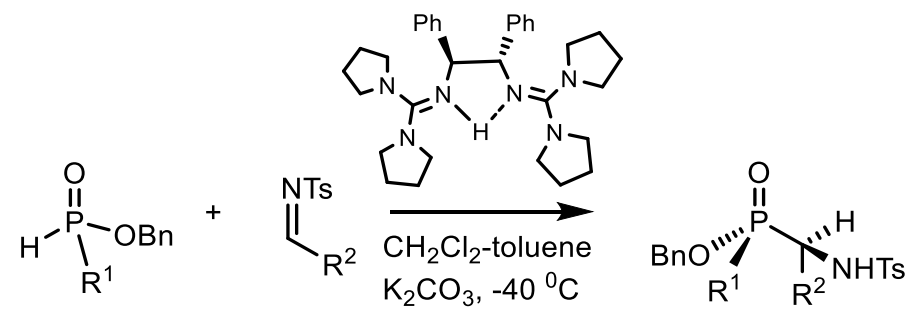


Table 7. Phospha-Mannich reaction of Benzyl Alkylphosphinates with Various Imines Catalyzed by Guanidinium Salt HBArF (Equation (122)).

\begin{tabular}{|c|c|c|c|c|}
\hline $\mathrm{R}^{1}$ & $\mathbf{R}^{2}$ & Yield (\%) & $d r$ & $e e(\%)$ \\
\hline $\mathrm{Bn}$ & $\mathrm{Ph}$ & 83 & $6: 1$ & 94 \\
\hline $\mathrm{Bn}$ & $4-\mathrm{FC}_{6} \mathrm{H}_{4}$ & 90 & $6: 1$ & 90 \\
\hline $\mathrm{Bn}$ & $4-\mathrm{ClC}_{6} \mathrm{H}_{4}$ & 90 & $4: 1$ & 92 \\
\hline $\mathrm{Bn}$ & 4-Tol & 85 & $4: 1$ & 90 \\
\hline $\mathrm{Bn}$ & 2-naphthyl & 93 & $6: 1$ & 91 \\
\hline $\mathrm{Bn}$ & 2-furyl & 71 & $7: 1$ & 94 \\
\hline $\mathrm{Bn}$ & $\mathrm{E}-\mathrm{CH}=\mathrm{CHPh}$ & 92 & $3: 1$ & 90 \\
\hline 2-Naphthylmethyl & $\mathrm{Ph}$ & 92 & $6.5: 1$ & 94 \\
\hline $4-\mathrm{F}_{3} \mathrm{CC}_{6} \mathrm{H}_{4} \mathrm{CH}_{2}$ & $\mathrm{Ph}$ & 92 & $16: 1$ & 94 \\
\hline $4-\mathrm{TolCH}_{2}$ & $\mathrm{Ph}$ & 83 & $5: 1$ & 88 \\
\hline$(E)-\mathrm{H}_{2} \mathrm{CCH}=\mathrm{CHPh}$ & $\mathrm{Ph}$ & 82 & $7: 1$ & 82 \\
\hline
\end{tabular}

An effective method for the formation of P-C bonds with substoichiometric amounts of copper iodide as a catalyst has been developed. A number of sterically hindered phosphines were introduced into the addition reaction with diazo compounds and the corresponding products were obtained in high yield and with retention of configuration. The reaction proceeded under neutral conditions, which avoided the base-catalyzed racemization. For example, $(R)$-tert-butyl-phenylphosphine-borane was reacted with ethyl diazoacetate in the presence of $5 \mathrm{~mol} \% \mathrm{CuI}$ in acetonitrile at room temperature to form ethyl (R)-2-(tert-butyl(phenyl)phosphonoacetate, which was isolated in $80 \%$ yield. The phosphonoacetate was hydrolyzed, followed by decarboxylation, resulting in the formation of the $\left(R_{\mathrm{P}}\right)$-tert-butyl(methyl)(phenyl)phosphine borane in 75\% yield (Equation (123)) [169].

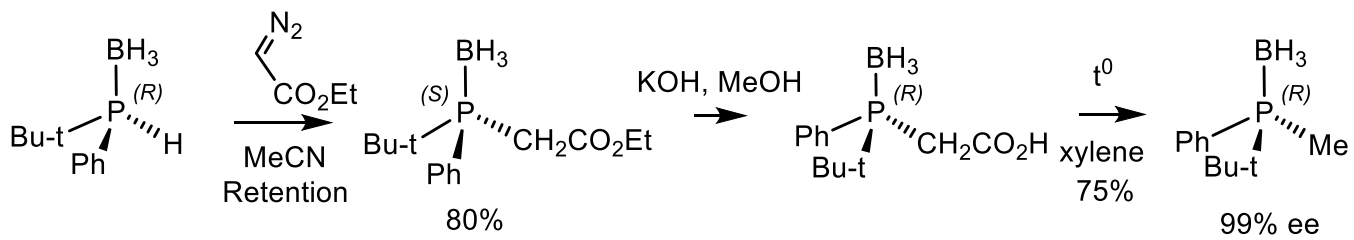

The phospha-Michael reaction (Pudovik reaction) representing the addition of trivalent phosphorus anions to the activated carbon-carbon multiple bond is one of the most convenient methods for the formation of PC bonds [2,156,173-178]. As a result of this reaction, dialkylphosphites are attached to compounds with activated multiple bond $\mathrm{C}=\mathrm{C}$ under the action of bases. As $\mathrm{P}$ (III) reagents anions of the compounds $\mathrm{R}_{2} \mathrm{P}(\mathrm{O}) \mathrm{H}$ or $\mathrm{R}_{2} \mathrm{PH}$ can be used. The phospha-Michael asymmetric reaction can be carried out in two ways: by substrate-controlled diastereoselective coupling, using chiral starting reagents and chiral inducers or catalytic enantioselective coupling (Equation (124)). For example, the addition of unsaturated carbonyl compounds to lithium tert-butyl (phenyl) phosphine oxide leads to the formation of chiral tertiary phosphines in good yields and with a diastereoselectivity of $82-96 \%$ $d e$. In most cases, the reaction proceeds with retention of the configuration at the phosphorus atom. The absolute configuration of the products was established by X-ray analysis (Scheme 15) $[156,160]$.

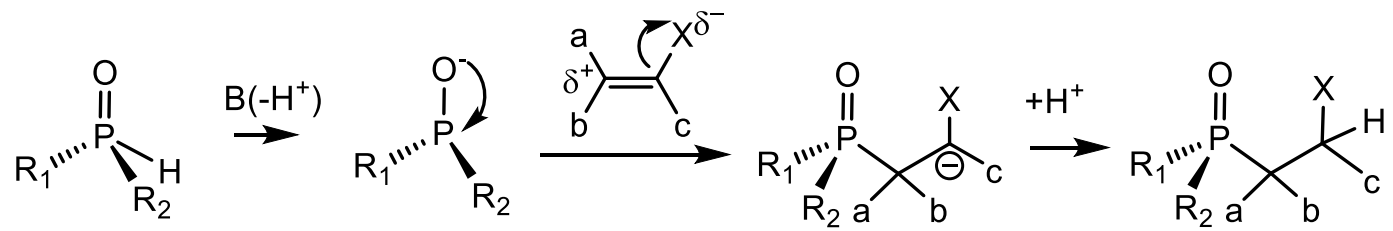




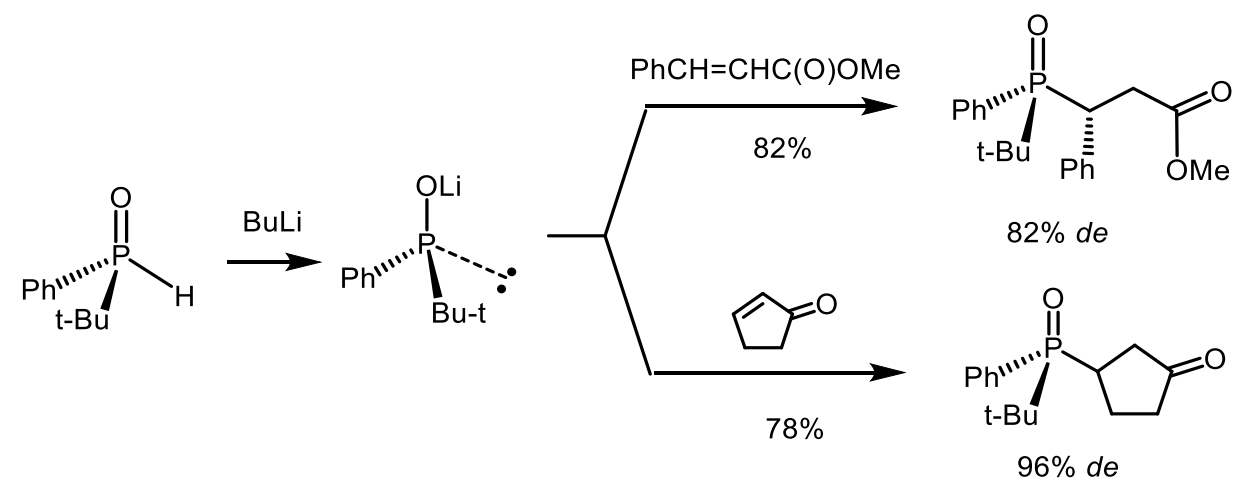

Scheme 15. The stereospecificity of phospha-Michael reaction.

Chiral phosphite obtained from TADDOL was used in addition reactions with aromatic alkylidene malonates or nitrostyrenes (Equation (125)) [169]. The reactions were carried out under heterogeneous conditions using $\mathrm{KOH}$ supported on solid $\mathrm{Fe}_{2} \mathrm{O}_{3}$. Phosphonates were obtained with moderate or good yields (86-91\%) and very good stereoselectivity. The chiral inductor was removed by treatment with $\mathrm{Me}_{3} \mathrm{SiCl} / \mathrm{NaI}$ and subsequent hydrolysis. Alkyl substituted alkylidene malonates reacted in good yields but with low diastereoselectivity. The stereoselective addition of nucleophiles to an asymmetrically substituted tert-butyl(1,4-cyclohexadienyl)phosphine oxide and its derivative proceeded with $65-94 \%$ ee.

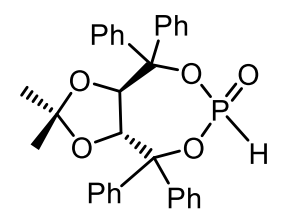<smiles>[R]/C(=C/[R6](=O)O)CC</smiles>

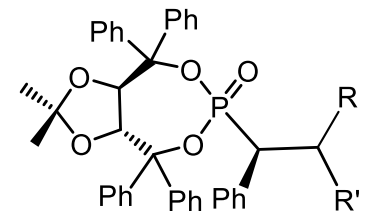<smiles>[R]C([R])[C@H](P)P(=O)(O)O</smiles>

$81-95 \%$ ee

$\mathrm{R}=\mathrm{Ph}, 4-\mathrm{BrC}_{6} \mathrm{H}_{4}, 3,4,5-(\mathrm{MeO})_{3} \mathrm{C}_{6} \mathrm{H}_{2}, 4-\mathrm{Tol}, 2-\mathrm{Np} ; \mathrm{CRR}^{\prime}=\mathrm{CHNO}_{2}, \mathrm{C}\left(\mathrm{CO}_{2} \mathrm{Me}\right)_{2}$

Functionalized P,C-stereogenic tertiary phosphine oxides were obtained by the addition of $\left(R_{\mathrm{P}}\right)$-phenylphosphine oxide to activated olefins with a high $d r(\mathrm{P})$ and $d r(\mathrm{C})$ values and were isolated in very high yields (Equation (126)). The reaction was catalyzed by metal hydroxides or carried out by heating. The $\left(R_{\mathrm{P}}\right)-(-)$-menthylphenylphosphine oxide is configurationally stable during electrophilic addition reactions, since the (-)-menthyl group stabilizes the configuration of phosphorus. The addition of secondary phosphine oxide to various activated alkenes catalyzed by calcium hydroxide at $+20{ }^{\circ} \mathrm{C}$ proceeded completely stereospecifically with retention of configuration on the phosphorus center. Functional P,C-stereogenic tertiary phosphine oxides were obtained with 94-98\% de. Optically pure stereoisomers were isolated in high yields and converted into P-stereogenic tertiary phosphines (Equation (127)) [175,176].

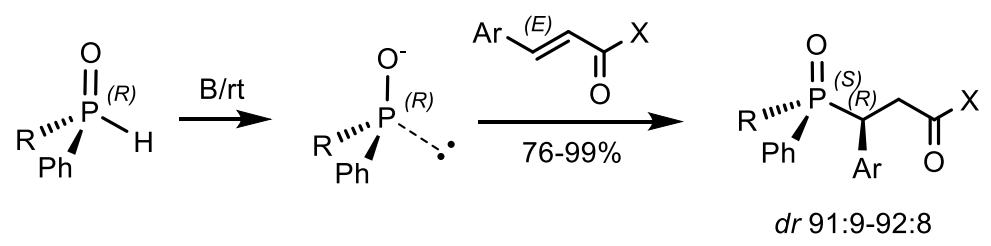

$\mathrm{B}=\mathrm{LiOH}, \mathrm{KOH}, \mathrm{Ca}(\mathrm{OH})_{2}, \mathrm{BuLi} ; \mathrm{Ar}=\mathrm{C}_{6} \mathrm{H}_{4} \mathrm{Y}-4, \mathrm{Y}=\mathrm{H}, \mathrm{Me}, \mathrm{OMe}, \mathrm{Cl}, \mathrm{Br}$

$\mathrm{X}=\mathrm{Me}, \mathrm{OR}, \mathrm{CN}, \mathrm{NO}_{2}, \mathrm{C}_{6} \mathrm{H}_{4} \mathrm{Y}, \mathrm{Y}=\mathrm{H}, \mathrm{Me}, \mathrm{OMe} ; \mathrm{R}=\mathrm{Mnt}$ 


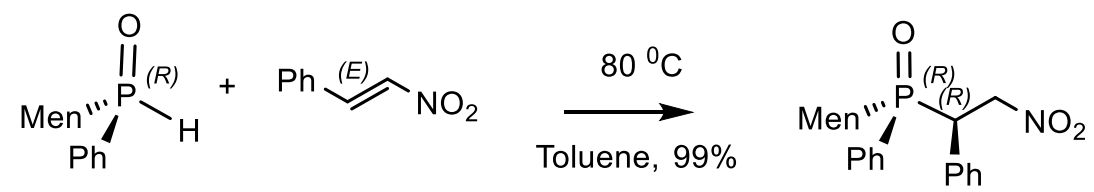

\section{Conclusions}

Summarizing the data considered in this review, we can conclude that the electrophilic reactions of organophosphorus compounds is interesting from both theoretical and practical considerations. The reactions of bimolecular electrophilic substitution $\mathrm{S}_{\mathrm{E}} 2(\mathrm{P})$, as a rule, proceed stereospecifically with the retention of absolute configuration at the phosphorus center, in contrast to the reactions of bimolecular nucleophilic substitution $\mathrm{S}_{\mathrm{N}} 2(\mathrm{P})$, which proceed with inversion of absolute configuration. This conclusion was made on the basis of stereochemical analysis of wide range of trivalent phosphorus reactions with typical electrophiles and investigation of a big number of diverse compounds. The combination of stereospecific electrophilic reactions and stereoselective nucleophilic reactions is useful and promising for the further development of organophosphorus chemistry $[176,177]$. In particular, for the design of synthesis schemes of new chiral organophosphorus compounds.

The electrophilic substitution reaction at the trivalent phosphorus usually proceeds in one step by the addition of electrophile to the phosphorus substrate or in two steps, by the type of addition-elimination, that is, first the electrophile is linking with the phosphorus to form an adduct and then the leaving group is removed. An electrophile providing a free orbital to a substrate interacts with the front-side of the phosphorus center, where a free pair of electrons is located, forming a new bond with the phosphorus atom. For example, the reactions such as the alkylation of tertiary phosphines proceed in one step according to the type of addition with the formation of phosphonium salts but the Michaelis-Arbuzov reaction passes in two steps - first with formation of a quasi-phosphonium intermediate, which then eliminates alkyl halide. To this type of reaction is also refer the phospha-Aldol, phospha-Mannich, phospha-Michael reactions, as well as halogenophilic, oxidation, reduction, imination and some other reactions. An interesting type of electrophilic reactions of phosphorus compounds is electrophilic catalysis, which results in the formation of various phosphine ligands for the transition metal complexes, some of which have found practical application. Thus, the study of electrophilic reactions in phosphorus chemistry has promising prospects. And therefore, we can expect that the study of the features of electrophilic reactions of organophosphorus compounds will be the subject of intensive research, especially in the field of creating ligands for metal complex catalysts or as potentially biologically active compounds.

Author Contributions: O.I.K. and A.O.K. wrote the paper. All authors have read and agreed to the published version of the manuscript.

Funding: This research received no external funding.

Conflicts of Interest: The authors declare no conflict of interest, financial or otherwise.

\section{Abbreviations}

Ad-1-adamantyl; Boc-tert-butoxycarbonyl; de-diastereomeric excess; dppf-1,1'-bis(diphenylphosphino) ferrocene; DIPAMP—ethane-1,2-diylbis[(2-methoxyphenyl)phenylphosphine]; dmpe-1,2-bis(dimethylphosphino) ethane; DPTA — diisopropyl tartrate; DiPE—diisopropyl ether; DIPEA — diisopropylethylamine; $e e$ - enantiomeric excess; es-enantiospecificity; Fc-ferrocenyl; Fu-furyl; HBPin-4,4,5,5-tetramethyl-1,3,2-dioxaborolan; is-2,4,6-(i-Pr) ${ }_{3} \mathrm{C}_{6} \mathrm{H}_{2}-2,4,6$-triisopropylbenzene; LDBB-lithium 4,4'-di-tert-butylbiphenylide; Mes-mesyl; Mnt- $(1 R, 2 S, 5 R)-$ Menthyl; MTBE-methyl tert-butyl ether; Np-naphthyl; NCS-N-chlorosuccinimide; PTC - interphase catalysis; QuinoxP-2,3-bis(tert-butylmethylphosphino) quinoxaline; rac-racemate; TADDOL- $\alpha, \alpha, \alpha^{\prime}, \alpha^{\prime}$-tetraaryl-1,3-dioxolane-4,5-dimethanol; TBDMS-tert-butyldimethylsilyl; Tf-trifluoromethanesulfonyl; TFA—-trifluoroacetic acid; TMS—-trimethylsilyl; Tol-Tolyl; Ts—4-toluenesulfonyl (tosyl). 


\section{References}

1. Fukuto, J.; Jensen, F.R. Mechanisms of SE2 reactions: Emphasis on organotin compounds. Acc. Chem. Res. 1983, 16, 177-184. [CrossRef]

2. Kolodiazhnyi, O.I. Asymmetric Synthesis in Organophosphorus Chemistry: Synthetic Methods, Catalysis and Application; Wiley-VCH: Weinheim, Germany, 2016.

3. Kolodiazhnyi, O.I.; Kolodiazhna, A.O. Nucleophilic substitution at phosphorus: Stereochemistry and mechanisms. Tetrahedron Asymmetry 2017, 28, 1651-1674. [CrossRef]

4. Kolodiazhnyi, O.I. Recent Advances in Asymmetric Synthesis of P-Stereogenic Phosphorus Compounds. In Topics in Current Chemistry; Montchamp, J.-L., Ed.; Springer Intern. Publ.: Cham, Switzerland, 2015; Volume 361, pp. 161-236. [CrossRef]

5. Eliel, E.L.; Wilen, S.H.; Doyle, P. Basic Organic Stereochemistry; J. Wiley Interscience: New York, NY, USA, 2001.

6. Kolodiazhnyi, O.I.; Kolodiazhna, A.O. Stereoselective Synthesis of Organophosphorus Compounds; Naukova Dumka: Kiev, Ukraine, 2017.

7. Nandi, P.; Dye, J.L.; Bentley, P.; Jackson, J.E. Preparation of diphenyl phosphide and substituted phosphines using alkali metal in silica gel (M-SG). Org. Lett. 2009, 11, 1689-1692. [CrossRef] [PubMed]

8. Naylor, R.A.; Walker, B. New routes to optically active phosphorus compounds. Asymmetric alkylation of phosphide anions. J. Chem. Soc. Chem. Commun. 1975, 6, 45-46. [CrossRef]

9. Valentine, D., Jr.; Blount, J.F.; Toth, K. Synthesis of phosphines having chiral organic groups ligated to chiral phosphorus. J. Org. Chem. 1980, 45, 3691-3698. [CrossRef]

10. Fisher, C.; Mosher, H. Asymmetric homogeneous hydrogenation with phosphine-rhodium complexes chiral both at phosphorus and carbon. Tetrahedron Lett. 1977, 18, 2487-2490. [CrossRef]

11. Burgess, K.; Ohimeyer, M.J.; Whitmire, K.H. Stereochemically matched (and mismatched) bisphosphine ligands: DIOP-DIPAMP hybrids. Organometallics 1992, 11, 3588-3600. [CrossRef]

12. Nagel, U.; Krink, T. Neue optisch reine 3,4-Bis(phosphanyl)pyrrolidine mit Phenyl-und Anisylgruppen sowie deren Palladium-und Rhodiumkomplexe. Chem. Ber. 1993, 126, 1091-1100. [CrossRef]

13. Nagel, U.; Bublewitz, A. Neue 1,2-Bisphosphanliganden mit vier stereogenen Zentren und zusatzlichen Methoxygruppen fur die asymmetrische katalytische Hydrierung. Chem. Ber. 1992, 125, 1061-1072. [CrossRef]

14. Kolodiazhnyi, O.I. Recent developments in the asymmetric synthesis of P-chiral phosphorus compounds. Tetrahedron Asymmetry 2012, 23, 1-46. [CrossRef]

15. Mathey, F.; Herrmann, G.; Bellus, D.; Błażewska, K.M. Science of Synthesis: Houben-Weyl Methods of Molecular Transformations. Category 5. Compounds with One Saturated Carbon-Heteroatom Bond. Organophosphorus Compounds; Georg Thieme Verlag KG: Stuttgard, Germany; New York, NY, USA, 2009; Volume 42.

16. Remond, E.; Tessier, A.; Leroux, F.R.; Bayardon, J.; Juge, S. Efficient synthesis of quaternary and p-stereogenic phosphonium triflates. Org. Lett. 2010, 12, 1568-1571. [CrossRef]

17. Meddour, A.; Uziel, J.; Courtieu, J.; Juge, S. Enantiodifferentiation of acyclic phosphonium salts in chiral liquid crystalline solutions. Tetrahedron Asymmetry 2006, 17, 1424-1429. [CrossRef]

18. Beaumont, A.J.; Kiely, C.; Rooney, A.D. Synthesis of novel chiral quaternary phosphonium fluorides: Reagents for simple asymmetric nucleophilic fluorination reactions. J. Fluor. Chem. 2001, 108, 47-50. [CrossRef]

19. Coumbe, T.; Lawrence, N.J.; Muhammad, F. Titanium (IV) catalysis in the reduction of phosphine oxides. Tetrahedron Lett. 1994, 35, 625-628. [CrossRef]

20. Dutartre, M.; Bayardon, J.; Jugé, S. Applications and stereoselective syntheses of P-chirogenic phosphorus compounds. Chem. Soc. Rev. 2016, 45, 5771-5794. [CrossRef] [PubMed]

21. Reynolds, S.C.; Hughes, R.P.; Glueck, D.S.; Rheingold, A.L. Synthesis, reactivity, and resolution of a C2Symmetric, PStereogenic benzodiphosphetane, a building block for chiral bis(phosphines). Org. Lett. 2012, 14, 4238-6241. [CrossRef]

22. Vedejs, E.; Donde, Y. Stereogenic P-Trisubstituted phosphorus by crystallization-induced asymmetric transformation: A practical synthesis of phenyl(o-anisyl)methylphosphine borane. J. Am. Chem. Soc. 1997, 119, 9293-9294. [CrossRef]

23. Vedejs, E.; Donde, Y. Crystallization-induced asymmetric transformation of a tertiary phosphine. J. Org. Chem. 2000, 65, 2337-2343. [CrossRef] 
24. Alayrac, C.; Lakhdar, S.; Abdellah, I.; Gaumont, A.-C. Recent advances in synthesis of P-BH $\mathrm{B}_{3}$ compounds. Top. Curr. Chem. 2015, 361, 1-83. [CrossRef]

25. Izod, K.; Watson, J.M.; Clegg, W.; Harrington, R.W. Phosphido-borane and phosphido-bis(borane) complexes of the alkali metals, a comparative study. Inorg. Chem. 2013, 52, 1466-1475. [CrossRef]

26. Imamoto, T. Synthesis and reactions of new phosphine-boranes. Pure Appl. Chern. 1993, 65, 655-660. [CrossRef]

27. Petit, C.; Favre-Reguillon, A.; Mignani, G.; Lemaire, M. A straightforward synthesis of unsymmetrical secondary phosphine-boranes. Green Chem. 2010, 12, 326-330. [CrossRef]

28. Stankevic, X.M.; Pietrusiewicz, K.M. Resolution and stereochemistry of tert-butylphenylphosphinous acid-borane. J. Org. Chem. 2007, 72, 816-822. [CrossRef]

29. Wauters, I.; Debrouwer, W.; Stevens, C.V. Preparation of phosphines through C-P bond formation. Beilstein J. Org. Chem. 2014, 10, 1064-1096. [CrossRef]

30. Gatineau, D.; Giordano, L.; Buono, G. Optically active p-stereogenic Phosphine-boranes from pure h-menthylphosphinates. J. Am. Chem. Soc. 2011, 133, 10728-10731. [CrossRef]

31. Imamoto, T.; Oshiki, T.; Onozawa, T.; Matsuo, M.; Hikosaka, T.; Yanagawa, M. Synthesis and reactions of optically active phosphine-boranes. Heteroatom Chem. 1992, 3, 563-575. [CrossRef]

32. Bauduin, C.; Moulin, D.; Kaloun, E.B.; Darcel, C.; Juge, S. Highly enantiomerically enriched chlorophosphine boranes: Synthesis and applications as p-chirogenic electrophilic blocks. J. Org. Chem. 2003, 68, 4293-4301. [CrossRef]

33. Rajendran, K.V.; Gilheany, D.G. Simple unprecedented conversion of phosphine oxides and sulfides to phosphine-boranes using sodium borohydrides. Chem. Commun. 2012, 48, 817-819. [CrossRef]

34. Ye, J.-J.; Nie, S.-Z.; Wang, J.-P.; Wen, J.-H.; Zhang, Y.; Qiu, M.-R.; Zhao, C.-Q. Nucleophilic substitution of p-stereogenic chlorophosphines: Mechanism, stereochemistry, and stereoselective conversions of diastereomeric secondary phosphine oxides to tertiary phosphines. Org. Lett. 2017, 19, 5384-5387. [CrossRef]

35. Al-Masum, M.; Kumaraswamy, G.; Livinghouse, T. A New Synthetic Route to P-Chiral Phosphine-Boranes of High Enantiopurity via Stereocontrolled $\mathrm{Pd}(0)-\mathrm{Cu}(\mathrm{I})$ Cocatalyzed Aromatic Phosphorylation. J. Org. Chem. 2000, 65, 4776-4778. [CrossRef]

36. Wolfe, B.; Livinghouse, T. A Direct Synthesis of P-Chiral Phosphine-Boranes via Dynamic Resolution of Lithiated Racemic tert-Butylphenylphosphine-Borane with (-)-Sparteine. J. Am. Chem. Soc. 1998, 120, 5116-5117. [CrossRef]

37. Nie, S.-Z.; Zhou, Z.-Y.; Wang, J.-P.; Yan, H.; Wen, J.-H.; Ye, J.-J.; Cui, Y.-Y.; Zhao, C.-Q. Nonepimerizing Alkylation of H-P Species to Stereospecifically Generate P-Stereogenic Phosphine Oxides: A Shortcut to Bidentate Tertiary Phosphine Ligands. J. Org. Chem. 2017, 82, 9425-9434. [CrossRef] [PubMed]

38. Moraleda, D.; Gatineau, D.; Martin, D.; Giordano, L.; Buono, G. A simple route to chiral phosphinous acid-boranes. Chem. Commun. 2008, 3031-3033. [CrossRef] [PubMed]

39. Juge, S. Enantioselective Synthesis of P-Chirogenic Phosphorus Compounds via the Ephedrine-Borane Complex Methodology. Phosphorus Sulfur Silicon Relat. Elem. 2008, 183, 233-248. [CrossRef]

40. Bayardon, J.; Laureano, H.; Diemer, V.; Dutartre, M.; Das, U.; Rousselin, Y.; Henry, J.-C.; Colobert, F.; Leroux, F.R.; Jugeé, S. Stereoselective synthesis of o-bromo (or iodo)aryl P-chirogenic phosphines based on aryne chemistry. J. Org. Chem. 2012, 77, 5759-5769. [CrossRef]

41. Kaloun, E.B.; Merdes, R.; Genet, J.P.; Uziel, J.; Jugé, S. Asymmetric synthesis of (S,S)-(+)-1,1'-bis(methyl-phenylphosphino)ferrocene. J. Organometall. Chem. 1997, 529, 455-463. [CrossRef]

42. Uziel, J.; Riegel, N.; Aka, B.; Figuiere, P.; Juge, S. A Practical Synthesis of Chiral and Achiral Phosphonium Salts. Tetrahedron Lett. 1997, 38, 3405-3408. [CrossRef]

43. Maienza, F.; Spindler, F.; Thommen, T.M.; Pugin, B.; Mezzetti, A. Exploring Stereogenic Phosphorus: The Search for New Chiral Diphosphines. Chimia 2001, 55, 694-698. [CrossRef]

44. Minois, P.; Bayardon, J.; Meunier-Prest, R.; Jugé, S. Fullerene l-Amino Acids and Peptides: Synthesis under Phase-Transfer Catalysis Using a Phosphine-Borane Linker. Electrochemical Behavior. J. Org. Chem. 2017, 82, 11358-11369. [CrossRef]

45. Imamoto, T.; Yamanoi, Y. Methylene Insertion Reactions of Samarium Carbenoids into Boron-Hydrogen and Phosphorus-Hydrogen Bonds. Chem. Lett. 1996, 8, 705-706. [CrossRef] 
46. Imamoto, T. Development of P-Chirogenic Phosphine Ligands Based on Chemistry of Phosphine-Boranes: Searching for Novelty and Utility in Synthetic Organic Chemistry. TCIMAIL 2017, N174, 1-18. Available online: https://www.tcichemicals.com/en/in/support-download/tcimail/backnumber/article/174drE_1.pdf (accessed on 15 November 2019).

47. Katagiri, K.; Danjo, H.; Yamaguchi, K.; Imamoto, T. Nucleophilic aromatic substitution reactions of fluorobenzenechromium complexes with P-chiral secondary phosphine-boranes: Synthesis of optically pure P-chiral (dialkyl) arylphosphine-boranes. Tetrahedron 2005, 61, 4701-4707. [CrossRef]

48. Jayaraman, A.; Nilewar, S.; Jacob, T.V.; Sterenberg, B.T. Sequential Electrophilic Substitution Reactions of Tungsten-Coordinated Phosphenium Ions and Phosphine Triflates. ACS Omega 2017, 2, 7849-7861. [CrossRef] [PubMed]

49. Kato, T.; Kobayashi, K.; Masuda, S.; Segi, M.; Nakajima, T.; Suga, S. Asymmetric Synthesis of Phosphine Oxides with the Arbuzov Reaction. Chem. Lett. 1987, 1915-1918. [CrossRef]

50. Bhatacharya, A.K.; Thyagarman, G. The Michaelis-Arbuzov Rearrangement. Chem. Rev. 1981, 81, 415-430. [CrossRef]

51. Berlin, K.D.; Hellwege1, D.M.; Nagabhushanam, M.; Gaudy, E.T. Evidence for a stereospecific Michaelis-Arbuzov rearrangement in 4-t-butylcyclohexyl diphenylphosphinite, a conformationally homogeneous system-III. Tetrahedron 1966, 22, 2191-2201. [CrossRef]

52. Segi, M.; Nakamura, Y.; Nakajima, T.; Suga, S. Preparation of optically active phosphine oxides by regioselective cleavage of cyclic phenylphosphonite with alkyl halides. Chem. Lett. 1983, 913-916. [CrossRef]

53. Fernández-Valle, M.E.; Martínez-Álvarez, R.; Molero-Vílchez, D.Z. 2D Ultrafast HMBC 1H,31P: Obtaining Mechanistic Details on the Michaelis-Arbuzov Reaction. J. Org. Chem. 2015, 80, 799-805. [CrossRef]

54. Michalski, J.; Mikołajczak, J.; Pakulski, M.; Skowronska, A. The stereochemistry of dealkylation step in the Arbuzov reaction involving fivecoordinate intermediate. Evidence for equilibrium between phosphorane and phosphonium species. Phosphorus Sulfur Silicon Relat. Elem. 1978, 4, 233-234. [CrossRef]

55. van den Berg, G.R.; Platenburg, D.H.J.M.; Benschop, H.P. Stereochemistry of a Michaelis-Arbusov reaction: Alkylation of optically active ethyl trimethylsilyl phenylphosphonite with retention of configuration. Chem. Commun. 1971, 606-607. [CrossRef]

56. Bodalski, R.; Rutkowska-Olma, E.; Pietrusiewicz, K.M. Optically active Phosphine oxides: Synthesis and absolute configuration of (menthoxycarbonylmethyl) phenylvinyl phosphine oxide. Tetrahedron 1980, 36, 2353-2355. [CrossRef]

57. Pietrusiewicz, K.M. Stereoselective Synthesis and Resolution of P-Chiral Phosphine Chalcogenides. Phosphorus Sulfur Silicon Relat. Elem. 1996, 109, 573-576. [CrossRef]

58. Johnson, C.R.; Imamoto, T. Synthesis of Polydentate Ligands with Homochiral Phosphine Centers. J. Org. Chem. 1987, 52, 2170-2174. [CrossRef]

59. Faure, B.; Archavlis, A.; Buono, G. Stereoselective synthesis of (Rp)-benzylphenyl-[2-(S)bromomethylpyrrolidine-1-yl]phosphine oxide from (S)-(+)-prolinol by the Michaelis-Arbuzov reaction: Application in the synthesis of a chiral hybrid phosphine-phosphine oxide ligand. Chem. Commun. 1989, 805-807. [CrossRef]

60. Savignac, P.; Iorga, B. Modern Phosphonate Chemistry; CRC Press: Boca Raton, FL, USA, 2003; p. 552.

61. Zhang, J.; Xu, Y.; Huang, G.; Guo, H. Palladium-catalyzed synthesis of chiral, nonracemic isopropyl arylmethylphosphinates. Tetrahedron Lett. 1988, 29, 1955-1958. [CrossRef]

62. Kato, T.; Tejlma, M.; Ebiike, H.; Achiwa, K. Asymmetric synthesis of (S)-(+)-and (R)-(-)-NZ-105 through the modified Michaelis-Arbuzov rearrangement as a key step. Chem. Pharm. Bull. 1996, 44, 1132-1134. [CrossRef]

63. Mikolajczyk, M.; Krzywanski, J.; Ziemnicka, B.J. Stereochemistry of organophosphorus cyclic compounds. 6. Stereochemistry of the reaction between sulfenyl chlorides and trivalent phosphorus compounds. J. Org. Chem. 1977, 42, 190-199. [CrossRef]

64. Berger, O.A.; Montchamp, J.L. A General Strategy for the Synthesis of P-Stereogenic Compounds. Angew. Chem. Int. Ed. Engl. 2013, 52, 11377-11380. [CrossRef]

65. Montchamp, J.L. Organophosphorus synthesis without phosphorus trichloride: The case for the hypophosphorous pathway. Phosphorus Sulfur Silicon Relat. Elem. 2013, 188, 66-75. [CrossRef] 
66. Haynes, R.K.; Freeman, R.N.; Mitchell, C.R.; Vonwiller, S.C. Preparation of Enantiomerically Pure Tertiary Phosphine Oxides from, and Assay of Enantiomeric Purity with, (Rp)- and (Sp)-tertButylphenylphosphinothioic Acids. J. Org. Chem. 1994, 59, 2919-2921. [CrossRef]

67. Hirao, T.; Masunaga, T.; Ohshiro, Y.; Agawa, T. Stereoselective synthesis of vinylphosphonate. Tetrahedron Lett. 1980, 21, 3595-3596. [CrossRef]

68. Keglevich, G.; Jablonkai, E.; Balázsa, L.B. A “green” variation of the Hirao reaction: The P-C coupling of diethyl phosphite, alkyl phenyl-Hphosphinates and secondary phosphine oxides with bromoarenes using a P-ligand-free Pd(OAc)2 catalyst under microwave and solvent-free conditionst. RSC Adv. 2014, 4, 22808-22816. [CrossRef]

69. Xu, Y.; Wei, H.; Zhang, J.; Huang, G. An efficient synthesis of chiral, nonracemic isopropyl alkenylmethylpbosphinates via palladium route. Tetrahedron Lett. 1989, 30, 949-952. [CrossRef]

70. Kalek, M.; Jezowska, M.; Stawinskia, J. Preparation of Arylphosphonates by Palladium(0)-Catalyzed Cross-Coupling in the Presence of Acetate Additives: Synthetic and Mechanistic Studies. Adv. Synth. Catal. 2009, 351, 3207-3216. [CrossRef]

71. Zhang, Y.; He, H.; Wang, Q.; Cai, Q. Asymmetric synthesis of chiral P-stereogenic triaryl phosphine oxides via Pd-catalyzed kinetic arylation of diaryl phosphine oxides. Tetrahedron Lett. 2016, 57, 5308-5311. [CrossRef]

72. Zhang, J.; Xu, Y. Stereochemistry at the Phosphorus Atom during Palladium-catalysed Formation of Carbon-Phosphorus Bonds and Mechanistic Implications. Chem. Commun. 1986, 1606. [CrossRef]

73. Anderson, B.J.; Glueck, D.S.; DiPasquale, A.G.; Rheingold, A.L. Substrate and Catalyst Screening in Platinum-Catalyzed Asymmetric Alkylation of Bis(secondary) Phosphines. Synthesis of an Enantiomerically Pure C2-Symmetric Diphosphine. Organometallics 2008, 27, 4992-5001. [CrossRef]

74. Whittaker, B.; de Lera Ruiz, M.; Hayes, C.J. Stereoselective synthesis of highly functionalised P-stereogenic nucleosides via palladium-catalysed P-C cross-coupling reactions. Tetrahedron Lett. 2008, 49, 6984-6987. [CrossRef]

75. Kolodiazhnyi, O.I. Reaction of sterically hindered phosphines with tetrahalo methanes. P-Halogenylides. Russ. J. Gen. Chem. 1981, 51, 2466-2480.

76. Zhou, Y.; Wang, G.; Saga, Y.; Shen, R.; Goto, M.; Zhao, Y.; Han, L.-B. Stereospecific Halogenation of P(O)-H Bonds with Copper(II) Chloride Affording Optically Active Z1Z2P(O)Cl. J. Org. Chem. 2010, 75, 7924-7927. [CrossRef]

77. Appel, R. Tertiary Phosphane/Tetrachloromethane, a Versatile Reagent for Chlorination, Dehydration, and P-N Linkage. Angew. Chem. Int. Ed. Engl. 1975, 14, 801-811. [CrossRef]

78. Sazonov, P.K.; Artamkina, G.A.; Beletskaya, I.P. Nucleophilic substitution at the halogen atom (halogenophilic reactions). Russ. Chem. Rev. 2012, 81, 317-335. [CrossRef]

79. Atherton, F.R.; Openshaw, H.T.; Todd, A.R. Studies on Phosphorylation. Part 11. The Reaction of Diallcyl Phosphites with Polyhalogen Compounds in Presence of Bases. A New Method for the Phosphorylation of Amines. J. Chem. Soc. 1945, 660-664. [CrossRef]

80. Steinberg, G.M. Reactions of dialkyl phosphites. Synthesis of dialkyl chlorophosphates, tetraalkyl pyrophosphates, and mixed orthophosphate esters. J. Org. Chem. 1950, 15, 637-647. [CrossRef]

81. Wang, G.; Shen, R.; Xu, Q.; Goto, M.; Zhao, Y.; Han, L.-B. Stereospecific Coupling of H-Phosphinates and Secondary Phosphine Oxides with Amines and Alcohols: A General Method for the Preparation of Optically Active Organophosphorus Acid Derivatives. J. Org. Chem. 2010, 75, 3890-3892. [CrossRef]

82. Xiong, B.; Zhou, Y.; Zhao, C.; Goto, M.; Yin, S.-F.; Han, L.-B. Systematic study for the stereochemistry of the Athertone-Todd reaction. Tetrahedron 2013, 69, 9373-9380. [CrossRef]

83. Denton, R.M.; An, J.; Adeniran, B.; Blake, A.J.; Lewis, W.; Poulton, A.M. Catalytic Phosphorus(V)-Mediated Nucleophilic Substitution Reactions: Development of a Catalytic Appel Reaction. J. Org. Chem. 2011, 76, 6749-6767. [CrossRef]

84. Le Corre, S.S.; Berchel, M.; Couthon-Gourvès, H.; Haelters, J.-P.; Jaffrès, P.-A. Atherton-Todd reaction: Mechanism, scope and applications. Beilstein J. Org. Chem. 2014, 10, 1166-1196. [CrossRef]

85. Reiff, L.P.; Aaron, H.S. Stereospecific Synthesis and Reactions of Optically Active Isopropyl Methylphosphinate. J. Am. Chem. Soc. 1970, 92, 5275-5276. [CrossRef]

86. Stec, W.; Mikolajczyk, M. Stereochemistry of organophosphorus cyclic compounds-ii stereospecific synthesis of cis- and trans-2-halogeno-2-oxo-4-methyl-1,3,2-dioxaphosphorinans and their chemical transformations. Tetrahedron 1973, 29, 539-546. [CrossRef] 
87. Kolodiazhnyi, O.I. (1R,2S,5R)-Menthyl Phosphinate and Its Propertie. Russ. J. Gen. Chem. 2005, 75, 656-657. [CrossRef]

88. Cao, S.X.; Gao, P.; Guo, Y.C.; Zhao, H.M.; Wang, J.; Liu, Y.F.; Zhao, Y.F. Unexpected Insertion of $\mathrm{CO}_{2}$ into the Pentacoordinate P-N Bond: Atherton-Todd-Type Reaction of Hydrospirophosphorane with Amines. J. Org. Chem. 2013, 78, 11283-11293. [CrossRef] [PubMed]

89. Kolodiazhnyi, O.I. Stereoselective Oxidation of N-Phosphor (Ill) Substituted Amino Acids. Tetrahedron Lett. 1995, 36, 3921-3924. [CrossRef]

90. Bergin, E.; O'Connor, C.T.; Robinson, S.B.; McGarrigle, E.M.; O'Mahony, C.P.; Gilheany, D.G. Synthesis of P-stereogenic phosphorus compounds. asymmetric oxidation of phosphines under Appel conditions. J. Am. Chem. Soc. 2007, 129, 9566-9567. [CrossRef]

91. Rajendran, K.V.; Gilheany, D.G. Identification of a key intermediate in the asymmetric Appel process: One pot stereoselective synthesis of P-stereogenic phosphines and phosphine-boranes from racemic phosphine oxides. Chem. Commun. 2012, 48, 10040-10042. [CrossRef]

92. Rajendran, K.V.; Kennedy, L.; Gilheany, D.G. P-Stereogenic phosphorus compounds: Effect of aryl substituents on the oxidation of arylmethylphenylphosphanes under asymmetric Appel conditions. Eur. J. Org. Chem. 2010, $N$ 29, 5642-5649. [CrossRef]

93. Rajendran, K.V.; Kudavalli, J.S.; Dunne, K.S.; Gilheany, D.G. A U-turn in the asymmetric appel reaction: Stereospecific reduction of diastereomerically enriched alkoxyphosphonium salts allows the asymmetric synthesis of P-stereogenic phosphanes and phosphane boranes. Eur. J. Org. Chem. 2012, N 14, 2720-2723. [CrossRef]

94. Rajendran, K.V.; Kennedy, L.; O'Connor, C.T. Systematic survey of positive chlorine sources in the asymmetric Appel reaction: Oxalyl chloride as a new phosphine activator. Tetrahedron Lett. 2013, 54, 7009-7012. [CrossRef]

95. Kolodiazhna, A.O.; Kolodiazhnyi, O.I. Synthesis, Properties and Stereochemistry of 2-Halo1,2ג5-oxaphosphetanes. Molecules 2016, 21, 1371. [CrossRef]

96. Kolodiazhnyi, O.I. Thiocetenes phosphores. Tetrahedron Lett. 1987, 28, 881-884. [CrossRef]

97. Kolodiazhnyi, O.I. Chemistry of P-F Ylides. Russ. J. Gen. Chem. 2005, 75, 1017-1039. [CrossRef]

98. Kolodiazhnyi, O.I. Phosphorus Ylides. Chemistry and Application in Organic Synthesis; J. Wiley-VCH: Weinheim, Germany; New York, NY, USA; Chichester, UK, 1999.

99. Kolodyazhnyi, O.I.; Kolodyazhnaya, A.O. A New Approach Towards Synthesis of Phosphorylated Alkenes. Russ. J. Gen. Chem. 2015, 85, 359-365. [CrossRef]

100. Kolodiazhna, A.O.; Kolodiazhnyi, O.I. Synthesis and Properties of Four-Membered Phosphorus Heterocycles-2-Fluoro-1,2ג5-Oxaphosphetanes. Phosphorus Sulfur Silicon Relat. Elem. 2015, 190, 2232-2245. [CrossRef]

101. Kolodyazhna, O.O.; Grishkun, E.V.; Sheiko, S.Y.; Kolodyazhna, A.O.; Kolodyazhnyi, O.I. Synthesis and Properties of tert-Butylphenylmethylene(chloro)phosphorane. Russ. J. Gen. Chem. 2015, 85, 1639-1643. [CrossRef]

102. Kolodiazhnyi, O.I. Phosphorus Ylide Chemistry; Naukova Dumka: Kiev, Ukraine, 1994.

103. Corey, E.J.; Fuchs, P.L. A synthetic method for formyl $\rightarrow$ ethynyl conversion $(\mathrm{RCHO} \rightarrow \mathrm{RCCH}$ or $\mathrm{RCCR}$ ). Tetrahedron Lett. 1972, 1972, 3769-3772. [CrossRef]

104. Kolodiazhnyi, O.I. P-Halogen-substituted phosphorus ylids. Russ. Chem. Rev. 1991, 60, 391-409. [CrossRef]

105. Anderson, B.J.; Reynolds, S.C.; Guino-o, M.A.; Xu, Z.; Glueck, D.S. Effect of Linker Length on Selectivity and Cooperative Reactivity in Platinum-Catalyzed Asymmetric Alkylation of Bis(phenylphosphino)alkanes. ACS Catal. 2016, 6, 8106-8108. [CrossRef]

106. Scriban, C.; Glueck, D.S. Platinum-Catalyzed Asymmetric Alkylation of Secondary Phosphines: Enantioselective Synthesis of P-Stereogenic Phosphines. J. Am. Chem. Soc. 2006, 128, 2788-2789. [CrossRef]

107. Scriban, C.; Glueck, D.S.; Golen, J.A.; Rheingold, A.L. Platinum-Catalyzed Asymmetric Alkylation of a Secondary Phosphine: Mechanism and Origin of Enantioselectivity. Organometallics 2007, 26, 1788-1800. [CrossRef]

108. Chan, V.S.; Chiu, M.; Bergman, R.G.; Toste, F.D. Development of Ruthenium Catalysts for the Enantioselective Synthesis of P-Stereogenic Phosphines via Nucleophilic Phosphido Intermediates. J. Am. Chem. Soc. 2009, 131, 6021-6032. [CrossRef] 
109. Chan, V.S.; Stewart, I.C.; Bergman, R.G.; Toste, F.D. Asymmetric Catalytic Synthesis of P-Stereogenic Phosphines via a Nucleophilic Ruthenium Phosphido Complex. J. Am. Chem. Soc. 2006, 128, 2786-2787. [CrossRef] [PubMed]

110. Scriban, C.; Glueck, D.S.; DiPasquale, A.G.; Rheingold, A.L.; Scriban, C. Chiral Platinum Duphos Terminal Phosphido Complexes: Synthesis, Structure, Phosphido Transfer, and Ligand Behavior. Organometallics 2006, 25, 5435-5448. [CrossRef]

111. Chapp, T.W.; Schoenfeld, A.J.; Glueck, D.S. Effects of Linker Length on the Rate and Selectivity of Platinum-Catalyzed Asymmetric Alkylation of the Bis(isitylphosphino)alkanes $\operatorname{IsHP}\left(\mathrm{CH}_{2}\right)_{n} \mathrm{PHIs}$ (Is = 2,4,6-(i-Pr) $\left.{ }_{3} \mathrm{C}_{6} \mathrm{H}_{2}, \mathrm{n}=1-5\right)$. Organometallics 2010, 29, 2465-2473. [CrossRef]

112. Moncarz, J.R.; Brunker, T.J.; Glueck, D.S.; Sommer, R.D.; Rheingold, A.L. Stereochemistry of Palladium-Mediated Synthesis of $\mathrm{PAMP}-\mathrm{BH}_{3}$ :Retention of Configuration at $\mathrm{P}$ in Formation of $\mathrm{Pd}-\mathrm{P}$ and P-C Bonds. J. Am. Chem. Soc. 2003, 125, 1180-1181. [CrossRef] [PubMed]

113. Glueck, D.S. Recent Advances in Metal-Catalyzed C-P Bond Formation. Top. Organomet. Chem. 2010, 31, 65-100. [CrossRef]

114. Kolodiazhnyi, O.I.; Kukhar, V.P.; Kolodiazhna, A.O. Asymmetric catalysis as a method for the synthesis of chiral organophosphorus compounds. Tetrahedron Asymmetry 2014, 25, 865-922. [CrossRef]

115. Chapp, T.W.; Glueck, D.S.; Golen, J.A.; Moore, C.E.; Rheingold, A.L. Platinum-Catalyzed Asymmetric Alkylation of Bis(isitylphosphino)ethane: Stereoselectivity Reversal in Successive Formation of Two P-C Bonds. Organometallics 2010, 29, 378-388. [CrossRef]

116. Imamoto, T.; Yashio, K.; Crépy, K.V.L.; Katagiri, K.; Takahashi, H.; Kouchi, M.; Gridnev, I.D. P-Chiral tetraphosphine dirhodium complex as a catalyst for asymmetric hydrogenation: Synthesis, structure, enantioselectivity, and mechanism. stereoselective formation of a dirhodium tetrahydride complex and its reaction with methyl (Z)- $\alpha$-acetamidocinnamate. Organometallics 2006, 25, 908-914. [CrossRef]

117. Guino'o, M.A.; Zureick, A.H.; Blank, N.F.; Anderson, B.J.; Chapp, T.W.; Kim, Y.; Glueck, D.S.; Rheingold, A.L. Synthesis and Structure of Platinum Bis(phospholane) Complexes $\operatorname{Pt}\left(\operatorname{diphos}^{*}\right)(\mathrm{R})(\mathrm{X})$, Catalyst Precursors for Asymmetric Phosphine Alkylation. Organometallics 2012, 31, 6900-6910. [CrossRef]

118. Moncarz, J.R.; Brunker, T.J.; Jewett, J.C.; Orchowski, M.; Glueck, D.S.; Sommer, R.D.; Lam, K.C.; Incarvito, C.D.; Concolino, T.E.; Ceccarelli, C.; et al. Palladium Catalyzed Asymmetric Phosphination Enantioselective Synthesis of PAMP-BH $\mathrm{BH}_{3}$, Ligand Effects on Catalysis, and Direct Observation of the Stereochemistry of Transmetalation and Reductive Elimination. Organometallics 2003, 22, 3205-3221. [CrossRef]

119. Chan, V.S.; Bergman, R.G.; Toste, F.D. Catalyzed Dynamic Kinetic Enantioselective Arylation of Silylphosphines. J. Am. Chem. Soc. 2007, 129, 15122-15123. [CrossRef] [PubMed]

120. Julienne, D.; Lohier, J.F.; Delacroix, O.; Gaumont, A.C. Palladium-Catalyzed C-P Coupling Reactions between Vinyl Triflates and Phosphine-Boranes: Efficient Access to Vinylphosphine-Boranes. J. Org. Chem. 2007, 72, 2247-2250. [CrossRef] [PubMed]

121. Korff, C.; Helmchen, G. Preparation of chiral triarylphosphines by Pd-catalysed asymmetric P-C cross-coupling. Chem. Commun. 2004, 530-531. [CrossRef] [PubMed]

122. Blank, N.F.; Moncarz, J.R.; Brunker, T.J.; Scriban, C.; Anderson, B.J.; Amir, O.; Glueck, D.S.; Zakharov, L.N.; Golen, J.A.; Incarvito, C.D.; et al. Palladium-Catalyzed Asymmetric Phosphination. Scope, Mechanism, and Origin of Enantioselectivity. J. Am. Chem. Soc. 2007, 129, 6847-6858. [CrossRef] [PubMed]

123. Julienne, D.; Delacroix, O.; Gaumont, A.C. First study on the enantioselective palladium-catalyzed C-P crosscoupling reaction between an alkenyltriflate and a phosphine-borane. C. R. Chim. 2010, 13, 1099-1103. [CrossRef]

124. Liu, L.-J.; Wang, W.-M.; Yao, L.; Meng, F.J.; Sun, Y.-M.; Xu, H.; Xu, Z.-Y.; Li, Q.; Zhao, C.-Q.; Han, L.-B. Reinvestigation of the Substitutions Reaction of Stereogenic Phosphoryl Compounds: Stereochemistry, Mechanism, and Applications. J. Org. Chem. 2017, 82, 11990-12002. [CrossRef]

125. Skrzypczynski, Z.; Michalski, J. Stereoselective Synthesis and Stereochemistry of Optically Active tert-Butylphenylphosphine Sulfide. J. Org. Chem. 1988, 53, 4549-4551. [CrossRef]

126. Omelahczuk, J.; Mikolajczyk, M. Optically Active Trivalent Phosphorus Compounds. 2. Reactivity of Alkylthio- and Alkylselenophosphonium Salts. The First Stereospecific Synthesis of a Chiral Phosphinite. J. Am. Chem. Soc. 1979, 101, 7292-7295. [CrossRef] 
127. Le Maux, P.; Bahri, H.; Simonneaux, G.; Toupet, L. Enantioselective Oxidation of Racemic Phosphines with Chiral Oxoruthenium Porphyrins and Crystal Structure of [5,10,15,20-Tetrakis[o((2-methoxy-2-phenyl-3,3,3-trifluoropropanoyl)amino)phenyl] porphyrinato] (carbonyl) (tetrahydrofuran) ruthenium (II) (alpha, beta, alpha, beta. Isomer). Inorg. Chem. 1995, 34, 4691-4697. [CrossRef]

128. Van den Berg, G.R.; Platenburg, D.H.J.M.; Benschop, H.P. Organophosphorus compounds XI Stereochemistry of Grignard displacement reactions at phosphorus in isopropyl methylphosphonohalogenates. Recueil Pays-Bas 1972, 91, 929-934. [CrossRef]

129. Perlikowska, W.; Gouygou, M.; Daran, J.C.; Balavoine, G.; Mikołajczyk, M. Kinetic resolution of P-chiral tertiary phosphines and chlorophosphines: A new approach to optically active phosphoryl and thiophosphoryl compou.nds. Tetrahedron Lett. 2001, 42, 7841-7845. [CrossRef]

130. Michalski, J.; Skrzypczynski, Z. Novel Reaction of Phosphinothioic Methanesulphonic Anhydride with Aluminium Halides. Stereoselective Synthesis of Phosphinothioic Halides. Chem. Commun. 1977, 66-67. [CrossRef]

131. Gryshkun, E.V.; Andrushko, N.V.; Kolodiazhnyi, O.I. Stereoselective reactions of chiral amines with racemic chlorophosphines. Phosphorus Sulfur Silicon Relat. Elem. 2004, 179, 1027-1046. [CrossRef]

132. Kolodiazhnyi, O.I.; Andrushko, N.V.; Gryshkun, E.V. Stereoselective reactions of optically active derivatives of $\alpha$-methylbenzylaminophosphine. J. Russ. Gen. Chem. 2004, 74, 515-522. [CrossRef]

133. Herault, D.; Nguyen, D.H.; Nuel, D.; Buono, G. Reduction of secondary and tertiary phosphine oxides to phosphines. Chem. Soc. Rev. 2015, 44, 2508-2528. [CrossRef] [PubMed]

134. Imamoto, S.; Kikuchi, S.-I.; Miura, T.; Wada, Y. Stereospecific Reduction of Phosphine Oxides to Phosphines by the Use of a Methylation Reagent and Lithium Aluminum Hydride. Org. Lett. 2001, 3, 87-90. [CrossRef]

135. Cernia, E.; Giongo, G.M.; Marcati, F.; Marconi, W.; Palladino, N. Optically Active Phosphines by Asymmetric Reduction of Racemic Phosphine Oxides. Inorg. Chim. Acta 1974, 11, 195-200. [CrossRef]

136. Wu, H.-C.; Yu, J.-Q.; Spencer, J.B. Stereospecific Deoxygenation of Phosphine Oxides with Retention of Configuration Using Triphenylphosphine or Triethyl Phosphite as an Oxygen Acceptor. Org. Lett. 2004, 6, 4675-4678. [CrossRef]

137. Kerrigan, N.J.; Dunne, E.C.; Cunningham, D.; McArdle, P.; Gilligan, K.; Gilheany, D.G. Studies in the preparation of novel P-chirogenic binaphthyl monophosphanes (MOPs). Tetrahedron Lett. 2003, 44, 8461-8465. [CrossRef]

138. Keglevich, G.; Fekete, M.; Chuluunbaatar, T.; Dobo, A.; Harmat, V.; Toke, L. Studies in the preparation of novel P-chirogenic binaphthyl monophosphanes (MOPs). J. Chem. Soc. Perkin Trans. 2000, 1, 4451-4455. [CrossRef]

139. Marsi, K.L. Phenylsilane Reduction of Phosphine Oxides with Complete Stereospecificity. J. Org. Chem. 1974, 39, 265-267. [CrossRef]

140. Krenske, E.H. Theoretical Investigation of the Mechanisms and Stereoselectivities of Reductions of Acyclic Phosphine Oxides and Sulfides by Chlorosilanes. J. Org. Chem. 2012, 77, 3969-3977. [CrossRef] [PubMed]

141. Krenske, E.H. Reductions of Phosphine Oxides and Sulfides by Perchlorosilanes: Evidence for the Involvement of Donor-Stabilized Dichlorosilylene. J. Org. Chem. 2012, 77, 1-4. [CrossRef] [PubMed]

142. Kenny, N.P.; Rajendran, K.V.; Gilheany, D.G. Chemoselective reduction of the phosphoryl bond of O-alkyl phosphinates and related compounds: An apparently impossible transformation. Chem. Commun. 2015, 51, 16561-16566. [CrossRef] [PubMed]

143. Gololobov, Y.G.; Kasukhin, L.F. Recent advances in the Staudinger reaction. Trahedron 1992, 48, $1353-1406$. [CrossRef]

144. Gololobov, Y.G.; Zhmurova, I.N.; Kasukhin, L.F. Sixty years of Staudinger reaction. Tetrahedron 1981, 37, 437-472. [CrossRef]

145. Heesing, A.; Steinkamp, H. Mechanismen bei elektrophilen Reaktionen von reaktiven Stickstoffverbindungen mit Phosphanen. Chem. Ber. 1982, 115, 2854-2864. [CrossRef]

146. Horner, L.; Jordan, M. Phosphororganische verbindungen 92. Zur Stereochemie und zum chemischen Verhalten optisch aktiver Amidophosphoniumsalze und optisch aktiver Phosphinigsaureamide. Phosphorus Sulfur 1980, 8, 225-234. [CrossRef]

147. Dimukhametov, M.N.; Nuretdinov, I.A. Optically active silylphosphonites in the Staudinger reaction. Russ. Chem. Bull. 1983, 1103-1104. [CrossRef] 
148. Baccolini, G.; Todesco, P.E.; Bartoli, G. The Staudinger reaction between 2-h-1,2,3-diazaphospholenes and aromatic azides. Phosphorus Sulfur 1981, 10, 387-394. [CrossRef]

149. Kolodiazhnyi, O.I. Asymmetric synthesis of hydroxyphosphonates. Tetrahedron Asymmetry 2005, 16, 3295-3340. [CrossRef]

150. Andersen, N.G.; Ramsden, P.D.; Che, D.; Parvez, M.; Keay, B.A. A Novel Resolution Procedure for the Preparation of P-Stereogenic Phosphine Oxides. Org. Lett. 1999, 1, 2009-2011. [CrossRef]

151. Andersen, N.G.; Ramsden, P.D.; Che, D.; Parvez, M.; Keay, B.A. A Simple Resolution Procedure Using the Staudinger Reaction for the Preparation of P-Stereogenic Phosphine Oxides. J. Org. Chem. 2001, 66, 7478-7486. [CrossRef] [PubMed]

152. Headley, C.E.; Marsden, S.P. Synthesis and Application of P-Stereogenic Phosphines as Superior Reagents in the Asymmetric Aza-Wittig Reaction. J. Org. Chem. 2007, 72, 7185-7189. [CrossRef] [PubMed]

153. Scriven, E.F.V.; Turnbull, K. Azides: Their Preparation and Synthetic Uses. Chem. Rev. 1988, 88, $297-368$. [CrossRef]

154. Keglevich, G.; Bálint, E. The Kabachnik-Fields Reaction: Mechanism and Synthetic Use. Molecules 2012, 17, 12821-12835. [CrossRef] [PubMed]

155. Cherkasov, R.A.; Galkin, V.I. The Kabachnik-Fields reaction: Synthetic potential and the problem of the mechanism. Russ. Chem. Rev. 1998, 67, 857-882. [CrossRef]

156. Enders, D.; Saint-Dizier, A.; Lannou, M.-I.; Lenzen, A.; Enders, D. The Phospha-Michael Addition in Organic Synthesis. Eur. J. Org. Chem. 2006, 2006, 29-49. [CrossRef]

157. Gancarz, R. Nucleophilic Addition to Carbonyl Compounds. Competition Between Hard (Amine) and Soft (Phosphite) Nucleophile. Tetrahedron 1995, 51, 10627-10632. [CrossRef]

158. Wroblewski, A.E.; Konieczko, V.T. Stereochemistry of 1,2-oxaphospholanes, III Evidence for the retro-Abramov pathway in methoxide-catalysed equilibration of substituted 2-methoxy-2-oxo-1,2-oxaphospholan-3-ols. Monatsh. Chem. 1984, 115, 785-791. [CrossRef]

159. Kolodiazhnyi, O.I. Chiral hydroxy phosphonates: Synthesis, configuration and biological properties. Russ. Chem. Rev. 2006, 75, 227-253. [CrossRef]

160. Haynes, R.K.; Lam, W.W.L.; Yeung, L.L. Stereoselective Preparation of Functionalized Tertiary P-Chiral Phosphine Oxides by Nucleophilic Addition of Lithiated tert-Butylpbenylphospbine Oxide to Carbonyl Compounds. Tetrahedron Lett. 1996, 37, 4729-4732. [CrossRef]

161. Zhang, H.; Sun, Y.-M.; Zhao, Y.; Zhou, Z.-Y.; Wang, J.-P.; Xin, N.; Nie, S.-Z.; Zhao, C.-Q.; Han, L.-B. One-Pot Process That Efficiently Generates Single Stereoisomers of 1,3-Bisphosphinylpropanes Having Five Chiral Centers. Org. Lett. 2015, 17, 142-145. [CrossRef] [PubMed]

162. Kolodiazhnyi, O.I.; Guliaiko, I.V.; Kolodiazhna, A.O. Highly stereoselective addition of silylphosphines to chiral aldehydes. Tetrahedron Lett. 2004, 45, 6955-6957. [CrossRef]

163. Kortmann, F.A.; Chang, M.-C.; Otten, E.; Couzijn, E.P.A.; Lutz, M.; Minnaard, A. Consecutive dynamic resolutions of phosphine oxides. J. Chem. Sci. 2014, 5, 1322-1327. [CrossRef]

164. Holt, J.; Maj, A.M.; Schudde, E.P.; Pietrusiewicz, K.M.; Sieron, L.; Wieczorek, W.; Jerphagnon, T.; Arends, I.W.C.E.; Hanefeld, U.; Minnaard, A.J. On the Resolution of Secondary Phosphine Oxides via Diastereomeric Complex Formation: The Case of tert-Butylphenylphosphine Oxide. Synthesis 2009, 2061-2065. [CrossRef]

165. Sowa, S.; Stankevic, M.; Szmigielska, A.; Maluszynska, H.; Koziol, A.E.; Pietrusiewicz, K.M. Reduction of Functionalized Tertiary Phosphine Oxides with $\mathrm{BH}_{3}$. J. Org. Chem. 2015, 80, 1672-1688. [CrossRef]

166. Gatineau, D.; Nguyen, D.H.; Hrault, D.; Vanthuyne, N.; Leclaire, J.; Giordano, L.; Buono, G. H-Adamantylphosphinates as Universal Precursors of P-Stereogenic Compounds. J. Org. Chem. 2015, 80, 4132-4141. [CrossRef]

167. Lemouzy, S.; Nguyen, D.H.; Camy, V.; Jean, M.; Gatineau, D.; Giordano, L.; Naubron, J.-V.; Vanthuyne, N.; Hrault, D.; Buono, G. Stereospecific Synthesis of a- and b-Hydroxyalkyl P-Stereogenic Phosphine-Boranes and Functionalized Derivatives: Evidence of the $\mathrm{P}=\mathrm{O}$ Activation in the BH3-Mediated Reduction. Chem. Eur. J. 2015, 21, 15607-15621. [CrossRef]

168. Lemouzy, S.; Jean, M.; Giordano, L.; Hérault, D.; Buono, G. The Hydroxyalkyl Moiety as a Protecting Group for the Stereospecific Alkylation of Masked Secondary Phosphine-Boranes. Org. Lett. 2016, 18, 140-143. [CrossRef] 
169. Kumaraswamy, G.; Rao, G.V.; RamaKrishna, G. Stereocontrolled Copper Iodide Catalyzed Phosphorus-Carbon Bond Formation: An Efficient Synthesis of Scalemic Tertiary Phosphineboranes. Synlett 2006, 1122-1124. [CrossRef]

170. Fu, X.; Loh, W.-T.; Zhang, Y.; Chen, T.; Ma, T.; Liu, H.; Wang, J.; Tan, C.-H. Chiral Guanidinium Salt Catalyzed Enantioselective Phospha-Mannich Reactions. Angew. Chem. Int. Ed. 2009, 48, 7387-7390. [CrossRef] [PubMed]

171. Lin, Y.-C.; Hatzakis, E.; McCarthy, S.M.; Reichl, K.D.; Lai, T.-Y.; Yennawar, H.P.; Radosevich, A.T. P-N Cooperative Borane Activation and Catalytic Hydroboration by a Distorted Phosphorous Triamide Platform. J. Am. Chem. Soc. 2017, 139, 6008-6016. [CrossRef] [PubMed]

172. Keglevich, G.; Fehervari, A.; Csontos, I. A study on the Kabachnik-Fields reaction of benzaldehyde, propylamine, and diethyl phosphite by in situ Fourier transform IR spectroscopy. Heteroat. Chem. 2011, 22, 599-604. [CrossRef]

173. Kolodiazhna, A.O.; Guliaiko, I.V.; Kolodiazhnyi, O.I. Diasteroselective Addition of Mono and Bis-Silylphosphines to Chiral Aldehydes. Phosphorus Sulfur Silicon Relat. Elem. 2005, 180, 2335-2346. [CrossRef]

174. Tedeschi, L.; Enders, D. Asymmetric synthesis of beta-phosphono malonates via Fe2O3-mediated phospha-Michael addition to Knoevenagel acceptors. Org. Lett. 2001, 3, 3515-3517. [CrossRef]

175. Wang, J.-P.; Nie, S.-Z.; Zhou, Z.-Y.; Ye, J.-J.; Wen, J.-H.; Zhao, C.-Q. Preparation of optically pure tertiary phosphine oxides via the addition of P-Stereogenic secondary phosphine oxide to activated alkenes. J. Org. Chem. 2016, 81, 7644-7653. [CrossRef]

176. Kolodiazhna, A.O.; Kolodiazhnyi, O.I. Stereochemistry of nucleophilic substitution at trivalent phosphorus. Phosphorus Sulfur Silicon Relat. Elem. 2017, 192, 621-633. [CrossRef]

177. Kolodiazhnyi, O.I. Stereochemistry of electrophilic and nucleophilic substitutions at phosphorus. Pure Appl. Chem. 2019, 91, 43-57. [CrossRef]

178. Chmielewska, E.; Kafarski, P. Synthetic procedures leading towards aminobisphosphonates. Molecules 2016, 21, 1474. [CrossRef]

(C) 2020 by the authors. Licensee MDPI, Basel, Switzerland. This article is an open access article distributed under the terms and conditions of the Creative Commons Attribution (CC BY) license (http://creativecommons.org/licenses/by/4.0/). 